\title{
Anticoagulation for the initial treatment of venous thromboembolism in people with cancer (Review)
}

Hakoum MB, Kahale LA, Tsolakian IG, Matar CF, Yosuico VED, Terrenato I, Sperati F, Barba M, Schünemann $\mathrm{H}$, Akl EA

Hakoum MB, Kahale LA, Tsolakian IG, Matar CF, Yosuico VED, Terrenato I, Sperati F, Barba M, Schünemann H, AkI EA. Anticoagulation for the initial treatment of venous thromboembolism in people with cancer.

Cochrane Database of Systematic Reviews 2018, Issue 1. Art. No.: CD006649.

DOI: 10.1002/14651858.CD006649.pub7.

www.cochranelibrary.com 
TABLE OF CONTENTS

HEADER 1

ABSTRACT

PLAIN LANGUAGE SUMMARY

SUMMARY OF FINDINGS

BACKGROUND

OBJECTIVES

METHODS

RESULTS

Figure 1.

Figure 2.

Figure 3.

DISCUSSION

AUTHORS' CONCLUSIONS

ACKNOWLEDGEMENTS

REFERENCES

CHARACTERISTICS OF STUDIES

DATA AND ANALYSES

Analysis 1.1. Comparison 1 Low molecular weight heparin (LMWH) versus unfractionated heparin (UFH), Outcome 1 Mortality (3 months).

Analysis 1.2. Comparison 1 Low molecular weight heparin (LMWH) versus unfractionated heparin (UFH), Outcome 2 Any recurrent venous thromboembolism (3 months).

Analysis 2.1. Comparison 2 Fondaparinux versus heparin (low molecular weight heparin (LMWH) + unfractionated heparin (UFH)), Outcome 1 Mortality (3 months).

Analysis 2.2. Comparison 2 Fondaparinux versus heparin (low molecular weight heparin (LMWH) + unfractionated heparin (UFH)), Outcome 2 Recurrent venous thromboembolism (3 months).

Analysis 2.3. Comparison 2 Fondaparinux versus heparin (low molecular weight heparin (LMWH) + unfractionated heparin (UFH)), Outcome 3 Major bleeding (3 months).

Analysis 2.4. Comparison 2 Fondaparinux versus heparin (low molecular weight heparin (LMWH) + unfractionated heparin (UFH)), Outcome 4 Minor bleeding (3 months).

Analysis 3.1. Comparison 3 Dalteparin versus tinzaparin, Outcome 1 Mortality (3 months).

Analysis 3.2. Comparison 3 Dalteparin versus tinzaparin, Outcome 2 Recurrent venous thromboembolism ( 3 months).

Analysis 3.3. Comparison 3 Dalteparin versus tinzaparin, Outcome 3 Major bleeding (3 months).

Analysis 3.4. Comparison 3 Dalteparin versus tinzaparin, Outcome 4 Minor bleeding (3 months).

ADDITIONAL TABLES

APPENDICES

WHAT'S NEW

HISTORY

CONTRIBUTIONS OF AUTHORS

DECLARATIONS OF INTEREST

SOURCES OF SUPPORT

INDEX TERMS 
[Intervention Review]

\section{Anticoagulation for the initial treatment of venous thromboembolism in people with cancer}

Maram B Hakoum¹, Lara A Kahale², Ibrahim G Tsolakian², Charbel F Matar ${ }^{3}$, Victor ED Yosuico4, Irene Terrenato ${ }^{5}$, Francesca Sperati5, Maddalena Barba 6 , Holger Schünemann?7, Elie A Akl ${ }^{3}$

1Family Medicine, American University of Beirut, Beirut, Lebanon. 2Faculty of Medicine, American University of Beirut, Beirut, Lebanon. ${ }^{3}$ Department of Internal Medicine, American University of Beirut Medical Center, Beirut, Lebanon. ${ }^{4}$ Buffalo Medical Group, Buffalo, New York, USA. ${ }^{5}$ Biostatistics-Scientific Direction, Regina Elena National Cancer Institute, Rome, Italy. ${ }^{6}$ Division of Medical Oncology 2 Scientific Direction, IRCCS Regina Elena National Cancer Institute, Rome, Italy. ${ }^{7}$ Departments of Health Research Methods, Evidence, and Impact and of Medicine, McMaster University, Hamilton, Canada

Contact address: Elie A Akl, Department of Internal Medicine, American University of Beirut Medical Center, Riad El Solh, Beirut, 1107 2020, Lebanon.ea32@aub.edu.lb.

Editorial group: Cochrane Gynaecological, Neuro-oncology and Orphan Cancer Group.

Publication status and date: Edited (no change to conclusions), published in Issue 2, 2019.

Citation: Hakoum MB, Kahale LA, Tsolakian IG, Matar CF, Yosuico VED, Terrenato I, Sperati F, Barba M, Schünemann H, Akl EA. Anticoagulation for the initial treatment of venous thromboembolism in people with cancer. Cochrane Database of Systematic Reviews 2018, Issue 1. Art. No.: CD006649. DOI: 10.1002/14651858.CD006649.pub7.

Copyright @ 2019 The Cochrane Collaboration. Published by John Wiley \& Sons, Ltd.

\section{A B S T R A C T}

\section{Background}

Compared with people without cancer, people with cancer who receive anticoagulant treatment for venous thromboembolism (VTE) are more likely to develop recurrent VTE.

\section{Objectives}

To compare the efficacy and safety of three types of parenteral anticoagulants (i.e. fixed-dose low molecular weight heparin (LMWH), adjusted-dose unfractionated heparin (UFH), and fondaparinux) for the initial treatment of VTE in people with cancer.

\section{Search methods}

A comprehensive search included a major electronic search of the following databases: Cochrane Central Register of Controlled Trials (CENTRAL) (2018, Issue 1), MEDLINE (via Ovid) and Embase (via Ovid); handsearching of conference proceedings; checking of references of included studies; use of the 'related citation' feature in PubMed; and a search for ongoing studies. This update of the systematic review was based on the findings of a literature search conducted on 14 January 2018.

\section{Selection criteria}

Randomized controlled trials (RCTs) assessing the benefits and harms of LMWH, UFH, and fondaparinux in people with cancer and objectively confirmed VTE.

\section{Data collection and analysis}

Using a standardized form, we extracted data in duplicate on study design, participants, interventions outcomes of interest, and risk of bias. Outcomes of interested included all-cause mortality, symptomatic VTE, major bleeding, minor bleeding, postphlebitic syndrome, quality of life, and thrombocytopenia. We assessed the certainty of evidence for each outcome using the GRADE approach. 


\section{Main results}

Of 15440 identified citations, 7387 unique citations, 15 RCTs fulfilled the eligibility criteria. These trials enrolled 1615 participants with cancer and VTE: 13 compared LMWH with UFH enrolling 1025 participants, one compared fondaparinux with UFH and LMWH enrolling 477 participants, and one compared dalteparin with tinzaparin enrolling 113 participants. The meta-analysis of mortality at three months included 418 participants from five studies and that of recurrent VTE included 422 participants from 3 studies. The findings showed that LMWH likely decreases mortality at three months compared to UFH (risk ratio (RR) $0.66,95 \%$ confidence interval $(\mathrm{Cl}) 0.40$ to 1.10 ; risk difference (RD) 57 fewer per $1000,95 \% \mathrm{Cl} 101$ fewer to 17 more; moderate certainty evidence), but did not rule out a clinically significant increase or decrease in VTE recurrence (RR $0.69,95 \% \mathrm{Cl} 0.27$ to 1.76 ; RD 30 fewer per $1000,95 \% \mathrm{Cl} 70$ fewer to 73 more; moderate certainty evidence).

The study comparing fondaparinux with heparin (UFH or LMWH) did not exclude a beneficial or detrimental effect of fondaparinux on mortality at three months (RR 1.25, 95\% Cl 0.86 to 1.81; RD 43 more per $1000,95 \% \mathrm{Cl} 24$ fewer to 139 more; moderate certainty evidence), recurrent VTE (RR 0.93, 95\% Cl 0.56 to 1.54; RD 8 fewer per 1000, 95\% Cl 52 fewer to 63 more; moderate certainty evidence), major bleeding (RR 0.82, 95\% Cl 0.40 to 1.66; RD 12 fewer per 1000, 95\% Cl 40 fewer to 44 more; moderate certainty evidence), or minor bleeding (RR 1.53, $95 \% \mathrm{Cl} 0.88$ to 2.66 ; RD 42 more per $1000,95 \% \mathrm{Cl} 10$ fewer to 132 more; moderate certainty evidence)

The study comparing dalteparin with tinzaparin did not exclude a beneficial or detrimental effect of dalteparin on mortality (RR 0.86, 95\% $\mathrm{Cl} 0.43$ to 1.73; RD 33 fewer per $1000,95 \% \mathrm{Cl} 135$ fewer to 173 more; low certainty evidence), recurrent VTE (RR 0.44, 95\% Cl 0.09 to 2.16; RD 47 fewer per 1000, 95\% Cl 77 fewer to 98 more; low certainty evidence), major bleeding (RR 2.19, $95 \% \mathrm{Cl} 0.20$ to 23.42 ; RD 20 more per $1000,95 \% \mathrm{Cl} 14$ fewer to 380 more; low certainty evidence), or minor bleeding (RR $0.82,95 \% \mathrm{Cl} 0.30$ to 2.21 ; RD 24 fewer per $1000,95 \% \mathrm{Cl}$ 95 fewer to 164 more; low certainty evidence).

\section{Authors' conclusions}

LMWH is possibly superior to UFH in the initial treatment of VTE in people with cancer. Additional trials focusing on patient-important outcomes will further inform the questions addressed in this review. The decision for a person with cancer to start LMWH therapy should balance the benefits and harms and consider the person's values and preferences.

\section{PLAIN LANGUAGE SUMMARY}

\section{Blood thinners for the initial treatment of blood clots in people with cancer}

\section{Background}

People with cancer are at increased risk of blood clots. The blood thinner (anticoagulant) administered in the first few days after identifying a blood clot can consist of unfractionated heparin (infused through a vein), low molecular weight heparin (injected under the skin once or twice per day; dalteparin, and tinzaparin are two different types of low molecular weight heparin), or fondparinux (injected under the skin once daily). These blood thinners may have different effectiveness and safety profiles.

\section{Study characteristics}

We searched scientific databases for clinical trials comparing different blood thinners in people with cancer with a confirmed diagnosis of deep vein thrombosis (a blood clot in the limbs) or pulmonary thrombosis (a blood clot in the lungs). We included trials of adults and children with either solid tumors or blood cancer irrespective of the type of cancer treatment. The trials looked at death, recurrent blood clots, and bleeding. The evidence is current to January 2018. We included 15 trials.

\section{Key results}

In this systematic review, data from five studies with 422 participants suggested that the effect of low molecular weight heparin on death compared with unfractionated heparin was uncertain, but if anything of small size. There was not enough evidence to prove superiority in reducing recurrence of blood clots or risk of bleeding. We found no data to compare the safety profile of these two medications. Also, fondaparinux did not prove or exclude any important effect compared to heparins, on death, blood clots, or bleeding. Similarly,the available evidence did not show any difference between dalteparin and tinzaparin for all tested outcomes.

\section{Certainty of the evidence}

We judged the certainty of evidence for low molecular weight heparin versus unfractionated heparin to be moderate for all assessed outcomes.

We judged the certainty of evidence for fondaparinux versus heparin to be moderate for all tested outcomes.

We judged the certainty of evidence for tinzaparin versus dalteparin to be low for all tested outcomes. 


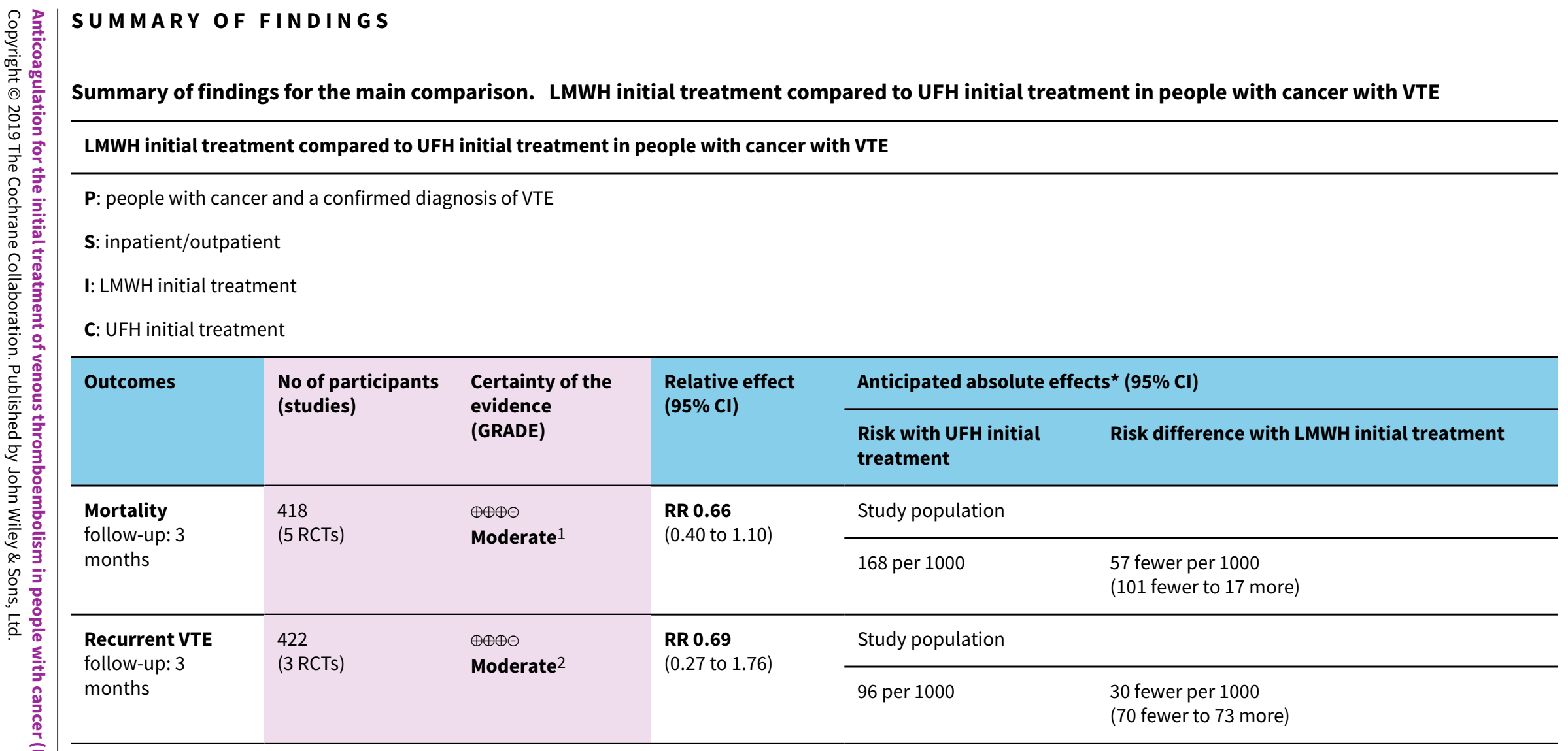

${ }^{\star}$ The risk in the intervention group (and its $95 \%$ confidence interval) is based on the assumed risk in the comparison group and the relative effect of the intervention (and its $95 \% \mathrm{Cl})$.

Cl: confidence interval; LMWH: low molecular weight heparin; RCT: randomized controlled trial; RR: risk ratio; UFH: unfractionated heparin; VTE: venous thromboembolism.

\section{GRADE Working Group grades of evidence}

High certainty: we are very confident that the true effect lies close to that of the estimate of the effect.

Moderate certainty: we are moderately confident in the effect estimate: the true effect is likely to be close to the estimate of the effect, but there is a possibility that it is substantially different.

Low certainty: our confidence in the effect estimate is limited: the true effect may be substantially different from the estimate of the effect.

Very low certainty: we have very little confidence in the effect estimate: the true effect is likely to be substantially different from the estimate of effect.

$195 \% \mathrm{Cl}$ was consistent with the possibility for important benefit (101 per 1000 absolute reduction) and possibility of important harm (17 per 1000 absolute increase), including 59 events in total. 


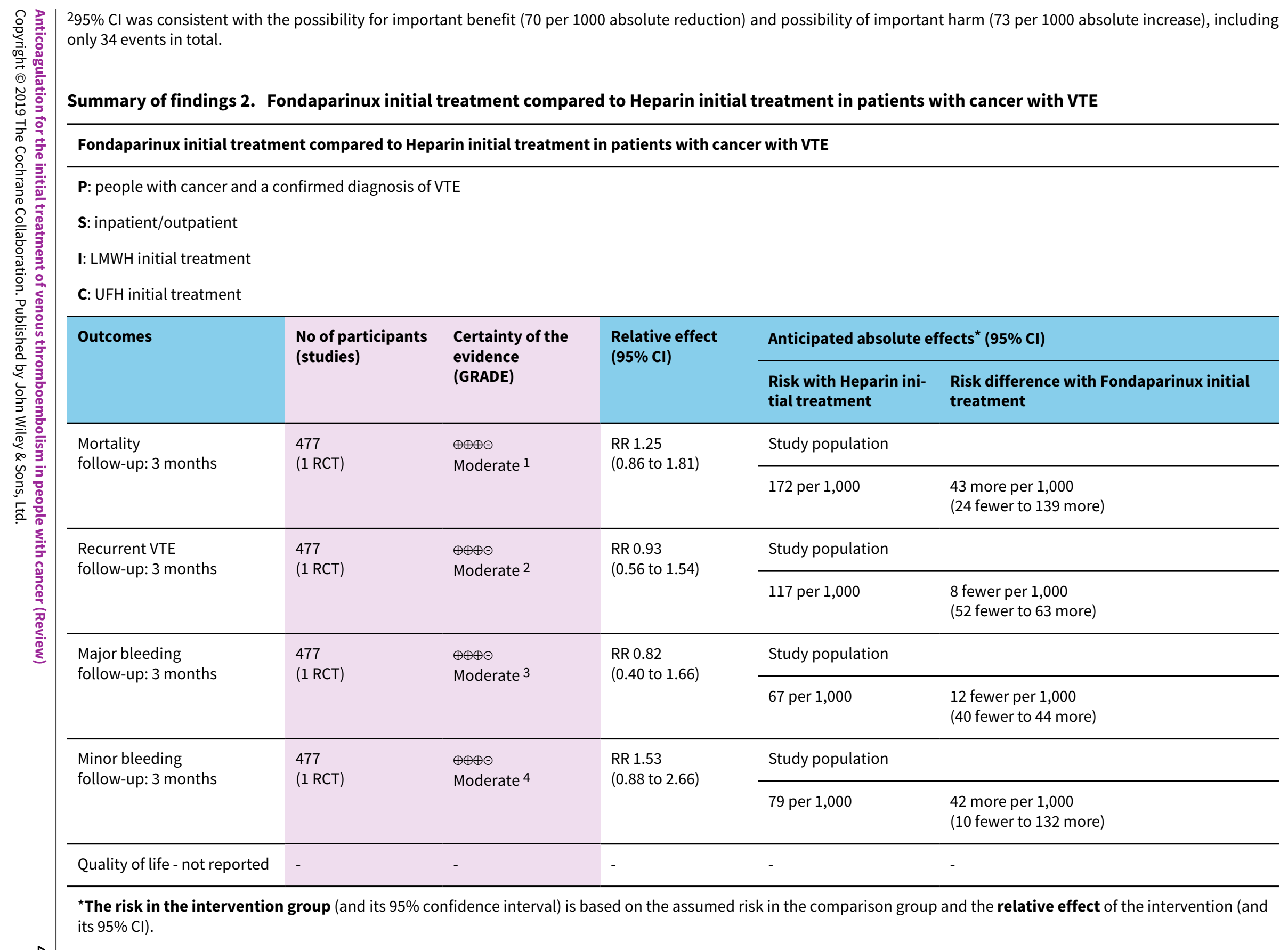


Cl: Confidence interval; LMWH: low molecular weight heparin; RCT: randomized controlled trial; RR: Rrisk ratio; OR: Odds ratio;UFH: unfractionated heparin; VTE: venous thromboembolism.

\section{GRADE Working Group grades of evidence}

High certainty: We are very confident that the true effect lies close to that of the estimate of the effect

Moderate certainty: We are moderately confident in the effect estimate: The true effect is likely to be close to the estimate of the effect, but there is a possibility that it is substantially different

Low certainty: Our confidence in the effect estimate is limited: The true effect may be substantially different from the estimate of the effect

Very low certainty: We have very little confidence in the effect estimate: The true effect is likely to be substantially different from the estimate of effect

$195 \% \mathrm{Cl}$ is consistent with the possibility for important benefit (24 per 1000 absolute reduction) and possibility of important harm (139 per 1000 absolute increase), including only 92 events in total

$295 \% \mathrm{Cl}$ is consistent with the possibility for important benefit (52 per 1000 absolute reduction) and possibility of important harm (63 per 1000 absolute increase), including only 54 events in total

$395 \% \mathrm{Cl}$ is consistent with the possibility for important benefit (40 per 1000 absolute reduction) and possibility of important harm (44 per 1000 absolute increase), including only 29 events in total

$495 \% \mathrm{Cl}$ is consistent with the possibility for important benefit (10 per 1000 absolute reduction) and possibility of important harm (132 per 1000 absolute increase), including only 48 events in total

\section{Summary of findings 3. Dalteparin compared to tinzaparin in people with cancer with VTE}

\section{Dalteparin initial treatment compared to tinzaparin initial treatment in people with cancer with VTE}

P: people with cancer and a confirmed diagnosis of VTE

S: inpatient/outpatient

I: dalteparin initial treatment

C: tinzaparin initial treatment

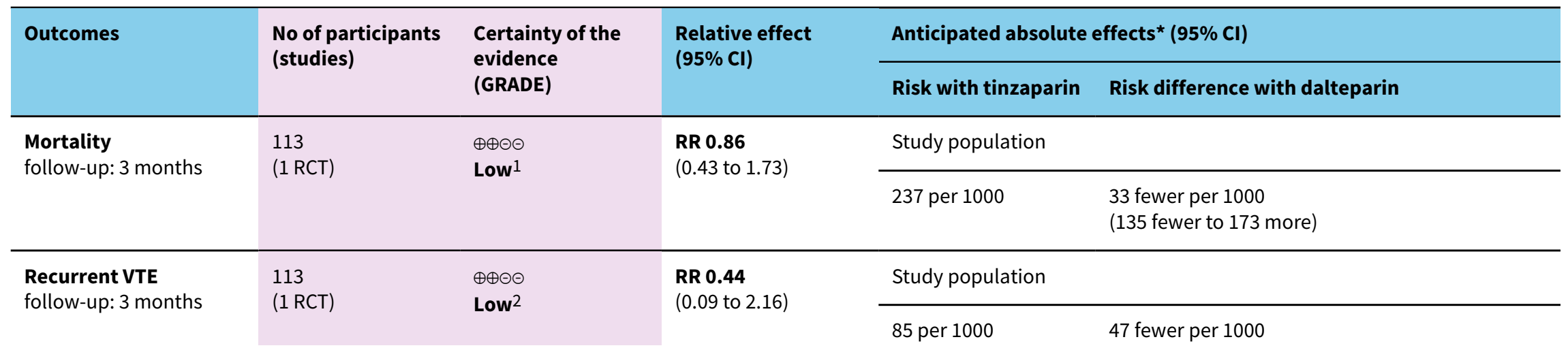




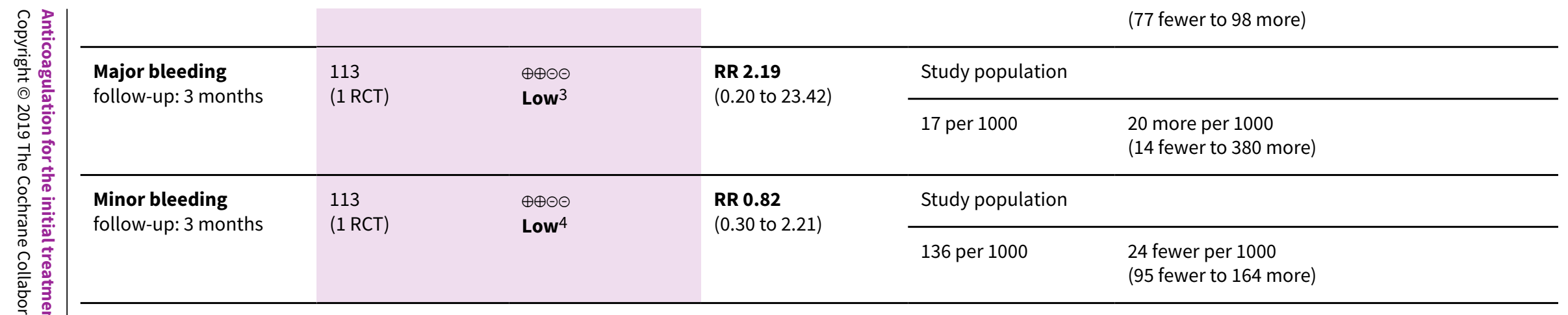

${ }^{\star}$ The risk in the intervention group (and its $95 \%$ confidence interval) is based on the assumed risk in the comparison group and the relative effect of the intervention (and its $95 \% \mathrm{Cl})$.

Cl: confidence interval; $\mathbf{R C T}$ : randomized controlled trial; RR: risk ratio; VTE: venous thromboembolism.

\section{GRADE Working Group grades of evidence}

High certainty: we are very confident that the true effect lies close to that of the estimate of the effect.

Moderate certainty: we are moderately confident in the effect estimate: the true effect is likely to be close to the estimate of the effect, but there is a possibility that it is substantially different.

Low certainty: our confidence in the effect estimate is limited: the true effect may be substantially different from the estimate of the effect.

Very low certainty: we have very little confidence in the effect estimate: the true effect is likely to be substantially different from the estimate of effect.

$195 \% \mathrm{Cl}$ was consistent with the possibility for important benefit (135 per 1000 absolute reduction) and possibility of important harm (173 per 1000 absolute increase), including 25 events among included participants.

$295 \% \mathrm{Cl}$ was consistent with the possibility for important benefit (77 per 1000 absolute reduction) and possibility of important harm (98 per 1000 absolute increase), including 7 events among included participants.

$395 \% \mathrm{Cl}$ was consistent with the possibility for important benefit (14 per 1000 absolute reduction) and possibility of important harm (380 per 1000 absolute increase), including 3 events among included participants.

$495 \% \mathrm{Cl}$ was consistent with the possibility for important benefit (95 per 1000 absolute reduction) and possibility of important harm (164 per 1000 absolute increase), including 14 events among included participants. 


\section{B A C K G R O U N D}

Please refer to the glossary for the definitions of technical terms (Table 1).

\section{Description of the condition}

Cancer status by itself increases the risk of venous thromboembolism (VTE) by four- to six-fold (Heit 2000). In addition, therapeutic interventions such as chemotherapy, hormonal therapy, and indwelling central venous catheters increase the risk of VTE (Heit 2000). Similarly, people undergoing surgery for cancer have a higher risk of VTE than people undergoing surgery for diseases other than cancer (Gallus 1997; Kakkar 1970). People with cancer and VTE have a higher risk of death than people with cancer alone or VTE alone (Levitan 1999; Sorensen 2000).

This heightened hypercoagulable state might alter the response to anticoagulant treatment and the risk of bleeding. Compared with people without cancer, people with cancer who receive anticoagulant treatment for VTE are more likely to develop recurrent VTE with an annual risk of $21 \%$ to $27 \%$, a two- to threefold risk increase (Hutten 2000; Prandoni 2002). These people are also more likely to develop major bleeding with an annual risk of $12 \%$ to $13 \%$, a two- to six-fold risk increase (Hutten 2000; Prandoni 2002).

\section{Description of the intervention}

Heparin, low molecular weight heparins (LMWHs), fondaparinux, and danaparoid do not have intrinsic anticoagulant activity but potentiate the activity of antithrombin III in inhibiting activated coagulation factors. These agents constitute indirect anticoagulants as their activity is mediated by plasma cofactors. Recombinant hirudin, bivalirudin, and argatroban directly inhibit thrombin and are classified as direct anticoagulants (Hirsh 2008). Heparin and its low molecular weight derivatives are not absorbed orally and must be administered parenterally by intravenous (IV) infusion or subcutaneous (SC) injection (Hirsh 1993).

\section{How the intervention might work}

In the initial treatment of VTE, LMWHs and unfractionated heparin (UFH) might have a different comparative efficacy in people with cancer than in people without cancer. Subgroup analyses of one Cochrane systematic review showed that in people without cancer there was no statistically significant difference between the effects of LMWH and UFH on overall mortality (odds ratio (OR) $0.97,95 \%$ confidence interval $(\mathrm{Cl}) 0.61$ to 1.56 ). However, in people with cancer, LMWH resulted in a lower overall mortality compared with UFH (OR 0.53, 95\% Cl 0.33 to 0.85) (Robertson 2017).

\section{Why it is important to do this review}

We initially conducted and updated this and other reviews on this topic to directly and better inform clinical practice guidelines. The last update of this systematic review, published in 2014, identified 16 trials enrolling 1606 participants (Breddin 2001; Buller 1997 (COLOMBUS); Duroux 1991; Hull 1992; Koopman 1996; Levine 1996; Lindmarker 1994; Lopaciuk 1992; Merli 2001; Prandoni 1992; Prandoni 2004 (GALILEI); Simonneau 1993; Simonneau 1997 (THESEE); van Doormaal 2009; Wells 2005). The review found statistically significant reduction in mortality at three months of follow-up with LMWH compared with UFH. No new reviews were identified since then.

\section{O B J E C T IVES}

To compare the efficacy and safety of three types of parenteral anticoagulants (i.e. fixed-dose low molecular weight heparin (LMWH), adjusted-dose unfractionated heparin (UFH), and fondaparinux) for the initial treatment of VTE in people with cancer.

\section{METHODS}

\section{Criteria for considering studies for this review}

\section{Types of studies}

Randomized controlled trials (RCTs).

\section{Types of participants}

Participants with cancer and a confirmed diagnosis of VTE (acute deep venous thrombosis (DVT) or pulmonary embolism (PE)). Participants could have been of any age group (including children) with either solid or hematologic cancer and at any stage of their cancer irrespective of the type of cancer therapy.

\section{Types of interventions}

Experimental arms consisted of initial parenteral anticoagulation (typically the first five to 10 days) with:

- LMWHs (e.g., dalteparin, tinzaparin, fragmin);

- UFHs (e.g., calciparine, multiparin, novoheparin);

- fondaparinux (e.g., arixtra).

We were interested in comparisons of any combination of the three management options listed above.

We excluded studies in which thrombolytic therapy (e.g. streptokinase) was part of the intervention. The protocol should have planned to provide evidence concerning all other co interventions (e.g. chemotherapy) similarly.

\section{Types of outcome measures}

\section{Primary outcomes}

- All-cause mortality.

\section{Secondary outcomes}

- Symptomatic recurrent DVT; events had to be diagnosed using one of the following objective diagnostic tests: venography, 125 fibrinogen uptake test, impedance plethysmography, or Doppler ultrasound.

- Symptomatic recurrent PE; events had to be diagnosed using one of the following objective diagnostic tests: pulmonary perfusion or ventilation scans, computed tomography, pulmonary angiography, or autopsy.

- Major bleeding: we accepted the authors' definitions of major bleeding.

- Minor bleeding: we accepted the authors' definitions of minor bleeding.

- Postphlebitic syndrome.

- Quality of life. 
- Thrombocytopenia.

\section{Search methods for identification of studies}

\section{Electronic searches}

The search was part of a comprehensive search for studies of anticoagulation in people with cancer. We used no language restrictions. We conducted comprehensive searches on 14 January 2018, following the original electronic searches performed in January 2007, February 2010, February 2013. We electronically searched the following databases: the Cochrane Central Register of Controlled Trials (CENTRAL), MEDLINE (via Ovid, starting 1946ID), and Embase (starting 1980; accessed via Ovid). The search strategies combined terms for anticoagulants, terms for cancer, and a search filter for RCTs. We used no language restrictions. We list the full search strategies for each of the electronic databases in Appendix 1; Appendix 2; and Appendix 3.

\section{Searching other resources}

We handsearched the conference proceedings of the American Society of Clinical Oncology (ASCO, 1982 up to September 2017) and the American Society of Hematology (ASH, starting with its 2003 issue up to September 2017). We also searched ClinicalTrials.gov and World Health Organization (WHO) International Clinical Trials Registry Platform for ongoing studies. We reviewed the reference lists of papers included in this review and of other relevant systematic reviews. We used the 'related citation' feature in PubMed to identify additional articles and 'citation tracking' of included studies in Web of Science Core Collection. In addition, we contacted experts in the field to check for unpublished and ongoing trials.

\section{Data collection and analysis}

\section{Selection of studies}

Two review authors independently screened the title and abstract of identified article citations for potential eligibility. We retrieved the full texts of articles judged potentially eligible by at least one review author. Two review authors then independently screened the full-text articles for eligibility using a standardized form with explicit inclusion and exclusion criteria. The two review authors resolved any disagreements concerning eligibility by discussion or by consulting a third review author.

\section{Data extraction and management}

Two review authors independently extracted data from each included study and resolved their disagreements by discussion. We aimed to collect data related to the following.

\section{Participants}

- Demographic characteristics (e.g. age, sex).

- Cancer characteristics (e.g. type, site of origin, stage at diagnosis, time since diagnosis, estimated life expectancy, current cancer treatments, performance status).

- Whether participants had DVT, PE, or both.

- Number of participants in each treatment arm.

- Number of participants randomized to each study arm.

- Number of participants followed up in each study arm.

- Number of participants who discontinued intervention in each arm.

\section{Interventions}

- Type, dosage, and administration schedule of LMWH.

- Dosage and administration schedule of UFH.

- Dosage schedule of fondaparinux.

- Duration of initial parenteral therapy.

- Type (oral anticoagulant versus LMWH) and duration of longterm anticoagulation.

- Cointerventions including radiation therapy or systemic therapy (type and duration).

\section{Outcomes}

We attempted to extract both time to event data (for survival outcome) and categorical data (for all outcomes). However, none of the studies reported time to event data for participants with cancer.

For dichotomous data, we extracted data necessary to conduct a complete case analysis as the primary analysis. We collected allcause mortality at three months. For studies where VTE was not reported as a separate outcome, we added the number of events of DVT and PE.

We attempted to contact study authors for incompletely reported data. We decided a priori to consider abstracts in the main analysis only if study authors supplied us with full reports of their methods and results; otherwise abstracts were included only in the sensitivity analysis.

\section{Other}

We extracted from each included trial any information on the following points:

- source of funding;

- ethical approval;

- conflict of interest.

\section{Assessment of risk of bias in included studies}

We assessed risk of bias at the study level using Cochrane's 'Risk of bias' tool (Higgins 2011). Two review authors independently assessed the methodologic quality of each included study and resolved their disagreements by discussion. 'Risk of bias' criteria included the following.

- Adequate sequence generation.

- Allocation concealment.

- Blinding of participants and personnel.

- Blinding of outcome assessment.

- Percentage of follow-up and whether incomplete outcome data were addressed.

- Whether the study was free of selective outcome reporting.

- Whether the study was stopped early for benefit (other bias).

See section on Dealing with missing data about assessing risk of bias associated with participants with missing data per outcome and across studies.

\section{Measures of treatment effect}

We collected and analyzed risk ratios (RRs) for dichotomous data. None of the outcomes of interest were meta-analyzed as a continuous variable. 


\section{Unit of analysis issues}

The unit of analysis was the individual participant.

\section{Dealing with missing data}

It was unclear whether certain participant categories (e.g. those described as 'withdrew consent' or 'experienced adverse events') were actually followed up by the trial authors (versus had missing participant data) (Akl 2016). To deal with this issue, we made the following considerations:

- 'ineligible participants' and 'did not receive the first dose' participant categories, which were defined prior to the initiation of the study intervention, most likely had missing participant data;

- 'withdrew consent', 'lost to follow-up' (LTFU) and 'outcome not assessable' participant categories and any other categories explicitly reported as not being followed-up, which were defined after the initiation of the study intervention, most likely had missing participant data;

- 'dead', 'experienced adverse events,' 'noncompliant,' and 'discontinued prematurely' (and similarly described) participant categories, less likely had missing participant data.

\section{Dealing with participants with missing data in the primary meta-analysis}

In the primary meta-analysis, we used a complete case analysis approach (i.e. we excluded participants considered to have missing data) (Guyatt 2017).

For categorical data, we used the following calculations for each study arm.

- Denominator: (number of participants randomized) - (number of participants most likely with missing data, both pre- and postintervention initiation);

- Numerator: number of participants with observed events (i.e. participants who experienced at least one event for the outcome of interest during their available follow-up time).

For continuous data, we planned to use for each study arm the reported mean and standard deviation (SD) for participants actually followed up by the trial authors.

\section{Assessing the risk of bias associated with participants with missing data}

When the primary meta-analysis of a specific outcome found a statistically significant effect, we conducted sensitivity metaanalyses to assess the risk of bias associated with missing participant data. Those sensitivity meta-analyses used a priori plausible assumptions about the outcomes of participants considered to have missing data. The assumptions we used in the sensitivity meta-analyses were increasingly stringent to progressively challenge the statistical significance of the results of the primary analysis (Akl 2013; Ebrahim 2013).

For categorical data, and for RR showing a reduction in effect (RR $<1$ ), we used the following increasingly stringent but plausible assumptions (Akl 2013):

- for the control arm, relative incidence (RI) among those with missing data (LTFU) compared to those with available data (followed up, $\mathrm{FU}$ ) in the same arm $\left(\mathrm{RI}_{\mathrm{LTFU} / \mathrm{FU}}\right)=1$; for the intervention arm, $\mathrm{RI}_{\mathrm{LTFU} / \mathrm{FU}}=1.5$;

- for the control arm, RI LTFU/FU = 1; for the intervention arm, $\mathrm{RI}_{\mathrm{LTFU} / \mathrm{FU}}=$ 2;

- for the control arm, $\mathrm{RI}_{\mathrm{LTFU} / \mathrm{FU}}=1$; for the intervention arm, $\mathrm{RI}_{\mathrm{LTFU} / \mathrm{FU}}=3$;

- for the control arm, $\mathrm{RI}_{\mathrm{LTFU} / \mathrm{FU}}=1$; for the intervention arm, $\mathrm{RI}_{\mathrm{LTFU} / \mathrm{FU}}=5$.

For RR showing an increase in effect (RR $>1)$, we switched the above assumptions between the control and interventions arms (i.e. used $\mathrm{RI}_{\mathrm{LTFU} / \mathrm{FU}}=1$ for the intervention arm).

Specifically, we used the following calculations for each study arm.

- Denominator: (number of participants randomized) - (number of participants most likely with missing data, preintervention initiation).

- Numerator: (number of participants with observed events) + (number of participants most likely with missing data postintervention initiation, with assumed events).

Assumed events were calculated by applying the a priori plausible assumptions to the participants considered most likely with missing data postintervention initiation.

For continuous data, we planned to use the four strategies suggested by Ebrahim and colleagues (Ebrahim 2013). The strategies imputed the means for participants with missing data based on the means of participants actually followed up in individual trials included in the systematic review. To impute SD, we used the median SD from the control arms of all included trials (Ebrahim 2013).

\section{Assessment of heterogeneity}

We assessed heterogeneity between trials by visual inspection of forest plots, estimation of the percentage heterogeneity between trials that could not be ascribed to sampling variation ( 12 test; Higgins 2003), and by a formal statistical test of the significance of the heterogeneity (Deeks 2001). If there was evidence of substantial heterogeneity, we investigated and reported the possible reasons for this (see Subgroup analysis and investigation of heterogeneity).

\section{Assessment of reporting biases}

We assessed selective outcome reporting by trying to identify whether the study was included in a trial registry, whether a protocol was available, and whether the methods section provided a list of outcomes. We compared the list of outcomes from those sources to the outcomes reported in the published paper. We did not create funnel plots due to the low number of included trials for each outcome.

\section{Data synthesis}

For dichotomous data, we calculated the RR separately for each study. When analyzing data related to participants who were reported as not compliant, we attempted to adhere to the principles of intention-to-treat (ITT) analysis. We approached the issue of noncompliance independently from that of missing data (Alshurafa 2012). We then pooled the results of the different studies using a random-effects model. We assessed the certainty of 
evidence at the outcome level using the GRADE approach (GRADE handbook).

\section{Subgroup analysis and investigation of heterogeneity}

We planned subgroup analyses based on characteristics of participants but did not conduct them as the data were not available.

\section{Sensitivity analysis}

Unlike the 2014 update of this review, we included in the sensitivity analysis the studies published as abstracts only. As described above, we also planned for sensitivity meta-analyses to assess the risk of bias associated with missing participant data when the primary meta-analysis of a specific outcome found a statistically significant effect.

\section{RE S U L T S}

\section{Description of studies}

\section{Results of the search}

The 14 January 2018 search strategy identified 7387 unique citations. Figure 1 shows the study flow. The title and abstract screening identified 150 citations as potentially eligible for this review. We included 13 eligible RCTs published as full reports (Breddin 2001; Buller 1997 (COLOMBUS); Duroux 1991; Hull 1992; Koopman 1996; Levine 1996; Merli 2001; Prandoni 1992; Prandoni 2004 (GALILEI); Simonneau 1993; Simonneau 1997 (THESEE); van Doormaal 2009; Wells 2005), and two studies published as abstracts (Lindmarker 1994; Lopaciuk 1992), and excluded the remaining 134. The January 2018 search identified no new eligible studies. Agreement between review authors for study eligibility was excellent (kappa $=0.94)$. 
Figure 1. Study flow diagram.

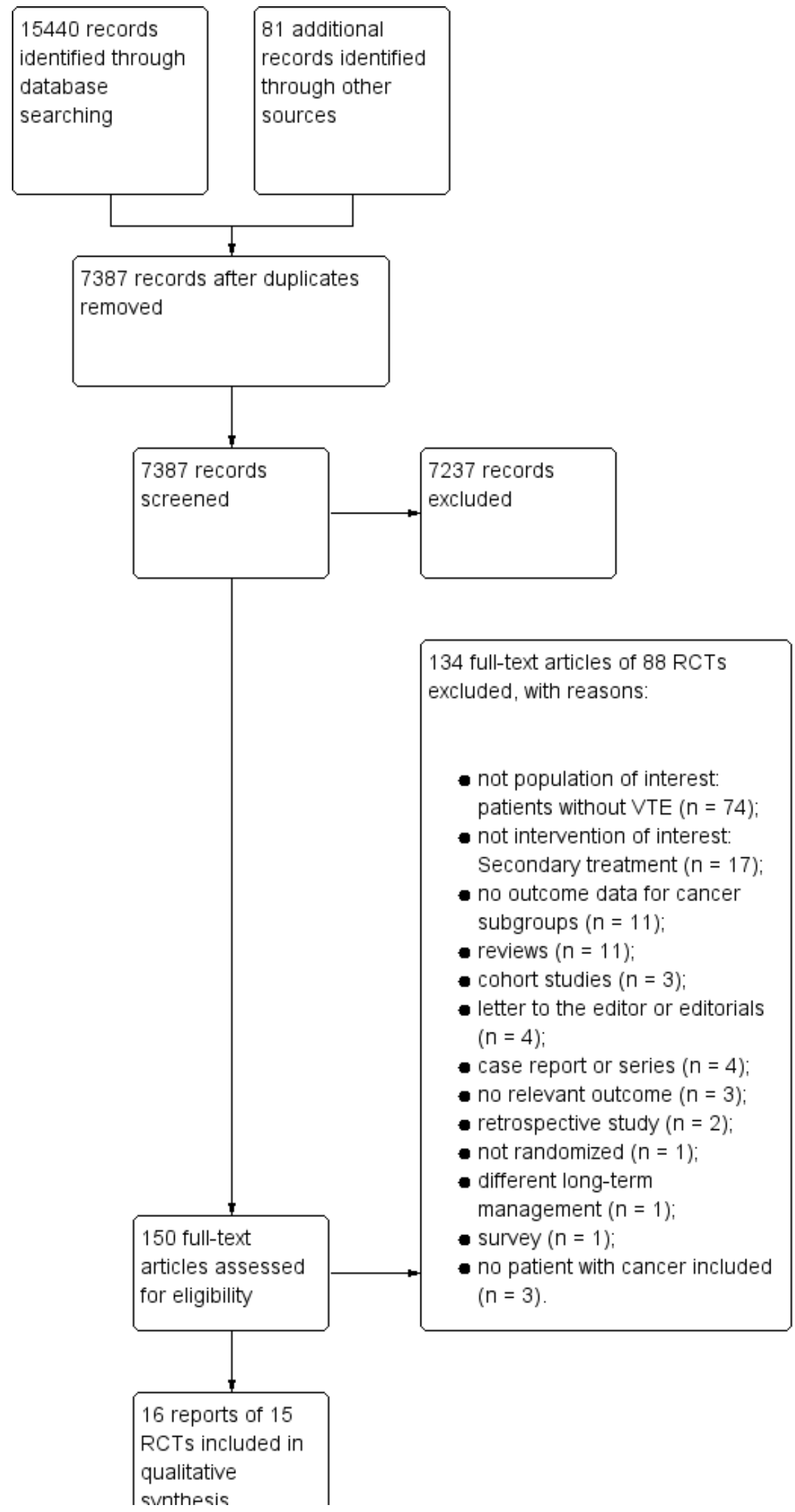


Figure 1. (Continued)

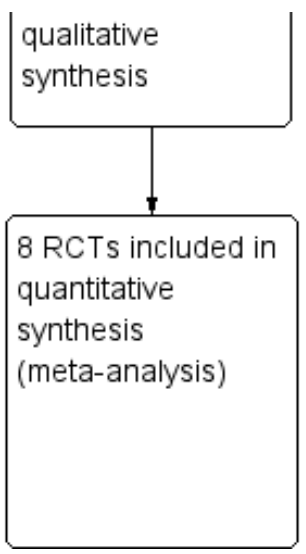

\section{Included studies}

In all 15 included studies, participants with cancer constituted subgroups. Of these 15 studies, three studies reported data for cancer subgroups (Prandoni 1992; Simonneau 1993; van Doormaal 2009), and three studies had follow-up publications reporting cancer subgroup data (Breddin 2001; Hull 1992; Merli 2001). For two studies, we obtained cancer subgroup data from the study authors (Prandoni 2004 (GALILEI); Wells 2005). Seven studies did not report cancer subgroup data (Buller 1997 (COLOMBUS); Duroux 1991; Koopman 1996; Levine 1996; Lindmarker 1994; Lopaciuk 1992; Simonneau 1997 (THESEE)), so we used the data as reported in two published systematic reviews (Hettiarachchi 1999; Robertson 2017). We excluded these seven studies from the main analysis and included them in the sensitivity analyses.

Of the 15 studies, 13 compared LMWH to UFH, one compared fondaparinux to heparin (UFH and LMWH) (van Doormaal 2009), and one compared dalteparin to tinzaparin (Wells 2005). None of the studies specified the types of cancer of the participants. In 14/15 studies, the initial parenteral anticoagulation was followed by oral anticoagulation for at least three months. In Duroux 1991, the longterm anticoagulation was either SC UFH or oral anticoagulation depending on the usual regimen of the participating center (Duroux 1991).

Breddin and colleagues recruited 83 people with cancer aged at least 18 years with DVT (Breddin 2001). Overall, the study enrolled 1137 participants. Participants were randomized to receive IV UFH for five to seven days or SC reviparin twice a day for five to seven days or once a day for a mean (SD) of $28 \pm 2$ days. All the participants received a vitamin $\mathrm{K}$ antagonist (VKA) until the end of the 90-day observation period. The primary efficacy outcome was a change in the venographically determined thrombus size. Assessed outcomes were recurrence of DVT or PE. Participants were followed up for 90 days. The author reported $91 \%$ follow-up.

Buller and colleagues recruited 232 people with cancer, aged at least 18 years, with proximal or distal DVT, PE, or both (Buller 1997 (COLOMBUS)). Participants were randomized to receive weightbased SC reviparin twice daily at home or IV UFH (target activated partial thromboplastin time (aPTT) 1.5 to 2.5) in hospital for five days. Oral anticoagulant treatment with a derivative of coumarin was begun concomitantly on the first or second day and continued for 12 weeks. Assessed outcomes were symptomatic recurrent VTE, major bleeding, and death. Participants were followed up for 12 weeks. The study authors reported complete follow-up.

Duroux and colleagues recruited 18 people with cancer, aged at least 18 years, with proximal DVT but no PE (Duroux 1991). Overall, the study enrolled 170 participants. Participants were randomized to receive nadroparin twice daily for 10 days, or IV UFH (target aPTT 1.5 to 2 ) for 10 days. After day 10, each center continued its usual anticoagulant regimen either by SC UFH at adjusted dose or by oral anticoagulant for 12 weeks. Assessed outcomes were mortality, recurrent venogram-detected VTE and major bleeding. There was no Information about the follow-up in cancer subgroup reported.

Hull and colleagues recruited 95 people with cancer, aged at least 18 years, with proximal DVT (Hull 1992). Overall, the study enrolled 432 participants. Participants were randomized to receive SC tinzaparin once daily or IV UFH (target aPTT 1.5 to 2.5 ) for six days. All participants received long-term therapy with warfarin for at least three months. Participants assigned to receive IV UFH also received a SC injection of placebo once every 24 hours. Participants assigned to receive SC LMWH also received an IV bolus of placebo and a continuous IV infusion of placebo throughout the initial therapy. Assessed outcomes were recurrent VTE, bleeding complications and participant death. Participants were followed up for three months. The authors reported complete follow-up.

Koopman and colleagues recruited 70 people with cancer, aged at least 18 years and with a life expectancy of minimum six months, with proximal DVT (Koopman 1996). Overall, the study enrolled 400 participants. Participants were randomized to receive SC nadroparin twice daily at home or IV UFH (target aPTT 1.5 to 2) for five days. In each participant, VKA therapy was begun on the first day after commencing initial therapy and continued for at least three months. The dose of VKA was adjusted to maintain the international normalized ratio (INR) between 2.0 and 3.0. The primary outcome studied was symptomatic recurrent VTE, while the secondary outcome was major bleeding. All participants were contacted daily during the initial treatment and at 4, 12, and 24 weeks. The authors reported complete follow-up.

Levine and colleagues recruited 103 people with cancer with proximal or distal DVT (Levine 1996). Overall, the study enrolled 500 participants. Participants were randomized to receive treatment with either SC enoxaparin at home or continuous IV UFH in the hospital for five days. In all participants, warfarin therapy was 
begun on the second day after commencing initial therapy and continued for at least three months. The dose of VKA was adjusted to maintain the INR between 2.0 and 3.0. Assessed outcomes were symptomatic recurrent VTE and bleeding during the period of administration of study medication or within 48 hours after its discontinuation. The participants were assessed monthly for three months. The authors reported complete follow-up.

Lindmarker and colleagues recruited 16 people with cancer, aged at least 18 years, with DVT (Lindmarker 1994). Overall, the study enrolled 204 participants. Participants were randomized to receive SC fragmin once daily compared to IV UFH (target aPTT 1.5 to 3.0) for five days. In all participants, warfarin therapy was given for at least three months. The dose of VKA was adjusted to maintain the INR between 2.0 and 3.0. Assessed outcomes were mortality, recurrent VTE and bleeding. Participants were followed up for six months. The authors reported complete follow-up.

Lopaciuk and colleagues recruited nine people with cancer with proximal, DVT, or both of the leg (Lopaciuk 1992). Overall, the study enrolled 149 participants. Participants were randomized to receive either fixed dose nadroparin (LMWH) or UFH (doses adjusted according to aPTT) for 10 days. In all participants, VKA therapy was begun on the seventh day after commencing initial therapy and continued for at least three months. The dose of VKA was adjusted to maintain the INR between 2.0 and 3.0. Assessed outcomes were size of the thrombus pre- and post-treatment and recurrent VTE. Participants were followed up for three months. The authors reported complete follow-up.

Merli and colleagues recruited 141 people with cancer, aged at least 18 years, with DVT or PE (Merli 2001). Overall, the study enrolled 204 participants. Participants were randomized to receive SC enoxaparin (1 mg/kg twice daily or $1.5 \mathrm{mg} / \mathrm{kg}$ once daily) or IV UFH (target aPTT 55 to 80 seconds) for five days. In all participants, warfarin was started within 72 hours of initial study drug administration to keep INR between 2.0 and 3.0. Assessed outcomes included recurrent DVT or PE. Participants were followed up for three months. There was no information about follow-up in cancer subgroup reported.

Prandoni and colleagues recruited 33 people with cancer, aged at least 18 years, with proximal DVT (Prandoni 1992). Overall, the study enrolled 170 participants. Participants were randomized to receive weight-based SC nadroparin twice daily or IV UFH (target aPTT 1.5 to 2.0) for 10 days. In all participants, coumarin was begun on the seventh day after commencing initial therapy and continued for at least three months. The dose of coumarin was adjusted to maintain the INR between 2.0 and 3.0. Assessed outcomes included symptomatic recurrent DVT or PE. Participants were followed up for six months. The authors reported complete follow-up.

Prandoni and colleagues recruited 156 people with cancer, aged at least 18 years and with a life expectancy of minimum three months, with DVT, PE, or both (Prandoni 2004 (GALILEI)). Overall, the study enrolled 720 participants. Participants were randomized to receive nadroparin twice daily or SC UFH twice daily (target aPTT 50 to 90 seconds) for five days. In all participants, VKA therapy was begun on the first or second day after commencing initial therapy and continued for 12 weeks. The dose of VKA was adjusted to maintain the INR between 2.0 and 3.0. The primary endpoint was the incidence of symptomatic recurrent VTE during the three-month study period. A secondary outcome was the incidence of major bleeding during the initial LMWH treatment and additional 48 hours. During the initial treatment with the study drugs, participants were examined daily. Follow-up visits were scheduled after one and three months. The authors report complete follow-up.

Simonneau recruited nine people with cancer, aged at least 18 years, with proximal DVT (Simonneau 1993). Overall, the study enrolled 134 participants. Participants were randomized to receive SC enoxaparin twice daily or IV UFH for 10 days (target aPTT 1.5 to 2.5). In all participants, VKA therapy was begun on the 10th day after commencing initial therapy and continued for at least three months. The dose of VKA was adjusted to maintain the INR between 2.0 and 3.0. Outcomes assessed were mortality, recurrent symptomatic VTE, and bleeding. Participants were followed up for three months. The authors reported complete follow-up.

Simonneau and colleagues recruited 60 people with cancer, aged at least 18 years and life expectancy of minimum three months, with clinically suspected PE (Simonneau 1997 (THESEE)). Overall, the study enrolled 612 participants. Participants were randomized to receive SC tinzaparin once daily or IV UFH (target aPTT 2 to 3 ) for five days. In all participants, VKA therapy was begun on the first three days after commencing initial therapy and continued for at least three months. The dose of VKA was adjusted to maintain the INR between 2.0 and 3.0. Outcomes assessed were mortality, recurrent symptomatic VTE, and major bleeding. Participants were followed up for 90 days. The authors reported complete follow-up.

Van Doormaal and colleagues recruited 477 people with cancer, aged at least 18 years, with acute symptomatic DVT without PE (subgroup analysis of MATISSE study) (van Doormaal 2009). Participants were randomized to receive SC fondaparinux once daily, or enoxaparin twice daily, or UFH (target aPTT 1.5 to 2.5). In all participants, VKA therapy was begun as soon as possible but not later than 72 hours after commencing initial therapy and continued for at least three months. The dose of VKA was adjusted to maintain the INR between 2.0 and 3.0. Assessed outcomes were mortality, symptomatic recurrent VTE, and bleeding. Participants were followed up for 90 days. The authors reported complete follow-up.

Wells and colleagues recruited 113 people with cancer, aged at least 18 years, with upper or lower extremity DVT (Wells 2005). Overall, the study enrolled 505 participants. Participants were randomized to receive SC tinzaparin once daily or SC dalteparin once daily on an outpatient basis. In all participants, warfarin therapy was begun within 24 hours of the first dose of LMWH and continued for three months. Assessed outcomes were mortality, symptomatic recurrent VTE, and major and minor bleeding. Participants were followed up for three months. The authors reported complete follow-up.

\section{Excluded studies}

Of the 134 excluded studies, in 11 studies people with cancer constituted study subgroups but their outcome data were not available (Albada 1989; Belcaro 1999; Bratt 1990; Buller 2004; Fiessinger 1996; Harenberg 1990; Harenberg 2000; Holm 1986; Hull 2000; Luomanmaki 1996; Riess 2003). We excluded the remaining 123 studies for the following reasons: not population of interest: participants without VTE (74 studies), no participants with cancer (three studies); not intervention of interest: secondary treatment 
(17 studies), different long-term management (one study); not design of interest: review (11 studies), case report or series (four studies), letter to the editor or editorial (four studies), cohort study (three studies), retrospective study (two studies), not randomized (one study), survey (one study); and not outcome of interest (three studies).

\section{Risk of bias in included studies}

The judgments for the risk of bias are summarized in Figure 2 and Figure 3. 
Figure 2. Risk of bias summary: review authors' judgments about each risk of bias item for each included study.

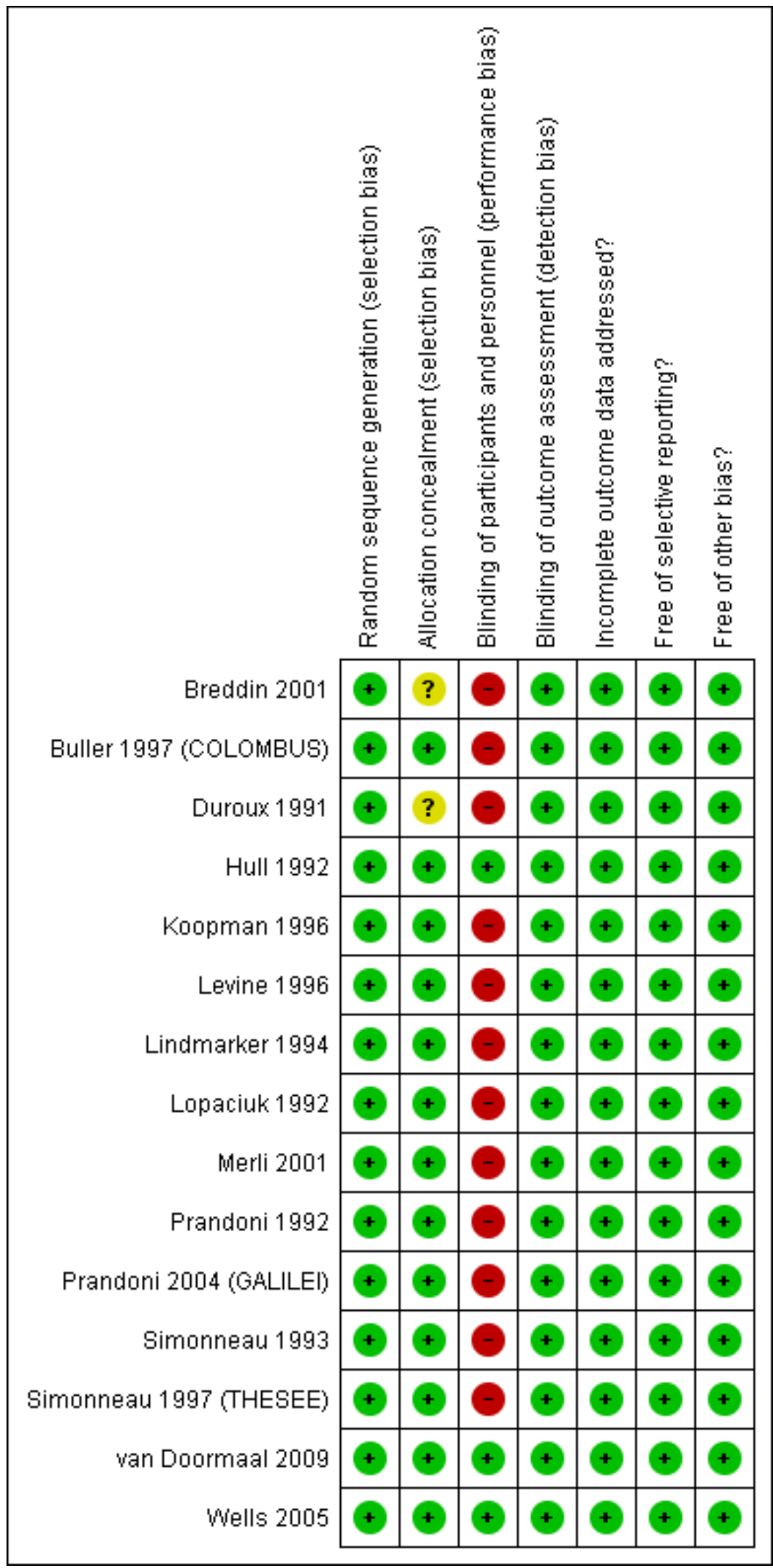

Anticoagulation for the initial treatment of venous thromboembolism in people with cancer (Review) 
Figure 3. Risk of bias graph: review authors' judgments about each risk of bias item presented as percentages across all included studies.

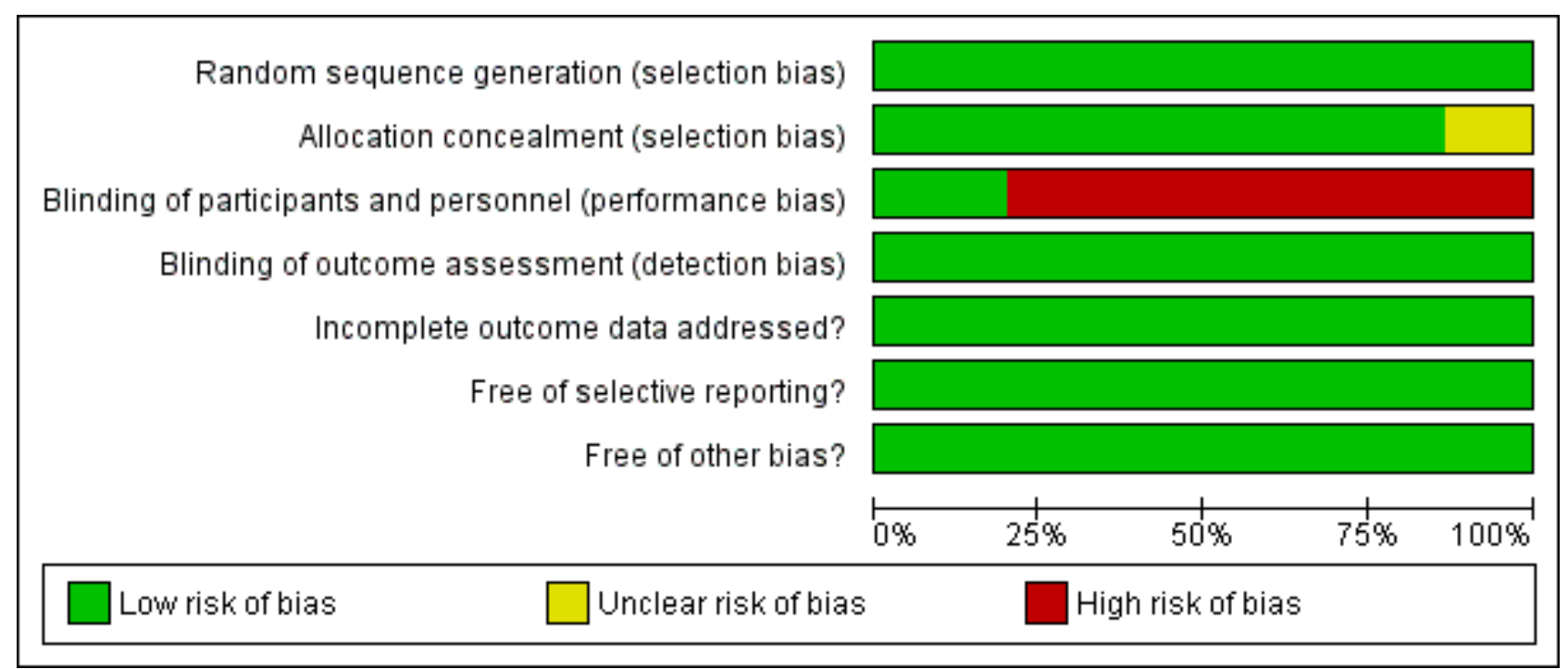

\section{Allocation}

We judged allocation to be adequately concealed in 13 of the 15 studies (Buller 1997 (COLOMBUS); Hull 1992; Koopman 1996; Levine 1996; Lindmarker 1994; Lopaciuk 1992; Merli 2001; Prandoni 1992; Prandoni 2004 (GALILEI); Simonneau 1993; Simonneau 1997 (THESEE); van Doormaal 2009; Wells 2005). Two studies did not report on allocation concealment (Breddin 2001; Duroux 1991).

\section{Blinding}

\section{Blinding of participants and personnel (performance bias)}

We judged participants and personnel to be definitely blinded in three of the 15 studies (Hull 1992; van Doormaal 2009; Wells 2005), and definitely not blinded in 12 studies (Breddin 2001; Buller 1997 (COLOMBUS); Duroux 1991; Koopman 1996; Levine 1996; Lindmarker 1994; Lopaciuk 1992; Merli 2001; Prandoni 1992; Prandoni 2004 (GALILEI); Simonneau 1993; Simonneau 1997 (THESEE)).

\section{Blinding of outcome assessment (detection bias)}

We judged outcome assessors to be definitely blinded in 14 studies (Breddin 2001; Buller 1997 (COLOMBUS); Hull 1992; Koopman 1996; Levine 1996; Lindmarker 1994; Lopaciuk 1992; Merli 2001; Prandoni 1992; Prandoni 2004 (GALILEI); Simonneau 1993; Simonneau 1997 (THESEE); van Doormaal 2009; Wells 2005) and probably not blinded in one study (Duroux 1991).

\section{Incomplete outcome data}

All but three studies (Breddin 2001; Duroux 1991; Merli 2001) reported complete follow-up.

Breddin and colleagues reported an approximate $91 \%$ follow-up in the cancer subgroup (Breddin 2001).

For the other two studies, we analyzed the available data assuming that any possibly missing data were missing at random (Duroux 1991; Merli 2001).

\section{Selective reporting}

The outcomes listed in the methods section were reported in the results section for all 15 studies.

We did not suspect selective reporting of outcomes for any of the studies. The cancer subgroup data were missing for seven studies.

\section{Other potential sources of bias}

None found.

\section{Effects of interventions}

See: Summary of findings for the main comparison LMWH initial treatment compared to UFH initial treatment in people with cancer with VTE; Summary of findings 2 Fondaparinux initial treatment compared to Heparin initial treatment in patients with cancer with VTE; Summary of findings 3 Dalteparin compared to tinzaparin in people with cancer with VTE

\section{Low molecular weight heparin versus unfractionated heparin Mortality}

Meta-analysis of the five RCTs, including 418 participants found that LMWH compared to UFH likely decreased mortality at three months (RR $0.66,95 \% \mathrm{Cl} 0.40$ to 1.10 ; risk difference (RD) 57 fewer per $1000,95 \% \mathrm{Cl} 101$ fewer to 17 more; moderate certainty evidence) (see Analysis 1.1) (Breddin 2001; Hull 1992; Prandoni 1992; Prandoni 2004 (GALILEI); Simonneau 1993). The I2 value showed no heterogeneity $\left(I^{2}=0 \%\right)$. We did not create funnel plots due to the low number of included trials for the outcome of mortality. The certainty of evidence for mortality was moderate due to imprecision (see Summary of findings for the main comparison). Appendix 4 includes the Evidence Profile (a more detailed version of the Summary of findings for the main comparison). These results did not change in a meta-analysis including the studies that did not report data for the cancer subgroup (Buller 1997 (COLOMBUS); Duroux 1991; Koopman 1996; Levine 1996; Simonneau 1997 (THESEE)), and the studies published as abstracts (Lindmarker 1994; Lopaciuk 1992) (RR 0.75, 95\% Cl 0.56 to 1.02 ). 


\section{Recurrent venous thromboembolism}

There were no data available for DVT or PE events separately. Meta-analysis of three RCTs including 422 participants comparing LMWH to UFH did not rule out a clinically significant increase or decrease in VTE (RR $0.69,95 \% \mathrm{Cl} 0.27$ to 1.76 ; RD 30 fewer per $1000,95 \% \mathrm{Cl} 70$ fewer to 73 more; moderate certainty evidence) (Breddin 2001; Merli 2001; Prandoni 2004 (GALILEI)). The I2 value indicated moderate heterogeneity $\left({ }^{2}=46 \%\right)$ (see Analysis 1.2). The certainty of evidence for recurrent VTE was moderate due to imprecision (see Summary of findings for the main comparison). Appendix 4 includes the Evidence Profile (a more detailed version of the Summary of findings for the main comparison).

There were no data available for bleeding outcomes, postphlebitic syndrome, quality of life, or thrombocytopenia.

\section{Fondaparinux versus heparin}

One study comparing fondaparinux with heparin (UFH and LMWH) did not show or exclude a beneficial or detrimental effect of fondaparinux on mortality at three months (RR $1.25,95 \% \mathrm{Cl} 0.86$ to 1.81; RD 43 more per $1000,95 \% \mathrm{Cl} 24$ fewer to 139 more, moderate certainty evidence), recurrent VTE (RR $0.93,95 \% \mathrm{Cl} 0.56$ to 1.54 ; RD 8 fewer per $1000,95 \% \mathrm{Cl} 52$ fewer to 63 more, moderate certainty evidence), major bleeding (RR $0.82,95 \% \mathrm{Cl} 0.40$ to 1.66 ; RD 12 fewer per $1000,95 \% \mathrm{Cl} 40$ fewer to 44 more, moderate certainty evidence), or minor bleeding (RR $1.53,95 \% \mathrm{Cl} 0.88$ to 2.66; RD 42 more per $1000,95 \% \mathrm{Cl}$ from 10 fewer to 132 more, moderate certainty evidence) (van Doormaal 2009). The certainty of evidence was moderate for mortality, major bleeding, minor bleeding, and recurrent VTE due to imprecision (see Summary of findings table 2). Appendix 5 includes the Evidence Profile (a more detailed version of the Summary of findings table 2).

There were no data available for postphlebitic syndrome, quality of life, thrombocytopenia.

\section{Dalteparin versus tinzaparin}

One study comparing dalteparin with tinzaparin did not show or exclude a beneficial or detrimental effect of dalteparin on mortality (RR 0.86, 95\% Cl 0.43 to 1.73; RD 33 fewer per 1000, 95\% Cl 135 fewer to 173 more; low certainty evidence), VTE recurrence (RR $0.44,95 \% \mathrm{Cl} 0.09$ to 2.16; RD 47 fewer per $1000,95 \% \mathrm{Cl} 77$ fewer to 98 more; low certainty evidence), major bleeding (RR 2.19, $95 \%$ $\mathrm{Cl} 0.20$ to 23.42; RD 20 more per $1000,95 \% \mathrm{Cl} 14$ fewer to 380 more; low certainty evidence), or minor bleeding (RR $0.82,95 \% \mathrm{Cl}$ 0.30 to 2.21; RD 24 fewer per 1000, 95\% Cl 95 fewer to 164 more; low certainty evidence). The certainty of evidence was low for all tested outcomes, due to imprecision (see Summary of findings 3). Appendix 6 includes the Evidence Profile (a more detailed version of the Summary of findings 3 ).

There were no data available for postphlebitic syndrome, quality of life, or thrombocytopenia.

\section{DISCUSSION}

\section{Summary of main results}

LMWH appeared to have a small effect on mortality compared to UFH in the initial treatment of VTE in people with cancer. The review did not prove or exclude a clinically important effect of fondaparinux compared to any heparin, on mortality, recurrent
VTE, or major or minor bleeding. The available evidence did not show a differential effect between dalteparin and tinzaparin for all tested outcomes.

\section{Overall completeness and applicability of evidence}

The completeness of the data was a major concern in this systematic review. First, of a total of 26 potentially eligible studies, we did not include 11 because the study authors did not report the required subgroup data for people with cancer. These 11 studies would have contributed 340 additional participants to the metaanalysis (1615 are currently included). If the treatment effect from those studies was different from the reported effect, their exclusion from the meta-analysis could have biased our results. Moreover, only three of the included studies reported cancer subgroup data for VTE recurrence and none reported cancer subgroup data for the bleeding outcomes.

\section{Quality of the evidence}

For the LMWH versus UFH comparison, the certainty of evidence for all tested outcomes was moderate due to imprecision. For the fondaparinux versus heparin comparison, the certainty of evidence was moderate for all tested outcomes due to imprecision. For the dalteparin versus tinzaparin comparison, the certainty of evidence was low for all tested outcomes due to imprecision.

\section{Potential biases in the review process}

Our systematic approach to searching for studies, selecting studies, and extracting data should have minimized the likelihood of missing relevant studies. The inclusion of different types of cancer in the same study precluded us from conducting the subgroup analyses to explore effect modifiers such as type and stage of cancer. A potential bias of our review might be the limitation of the electronic search strategy to people with cancer, while the data needed for this review came from studies not restricted to this subgroup.

\section{Agreements and disagreements with other studies or reviews}

Four previous systematic reviews compared the effects of LMWH and UFH on mortality in people with cancer and with VTE (Erkens 2010; Gould 1999; Hettiarachchi 1999; Robertson 2017). We limited our comparison to the newest systematic review.

Erkens and colleagues conducted in a Cochrane Review comparing fixed-dose LMWH versus UFH for treatment of acute VTE (Erkens 2010). In a subgroup analysis of people with cancer, they included six studies and 446 participants. The meta-analysis found a significant reduction in mortality in the LMWH group compared to the UFH group at three months of follow-up (OR $0.53,95 \% \mathrm{Cl} 0.33$ to 0.85 ). Erkens and colleagues did not include data from Breddin 2001 for the outcome of mortality, and that explains the difference between our results.

\section{AUTHORS' CONCLUSIONS}

\section{Implications for practice}

Low molecular weight heparin (LMWH) is possibly superior to unfractionated heparin (UFH) in reducing mortality in the initial treatment of venous thromboembolism (VTE) in people with cancer. The confidence in this effect is reduced by both the 
risk of bias in included studies and the likelihood of publication bias. However, there are additional advantages of LMWH related to subcutaneous administration and outpatient management (O'Brien 1999; Othieno 2007).

The decision for a person with cancer with VTE to start heparin therapy should balance the benefits and harms, and should integrate the person's values and preferences (Haynes 2002).

\section{Implications for research}

There is a need to conduct trials comparing anticoagulants in the initial treatment of VTE that are restricted to people with cancer. Researchers should consider making the raw data of randomized controlled trials available for individual participant data metaanalysis. In addition, as recognized by Cochrane, addressing all important outcomes including harm is of great importance in making evidence-based healthcare decisions.

\section{ACKNOWLEDGEMENTS}

We thank Dr Merli, Dr Prandoni, Dr Siragusa, and Dr Wells for providing us with data. We thank Ms Ann Grifasi for her administrative support. We thank Dr Sameer Gunukula, Dr Paola Muti, Dr Ignacio Neumann, and Dr Srinivasa Rao Vasireddi for their contributions to previous versions of this systematic review.

We also thank Dr Assem Khamis for his help with conducting the sensitivity analysis.

We thank Jo Morrison, Co-ordinating Editor for the Cochrane Gynaecological Neuro-oncology and Orphan Cancers Group. We also thank Gail Quinn, Managing Editor of the Cochrane Gynaecological Neuro-oncology and Orphan Cancers Group for her exceptional support. We thank Joanne Platt, the Information
Specialist of the Cochrane Gynaecological Neuro-oncology and Orphan Cancers Group, for setting up and managing the monthly alerts.

As described under "Sources of Support" this update was supported in part by the American Society of Hematology to inform ASH guidelines on the topic. We thank the ASH guideline panel for prioritizing questions previously addressed by our review and for critically reviewing our work, including Drs. Pablo Alonso, Waleed Alhazanni, Marc Carrier, Cihan Ay, Marcello DiNisio, Lisa Hicks, Alok Khorana, Andrew Leavitt, Agnes Lee, Gary Lyman, Fergus Macbeth, Rebecca Morgan, Simon Noble, and David Stenehjem and patient representatives Jackie Cook and Elizabeth Sexton. Their input was valuable in validating some of the review related decisions such as eligibility of included studies and the analytical approach.

For our update of these reviews, we followed Cochrane methods using the same eligibility criteria and outcomes used previously. The ASH guidelines group used slightly different methods that generated slightly different results. For example, the ASH guideline panel agreed to prioritize different outcomes; include unpublished data; include abstracts; use different definitions for duration of treatment; and rate certainty of evidence slightly differently for some outcomes, for instance because of imprecision or indirectness. These differences are not described in this publication. Instead, they will be described in the ASH guideline publication.

This project was supported by the National Institute for Health Research (NIHR), via Cochrane Infrastructure Funding. The views and opinions expressed therein are those of the review authors and do not necessarily reflect those of the Systematic Reviews Programme, NIHR, National Health Service, or the Department of Health. 


\section{RE F E R E N C E S}

\section{References to studies included in this review}

Breddin 2001 \{published data only\}

Breddin HK, Hach-Wunderle V, Nakov R, Kakkar VV, Cortes Investigators. Effects of a low-molecular-weight heparin on thrombus regression and recurrent thromboembolism in patients with deep-vein thrombosis. New England Journal of Medicine 2001;344(9):626-31.

\section{Buller 1997 (COLOMBUS) \{published data only\}}

Buller HR, Gent M, Gallus AS, Ginsberg J, Prins MH, Baildon R, et al. Low-molecular-weight heparin in the treatment of patients with venous thromboembolism. New England Journal of Medicine 1997;337(10):657-62.

\section{Duroux 1991 \{published data only\}}

Duroux P, Ninet J, Bachet P, Prandoni P, Ruol A, Vigo M, et al. $A$ randomised trial of subcutaneous low molecular weight heparin (CY 216) compared with intravenous unfractionated heparin in the treatment of deep vein thrombosis. A collaborative European multicenter study. Thrombosis and Haemostasis 1991;65(3):251-6.

Hull 1992 \{published data only\}

Hull RD, Raskob GE, Pineo GF, Green D, Trowbridge AA, Elliott CG, et al. Subcutaneous low-molecular-weight heparin compared with continuous intravenous heparin in the treatment of proximal-vein thrombosis. New England Journal of Medicine 1992;326(15):975-82.

\section{Koopman 1996 \{published data only\}}

Koopman MM, Prandoni P, Piovella F, Ockelford PA, Brandjes DP, van der Meer J, et al. Treatment of venous thrombosis with intravenous unfractionated heparin administered in the hospital as compared with subcutaneous low-molecular-weight heparin administered at home. The Tasman Study Group. New England Journal of Medicine 1996;334(11):682-7.

Levine 1996 \{published data only\}

Levine M, Gent M, Hirsh J, Leclerc J, Anderson D, Weitz J, et al. A comparison of low-molecular-weight heparin administered primarily at home with unfractionated heparin administered in the hospital for proximal deep-vein thrombosis. New England Journal of Medicine 1996;334(11):677-81.

\section{Lindmarker 1994 \{published data only\}}

Lindmarker P, Holstrom M, Granqvist S, Johnsson $\mathrm{H}$, Lockner D. Comparison of once-daily subcutaneous Fragmin with continuous intravenous unfractionated heparin in the treatment of deep vein thrombosis. Thrombosis and Haemostasis 1994;72(2):186-90.

\section{Lopaciuk 1992 \{published data only\}}

Lopaciuk S, Meissner AJ, Filipecki S, Zawilska K, Sowier J, Ciesielski L, et al. Subcutaneous low molecular weight heparin versus subcutaneous unfractionated heparin in the treatment of deep vein thrombosis: a Polish multicenter trial. Thrombosis and Haemostasis 1992;68(1):14-8.
Merli 2001 \{published data only\}

Merli G, Spiro TE. Subcutaneous enoxaparin once or twice daily compared with intravenous unfractionated heparin for treatment of venous thromboembolic disease. Annals of Internal Medicine 2001;134(3):191-202.

Prandoni 1992 \{published data only\} Prandoni P, Lensing AW, Büller HR, Carta M, Cogo A, Vigo M, et al. Comparison of subcutaneous low-molecular-weight heparin with intravenous standard heparin in proximal deepvein thrombosis. Lancet 1992;339(8791):441-5.

Prandoni 2004 (GALILEI) \{published data only\}

Prandoni P, Carnovali M, Marchiori A, Galilei Investigators. Subcutaneous adjusted-dose unfractionated heparin vs fixeddose low-molecular-weight heparin in the initial treatment of venous thromboembolism. Archives of Internal Medicine 2004;164(10):1077.

\section{Simonneau 1993 \{published data only\}}

Simonneau G, Charbonnier B, Decousus H, Planchon B, Ninet J, Sie $P$, et al. Subcutaneous low-molecular-weight heparin compared with continuous intravenous unfractionated heparin in the treatment of proximal deep vein thrombosis. Archives of Internal Medicine 1993;153(13):1541-6.

\section{Simonneau 1997 (THESEE) \{published data only\}}

Simonneau G, Sors H, Charbonnier B, Page Y, Laaban JP, Azarian $\mathrm{R}$, et al. A comparison of low-molecular-weight heparin with unfractionated heparin for acute pulmonary embolism. The THESEE Study Group. Tinzaparine ou Heparine Standard: Evaluations dans l'Embolie Pulmonaire. New England Journal of Medicine 1997;337(10):663-9.

\section{van Doormaal 2009 \{published data only\}}

Büller HR, Davidson BL, Decousus H, Gallus A, Gent M, Piovella $F$, et al. Fondaparinux or enoxaparin for the initial treatment of symptomatic deep venous thrombosis: a randomized trial. Annals of Internal Medicine 2004;140:867-73.

* van Doormaal FF, Raskob GE, Davidson BL, Decousus H, Gallus AG, Lensing AWA, et al. Treatment of venous thromboembolism in patients with cancer: subgroup analysis of the Matisse clinical trials. Thrombosis and Haemostasis 2009;101:762-9.

\section{Wells 2005 \{published data only\}}

Wells PS, Anderson DR, Rodger MA, Forgie MA, Florack P, Touchie $D$, et al. A randomized trial comparing 2 low-molecularweight heparins for the outpatient treatment of deep vein thrombosis and pulmonary embolism. Archives of Internal Medicine 2005;165:733-8.

\section{References to studies excluded from this review}

\section{Agnelli 1998 \{published data only\}}

Agnelli G, Piovella F, Buoncristiani P, Severi P, Pini M, D'Angelo A, et al. Enoxaparin plus compression stockings compared with 
compression stockings alone in the prevention of venous thromboembolism after elective neurosurgery. New England Journal of Medicine 1998;339:80-5.

\section{Agnelli 2005 \{published data only\}}

Agnelli G, Bergqvist D, Cohen AT, Gallus AS, Gent M. Randomized clinical trial of postoperative fondaparinux versus perioperative dalteparin for prevention of venous thromboembolism in high-risk abdominal surgery. British Journal of Surgery 2005;92(10):1212-20.

\section{Agnelli 2015 (AMPLIFY) \{published data only\}}

Agnelli G, Buller HR, Cohen A, Gallus AS, Lee TC, Pak R, et al. Apixaban for the treatment of venous thromboembolism in cancer patients: data from the amplify trial. Canadian Journal of Cardiology 2014;30:S278.

* Agnelli G, Buller HR, Cohen A, Gallus AS, Lee TC, Pak R, et al. Oral apixaban for the treatment of venous thromboembolism in cancer patients: results from the AMPLIFY trial. Journal of Thrombosis and Haemostasis 2015;13(12):2187-91.

\section{Albada 1989 \{published data only\}}

Albada J, Nieuwenhuis HK, Sixma JJ. Treatment of acute venous thromboembolism with low molecular weight heparin (Fragmin). Results of a double-blind randomized study. Circulation 1989;80(4):935-40.

\section{Alikhan 2003 (MEDENOX) \{published data only\}}

* Alikhan R, Cohen AT, Combe S, Samama MM, Desjardins L, Eldor A, et al. Prevention of venous thromboembolism in medical patients with enoxaparin: a subgroup analysis of the MEDENOX study. Blood Coagulation and Fibrinolysis 2003;14(4):341-6.

Samama MM, Cohen AT, Darmon JY, Desjardins L, Eldor A, Janbon C, et al. A comparison of enoxaparin with placebo for the prevention of venous thromboembolism in acutely ill medical patients. New England Journal of Medicine 1999;341(11):793-800.

\section{Altundag 2005 \{published data only\}}

Altundag K, Altundag O, Atik MA. Heparin and CXCL12 dimerization. Journal of Clinical Oncology 2005;23(28):7248.

\section{Anton 2001 \{published data only\}}

Anton N, Massicotte MP. Venous thromboembolism in pediatrics. Seminars in Vascular Medicine 2001;1(1):111-22.

\section{Auer 2011 \{published data only\}}

Auer R, Scheer A, Wells PS, Boushey R, Asmis T, Jonker D, et al. The use of extended perioperative low molecular weight heparin (tinzaparin) to improve disease-free survival following surgical resection of colon cancer: a pilot randomized controlled trial. Blood Coagulation and Fibrinolysis 2011;22(8):760-2.

\section{Bauer 2000 \{published data only\}}

Bauer KA. Venous thromboembolism in malignancy. Journal of Clinical Oncology 2000;18(17):3065-7.

\section{Belcaro 1999 \{published data only\}}

Belcaro G, Nicolaides AN, Cesarone MR, Laurora G, De Sanctis MT, Incandela L. Comparison of low-molecularweight heparin, administered primarily at home, with unfractionated heparin, administered in hospital, and subcutaneous heparin, administered at home for deep-vein thrombosis. Angiology 1999;50(10):781-7.

Bick 2003 \{published data only\}

Bick RL. Cancer-associated thrombosis. New England Journal of Medicine 2003;349(2):109-11.

Bigg 1992 \{published data only\}

Bigg SW, Catalona WJ. Prophylactic mini-dose heparin in patients undergoing radical retropubic prostatectomy. A prospective trial. Urology 1992;39(4):309-13.

Booth 1981 \{published data only\}

Booth BW, Weiss RB. Venous thrombosis during adjuvant chemotherapy. New England Journal of Medicine 1981;305:3.

Bratt 1985 \{published data only\}

Bratt G, Tornebohm E, Granqvist S, Aberg W, Lockner D. A comparison between low molecular weight heparin (KAB 2165) and standard heparin in the intravenous treatment of deep venous thrombosis. Thrombosis and Haemostasis 1985;54(4):813-7.

\section{Bratt 1990 \{published data only\}}

Bratt G, Aberg W, Johansson M, Tornebohm E, Granqvist S, Lockner D. Two daily subcutaneous injections of fragmin as compared with intravenous standard heparin in the treatment of deep venous thrombosis (DVT). Thrombosis and Haemostasis 1990;64(4):506-10.

Brooks 1969 \{published data only\}

Brooks MB. Heparin in the treatment of hemorrhagic diathesis associated with prostatic carcinoma. Journal of Urology 1969;102(2):240-3.

Buller 2004 \{published data only\}

Buller HR, Davidson BL, Decousus H, Gallus A, Gent M, Piovella $F$, et al. Fondaparinux or enoxaparin for the initial treatment of symptomatic deep venous thrombosis: a randomized trial. Annals of Internal Medicine 2004;140(11):867-73.

\section{Cahan 2000 \{published data only\}}

Cahan MA, Hanna DJ, Wiley LA, Cox DK, Killewich LA. External pneumatic compression and fibrinolysis in abdominal surgery. Journal of Vascular Surgery 2000;32(3):537-43.

Ciftci 2012 \{published data only\}

Ciftci A, Altiay G. The effect of warfarin on survival in patients with lung cancer. Journal of Thoracic Oncology 2012;7(7):S122.

Clarke-Pearson 1993 \{published data only\}

Clarke-Pearson DL, Synan IS, Dodge R, Soper JT, Berchuck A, Coleman RE. A randomized trial of low-dose heparin and intermittent pneumatic calf compression for the prevention of deep venous thrombosis after gynecologic oncology 
surgery. American Journal of Obstetrics and Gynecology 1993;168(4):1146-54.

\section{Cohen 1997 \{published data only\}}

Cohen AT, Wagner MB, Mohamed MS. Risk factors for bleeding in major abdominal surgery using heparin thromboprophylaxis. American Journal of Surgery 1997;174(1):1-5.

Kakkar VV, Cohen AT, Edmonson RA, Phillips MJ, Das SK, Maher KT, et al. Low molecular weight versus standard heparin for prevention of venous thromboembolism after major abdominal surgery. Lancet 1993;341(8840):259-65.

\section{Cohen 2006 \{published data only\}}

Cohen AT, Davidson BL, Gallus AS, Lassen MR, Prins MH, Tomkowski W, et al. Efficacy and safety of fondaparinux for the prevention of venous thromboembolism in older acute medical patients: randomised placebo controlled trial. BMJ 2006;332(7537):325-9.

\section{Cohen 2007 (PREVENT) \{published data only\}}

Cohen AT, Davidson BL, Gallus AS, Lassen MR, Prins MH, Tomkowski W, et al. Efficacy and safety of fondaparinux for the prevention of venous thromboembolism in older acute medical patients: randomised placebo controlled trial. $B M J$ 2006;332(7537):325-9.

* Cohen AT, Turpie AG, Leizorovicz A, Olsson CG, Vaitkus PT, Goldhaber SZ. Thromboprophylaxis with dalteparin in medical patients: which patients benefit?. Vascular Medicine 2007;12(2):123-7.

Leizorovicz A, Cohen AT, Turpie AG, Olsson CG, Vaitkus PT, Goldhaber SZ, PREVENT Medical Thromboprophylaxis Study Group. Randomized, placebo-controlled trial of dalteparin for the prevention of venous thromboembolism in acutely ill medical patients. Circulation 2004;110(7):874-9.

\section{Couban 2005 \{published data only\}}

Anderson D, Goodyear M, Burnell M, Dolan S, Wasi P, Barnes D, Macleod D, Burton E, Andreou P, \& Couban S. A randomized double-blind placebo controlled study of low dose warfarin for the prevention of symptomatic central venous catheterassociated thrombosis in patients with cancer. Journal of thrombosis and haemostasis. 2003:Abstract no: P198.

* Couban S, Goodyear M, Burnell M, Dolan S, Wasi P, Barnes D, et al. Randomized placebo-controlled study of low-dose warfarin for the prevention of central venous catheterassociated thrombosis in patients with cancer. Journal of Clinical Oncology 2005;23(18):4063-9.

Couban S, Goodyear M, Burnell M, Dolan S, Wasi P, Macleod D, Burton E, Andreou P, Anderson D. A randomized doubleblind placebo-controlled study of low dose warfarin for the prevention of symptomatic central venous catheter-associated thrombosis in patients with cancer. Blood. 2002; Vol. 100, issue 11:703.

Dickinson 1998 \{published data only\}

* Dickinson LD, Miller LD, Patel CP, Gupta SK. Enoxaparin increases the incidence of postoperative intracranial hemorrhage when initiated preoperatively for deep venous thrombosis prophylaxis in patients with brain tumors. Neurosurgery 1998;43(5):1074-81.

Dolovich 2004 \{published data only\}

Dolovich LR, Ginsberg JS, Douketis JD, Holbrook AM, Cheah G. A meta-analysis comparing low-molecular-weight heparins with unfractionated heparin in the treatment of venous thromboembolism: examining some unanswered questions regarding location of treatment, product type, and dosing frequency. Archives of Internal Medicine 2000;160(2):181-8.

\section{Douketis 2000 \{published data only\}}

Douketis JD, Foster GA, Crowther MA, Prins MH, Ginsberg JS. Clinical risk factors and timing of recurrent venous thromboembolism during the initial 3 months of anticoagulant therapy. Archives of Internal Medicine 2000;160(22):3431-6.

\section{Eikelboom 1998 \{published data only\}}

Eikelboom JW, Baker RI. Low-molecular-weight heparin for the treatment of venous thrombosis in patients with adenocarcinoma. American Journal of Hematology 1998;59(3):260-1.

\section{Elly 1969 \{published data only\}}

Elly GL. Heparin therapy for bleeding associated with hemangioma. Surgery 1969;65(6):894-7.

\section{Fiessinger 1996 \{published data only\}}

Fiessinger JN, Lopez-Fernandez M, Gatterer E, Granqvist S, Kher A, Olsson CG, et al. Once-daily subcutaneous dalteparin, a low molecular weight heparin, for the initial treatment of acute deep vein thrombosis. Thrombosis and Haemostasis 1996;76(2):195-9.

\section{Goldhaber 2002 \{published data only\}}

Goldhaber SZ, Dunn K, Gerhard-Herman M, Park JK, Black PM. Low rate of venous thromboembolism after craniotomy for brain tumor using multimodality prophylaxis. Chest 2002;122(6):1933-7.

\section{Gould 1999 \{published data only\}}

Gould MK, Dembitzer AD, Doyle RL, Hastie TJ, Garber AM. Lowmolecular-weight heparins compared with unfractionated heparin for treatment of acute deep venous thrombosis. A meta-analysis of randomized, controlled trials. Annals of Internal Medicine 1999;130(10):800-9.

\section{Green 1992 \{published data only\}}

Green D, Hull RD, Brant R, Pineo GF. Lower mortality in cancer patients treated with low-molecular-weight versus standard heparin. Lancet 1992;339(8807):1476.

\section{Haage 2002 \{published data only\}}

Haage P, Krings T, Schmitz-Rode T. Nontraumatic vascular emergencies: imaging and intervention in acute occlusion. European Radiology 2002;12(11):2627-43.

Haas 2011 \{published data only\}

Bauersachs R, Schellong SM, Haas S, Tebbe U, Gerlach HE, Abletshauser C, et al. CERTIFY: prophylaxis of venous 
thromboembolism in patients with severe renal insufficiency. Thrombosis and Haemostasis 2011;105(6):981-8.

Haas S, Schellong SM, Tebbe U, Gerlach H-E, Bauersachs R, Abletshauser C, et al. CERTIFY: certoparin versus UFH to prevent venous thromboembolic events in the patients with cancer. Hämostaseologie 2011;31(1):A10.

* Haas S, Schellong SM, Tebbe U, Gerlach HE, Bauersachs R, Melzer N, et al. Heparin based prophylaxis to prevent venous thromboembolic events and death in patients with cancer-a subgroup analysis of CERTIFY. BMC Cancer 2011;11(1):1.

\section{Handeland 1990 \{published data only\}}

Handeland GF. Dose adjusted heparin treatment of deep venous thrombosis: a comparison of unfractionated and low molecular weight heparin. European Journal of Clinical Pharmacology 1990;39(2):107-12.

\section{Harenberg 1990 \{published data only\}}

Harenberg J, Huck K, Bratsch H, Stehle G, Dempfle CE, Mall K, et al. Therapeutic application of subcutaneous low-molecularweight heparin in acute venous thrombosis. Haemostasis 1990;20 Suppl 1:205-19.

\section{Harenberg 1996 \{published data only\}}

* Harenberg J, Roebruck P, Heene DL. Subcutaneous low-molecular-weight heparin versus standard heparin and the prevention of thromboembolism in medical inpatients. Pathophysiology of Haemostasis and Thrombosis 1996;26(3):127-39.

Harenberg J, Roebruck P, Stehle G, Habscheid W, Biegholdt M, Heene DL. Heparin Study in Internal Medicine (HESIM): design and preliminary results. Thrombosis Research 1992;68(1):33-43.

\section{Harenberg 2000 \{published data only\}}

Harenberg J, Schmidt JA, Koppenhagen K, Tolle A, Huisman MV, Buller HR. Fixed-dose, body weight-independent subcutaneous LMW heparin versus adjusted dose unfractionated intravenous heparin in the initial treatment of proximal venous thrombosis. EASTERN Investigators. Thrombosis and Haemostasis 2000;83(5):652-6.

\section{Hata 2016 \{published data only\}}

Hata K, Kimura T, Tsuzuki S, Ishii G, Kido M, Yamamoto T, et al. Safety of fondaparinux for prevention of postoperative venous thromboembolism in urological malignancy: a prospective randomized clinical trial. International Journal of Urology 2016;23(11):923-8.

\section{Hettiarachchi 1998 \{published data only\}}

Hettiarachchi RJ, Prins MH, Lensing AW, Buller HR. Low molecular weight heparin versus unfractionated heparin in the initial treatment of venous thromboembolism. Current Opinion in Pulmonary Medicine 1998;4(4):220-5.

\section{Holm 1986 \{published data only\}}

Holm HA, Ly B, Handeland GF, Abildgaard U, Arnesen KE, Gottschalk $P$, et al. Subcutaneous heparin treatment of deep venous thrombosis: a comparison of unfractionated and low molecular weight heparin. Haemostasis 1986;16 Suppl 2:30-7.

\section{Holmstrom 1999 \{published data only\}}

Holmstrom M, Aberg W, Lockner D, Paul C. Long-term clinical follow-up in 265 patients with deep venous thrombosis initially treated with either unfractionated heparin or dalteparin: a retrospective analysis. Thrombosis and Haemostasis 1999;82(4):1222-6.

\section{Hull 2000 \{published data only\}}

Hull RD, Raskob GE, Brant RF, Pineo GF, Elliott G, Stein PD, et al. Low-molecular-weight heparin vs heparin in the treatment of patients with pulmonary embolism. American-Canadian Thrombosis Study Group. Archives of Internal Medicine 2000;160(2):229-36.

\section{Hull 2006 \{published data only\}}

Hull RD, Pineo GF, Brant RF, Mah AF, Burke N, Dear R, et al. LITE Trial Investigators. Long-term low-molecular-weight heparin versus usual care in proximal-vein thrombosis patients with cancer. American Journal of Medicine 2006;119(12):1062-72.

\section{Jahanzeb 2005 \{published data only\}}

Jahanzeb M, Jahanzeb M. Management of deep vein thrombosis in cancer patients. Journal of the Nation Comprehensive Cancer Network 2005;3 Suppl 1:50-3.

\section{Kakkar 2010 (CANBESURE) \{published data only\}}

Kakkar VV, Balibrea J, Martinez-Gonzalez J, Prandoni P. Late breaking clinical trial: a randomised double blind trial to evaluate the efficacy and safety of prolonging the thromboprophylaxis with bemiparin in patients undergoing cancer abdominal or pelvic surgery (the CANBESURE study). International Society on Thrombosis and Haemostasis 2009;7(Suppl 2):1202.

* Kakkar VV, Balibrea JL, Martinez-Gonzalez J, Prandoni P. Extended prophylaxis with bemiparin for the prevention of venous thromboembolism after abdominal or pelvic surgery for cancer: the CANBESURE randomized study. Journal of Thrombosis and Haemostasis 2010;8(6):1223-9.

Kakkar 2014 (SAVE-ABDO) \{published data only\}

* Kakkar AK, Agnelli G, Fisher W, George D, Lassen MR, Mismetti P, et al. SAVE-ABDO Investigators. Preoperative enoxaparin versus postoperative semuloparin thromboprophylaxis in major abdominal surgery: a randomized controlled trial. Annals of Surgery 2014;259(6):1073-9.

Kakkar AK, Agnelli G, Fisher WD, George D, Mouret P, Lassen MR, et al. The ultra-low-molecular-weight heparin semuloparin for prevention of venous thromboembolism in patients undergoing major abdominal surgery. Blood 2010;116(21):188.

\section{Khorana 2017 (PHACS) \{published data only\}}

Khorana AA, Francis CW, Kuderer N, Carrier M, Ortel TL, Wun T, et al. Dalteparin thromboprophylaxis in cancer patients at high risk for venous thromboembolism: a randomized trial. Blood 2015;126(23):427.

* Khorana AA, Francis CW, Kuderer N, Carrier M, Ortel TL, Wun T, et al. Dalteparin thromboprophylaxis in cancer patients at high risk for venous thromboembolism: a randomized trial. 
Thrombosis Research 2017. [DOI: http://dx.doi.org/10.1016/ j.thromres.2017.01.009]

\section{Koppenhagen 1992 \{published data only\}}

Koppenhagen K, Adolf J, Matthes M, Tröster E, Roder JD, Hass S, et al. Low molecular weight heparin and prevention of postoperative thrombosis in abdominal surgery. Thrombosis and Haemostasis 1992;67(6):627-30.

\section{Larocca 2012 \{published data only\}}

Larocca A, Cavallo F, Bringhen S, Raimondo FD, Falanga A, Evangelista A, et al. Aspirin or enoxaparin thromboprophylaxis for patients with newly diagnosed multiple myeloma treated with lenalidomide. Blood 2012;119:933-9.

\section{Lee 2015 (CATCH) \{published data only\}}

Bauersachs R. Catch-a randomised clinical trial comparing longterm tinzaparin versus warfarin for treatment of acute venous thromboembolism in cancer patients. Hematology Reports 2011;3(Suppl 1):13.

Bauersachs R, Lee AYY, Kamphuisen PW, Meyer G, Janas MS, Jarner MF, et al. Long-term tinzaparin versus warfarin for treatment of venous thromboembolism (VTE) in cancer patients - analysis of renal impairment (RI) in the catch study. Journal of Thrombosis and Haemostasis 2015;13:76.

Kamphuisen PW, Lee AYY, Meyer G, Bauersachs R, Janas MS, Jarner MF, et al. Characteristics and risk factors of major and clinically relevant non-major bleeding in cancer patients receiving anticoagulant treatment for acute venous thromboembolism-the CATCH study. Journal of Thrombosis and Haemostasis 2015;13:182-3.

Khorana AA, Bauersachs R, Kamphuisen PW, Meyer G, Janas MS, Jarner MF, et al. Clinical predictors of recurrent venous thromboembolism (VTE) in cancer patients from a randomized trial of long-term tinzaparin versus warfarin for treatment: the CATCH study. Journal of Clinical Oncology Conference 2015;33(15 Suppl):9621.

Lee AY, Bauersachs R, Janas MS, Jarner MF, Kamphuisen PW, Meyer G, Khorana AA. CATCH: a randomised clinical trial comparing long-term tinzaparin versus warfarin for treatment of acute venous thromboembolism in cancer patients. BMC cancer 2013;13:284.

Lee AY, Bauersachs R, Janas MS, Jarner MF, Kamphuisen PW, Meyer G, et al. CATCH: a randomised clinical trial comparing long-term tinzaparin versus warfarin for treatment of acute venous thromboembolism in cancer patients. PROTOCOL. BMC Cancer 2013;13(1):284. [NCT01130025]

Lee AY, Bauersachs R, Janas MS, Jarner MF, Kamphuisen PW, Meyer G, et al. CATCH: a randomized trial comparing tinzaparin versus warfarin for treatment of acute venous thromboembolism (VTE) in cancer patients. ASCO Annual Meeting. Journal of Clinical Oncology 2012;Suppl:TPS9149.

* Lee AY, Kamphuisen PW, Meyer G, Bauersachs R, Janas MS, Jarner MF. Tinzaparin vs warfarin for treatment of acute venous thromboembolism in patients with active cancer: a randomized clinical trial. JAMA 2015;314:677.
Lee AYY, Kamphuisen PW, Meyer G, Bauersachs R, Janas MS, Jarner MF, et al. A randomized trial of long-term tinzaparin, a low molecular weight heparin (LMWH), versus warfarin for treatment of acute venous thromboembolism (VTE) in cancer patients - the CATCH study. Blood 2014;124:21.

\section{Leizorovicz 1994 \{published data only\}}

Leizorovicz A, Simonneau G, Decousus H, Boissel JP. Comparison of efficacy and safety of low molecular weight heparins and unfractionated heparin in initial treatment of deep venous thrombosis: a meta-analysis. BMJ 1994;309(6950):299-304.

\section{Levine 2001 \{published data only\}}

Levine MN. Management of thromboembolic disease in cancer patients. Haemostasis 2001;31 Suppl 1:68-9.

\section{Luomanmaki 1996 \{published data only\}}

Loumanmaki K, Grankvist S, Hallert C, Jauro I, Ketola K, Kim HC. A multicentre comparison of once-daily subcutaneous dalteparin (low molecular weight heparin) and continuous intravenous heparin in the treatment of deep vein thrombosis. Journal of Internal Medicine 1996;240(2):85-92.

\section{Macbeth 2016 (FRAGMATIC) \{published data only\}}

Griffiths GO, Burns S, Noble SI, Macbeth FR, Cohen D, Maughan TS. FRAGMATIC: a randomised phase III clinical trial investigating the effect of fragmin ${ }^{\circledR}$ added to standard therapy in patients with lung cancer. BMC Cancer 2009;9(1):1.

* Macbeth F, Noble S, Evans J, Ahmed S, Cohen D, Hood K, et al. Randomized phase III trial of standard therapy plus low molecular weight heparin in patients with lung cancer: FRAGMATIC trial. Journal of Clinical Oncology 2016;34(5):488-94.

Macbeth F, Noble S, Griffiths G, Chowdhury R, Rolfe C, Hood K, et al. Preliminary results from the Fragmatic Trial: a randomised phase III clinical trial investigating the effect of Fragmin (R) added to standard therapy in patients with lung cancer. Journal of Thoracic Oncology 2013;8:S243.

Noble S, Robbins A, Alikhan R, Hood K, Macbeth F. Prediction of venous thromboembolism in lung cancer patients receiving chemotherapy. Journal of Thrombosis and Haemostasis 2015;13:143.

\section{Martin-Carbonero 2002 \{published data only\}}

Martin-Carbonero L, Salgado X, Pedrajas JM, Armengol JG, Jimenez Rodriguez-Madridejos R, Fernandez-Cruz A. Short-term and long-term evolution of deep vein thrombosis treated by a health care unit. Revista Clinica Espanola 2002;202(8):430-4.

\section{Maxwell 2001 \{published data only\}}

Maxwell GL, Synan I, Dodge R, Carroll B, Clarke-Pearson DL. Pneumatic compression versus low molecular weight heparin in gynecologic oncology surgery: a randomized trial. American College of Obstetricians and Gynecologists 2001;98(6):989-95.

\section{Mazilu 2014 (OVIDIUS) \{published data only\}}

Mazilu L, Parepa IR, Suceveanu AI, Suceveanu A, Baz R, Catrinoiu D. Venous thromboembolism: secondary prevention with dabigatran vs. acenocumarol in patients 
with paraneoplastic deep vein thrombosis. Results from a small prospective study in Romania. Cardiovascular Research 2014;103(Suppl 1):S39.

\section{Menzoian 1983 \{published data only\}}

Menzoian JO, Sequeira JC, Doyle JE, Cantelmo NL, Nowak M, Tracey K, et al. Therapeutic and clinical course of deep vein thrombosis. American Journal of Surgery 1983;146(5):581-5.

\section{Murakami 2002 \{published data only\}}

Murakami M, Wiley LA, Cindrick-Pounds L, Hunter GC, Uchida T, Killewich LA. External pneumatic compression does not increase urokinase plasminogen activator after abdominal surgery. Journal of Vascular Surgery 2002;36(5):917-21.

\section{Nagata 2015 \{published data only\}}

Nagata C, Tanabe H, Takakura S, Narui C, Saito M, Yanaihara N, et al. Randomized controlled trial of enoxaparin versus intermittent pneumatic compression for venous thromboembolism prevention in Japanese surgical patients with gynecologic malignancy. Journal of Obstetrics and Gynaecology Research 2015;41(9):1440-8.

\section{Naschitz 1994 \{published data only\}}

Naschitz JE. Thromboembolism in cancer: changing trends. Radiology 1994;19:2.

\section{Nurmohamed 1996 \{published data only\}}

Nurmohamed MT, van Riel AM, Henkens CM, Koopman MM, Que GT, d'Azemar P, et al. Low molecular weight heparin and compression stockings in the prevention of venous thromboembolism in neurosurgery. Thrombosis Haemostasis 1996;75:233-8.

\section{Palumbo 2011 \{published data only\}}

Cavo M, Palumbo A, Bringhen S, Di Raimondo F, Patriarca F, Rossi D, et al. Phase III study of enoxaparin versus aspirin versus low-dose warfarin as thromboprophylaxis for patients with newly diagnosed multiple myeloma treated upfront with thalidomide-containing regimens. Haematologica 2010;95:391.

Cavo M, Palumbo A, Bringhen S, Falcone A, Musto P, Ciceri F, et al. A phase III study of enoxaparin versus low-dose warfarin versus aspirin as thromboprophylaxis for patients with newly diagnosed multiple myeloma treated up-front with thalidomide-containing regimens. Blood 2008;112(11):3017.

Cavo M, Palumbo A, Bringhen S, Falcone A, Musto P, Ciceri F, et al. A phase III study of enoxaparin versus low-dose warfarin versus aspirin as thromboprophylaxis for patients with newly diagnosed multiple myeloma treated up-front with thalidomide-containing regimens. Haematologica 2009;94:s4.

Magarotto V, Brioli A, Patriarca F, Rossi D, Petrucci MT, Nozzoli C, et al. Enoxaparin, aspirin, or warfarin for the thromboprophylaxis in newly diagnosed myeloma patients receiving thalidomide: a randomized controlled trial. XI Congress of the Italian Society of Experimental Hematology 2010;95:S1-S162.

Palumbo A, Cavo M, Bringhen S, Zaccaria A, Spadano A, Palmieri $S$, et al. Enoxaparin versus aspirin versus low-fixed- dose of warfarin in newly diagnosed myeloma patients treated with thalidomide-containing regimens: a randomized, controlled trial [Abstract No. 0910]. Haematologica 2008;93:362.

* Palumbo A, Cavo M, Bringhen S, Zamagni E, Romano A, Patriarca F, et al. Aspirin, warfarin, or enoxaparin thromboprophylaxis in patients with multiple myeloma treated with thalidomide: a phase III, open-label, randomized trial. Journal of Clinical Oncology 2011;29:986-93.

Pelzer 2015 (CONKO-004) \{published data only\}

Pelzer U, Deutschinoff G, Opitz B, Stauch M, Reitzig P, Hahnfeld S, Müller J, Stieler B, Dörken H. A prospective, randomized trial of simultaneous pancreatic cancer treatment with enoxaparin and chemotherapy - first results of the CONKO 004 trial. Onkologie - DGHO meeting. October 2009; Vol. 580:Abstract.

Pelzer U, Hilbig A, Stieler J, Roll L, Riess H, Dorken B, et al. A prospective, randomized trial of simultaneous pancreatic cancer treatment with enoxaparin and chemotherapy (PROSPECT - CONKO 004). Onkologie 2005;28(Suppl 3):54.

Pelzer U, Hilbig A, Stieler J, Roll L, Stauch M, Opitz B, et al. A prospective, randomized trial of simultaneous pancreatic cancer treatment with enoxaparin and chemotherapy (PROSPECT-CONKO 004). ASCO Annual Meeting Proceedings 2006;24(18):4110.

Pelzer U, Hilbig A, Stieler JM, Bahra M, Sinn M, Gebauer B, et al. Intensified chemotherapy and simultaneous treatment with heparin in outpatients with pancreatic cancer - the CONKO 004 pilot trial. BMC cancer 2014;14:204.

Pelzer U, Oettle H, Stauch M, Opitz B, Stieler J, Scholten T, et al. Prospective, randomized open trial of enoxaparin in patients with advanced pancreatic cancer undergoing firstline chemotherapy. XXIst Congress of the International Society on Thrombosis and Haemostasis; 2007 July 6-12; Geneva, Switzerland. 2007:P-T-488.

* Pelzer U, Opitz B, Deutschinoff G, Stauch M, Reitzig PC, Hahnfeld S, et al. Efficacy of prophylactic low-molecular weight heparin for ambulatory patients with advanced pancreatic cancer: outcomes from the CONKO-004 Trial. Journal of Clinical Oncology 2015;33(18):2028-34.

Riess H, Pelzer U, Deutschinoff G, Opitz B, Stauch M, Reitzig P, et al. A prospective, randomized trial of chemotherapy with or without the low molecular weight heparin (LMWH) enoxaparin in patients (pts) with advanced pancreatic cancer (APC): results of the CONKO 004 trial. ASCO Annual Meeting Proceedings 2009;27(18S):LBA4506.

Riess H, Pelzer U, Hilbig A, Stieler J, Opitz B, Scholten T, et al. Rationale and design of PROSPECT-CONKO 004: a prospective, randomized trial of simultaneous pancreatic cancer treatment with enoxaparin and chemotherapy. BMC Cancer 2008;8:361.

Riess H, Pelzer U, Opitz B, Stauch M, Reitzig P, Hahnfeld S, et al. A prospective, randomized trial of simultaneous pancreatic cancer treatment with enoxaparin and chemotherapy: final results of the CONKO-004 trial. Journal of Clinical Oncology Conference 2010;28(15 Suppl):4033. 
Riess HB, Pelzer U, Opitz B, Hilbig A, Strauch M, Hahnfeld S, et al. Late breaking clinical trial: a prospective, randomized trial of chemotherapy with and without the low molecular weight heparin (LMWH) enoxaparin in advanced pancreatic cancer patients. International Society on Thrombosis and Haemostasis 2009;7(Suppl 2):1-1204.

\section{Prandoni 1988 \{published data only\}}

Prandoni P, Vigo M, Tropeano PF, Carletti E, Corbetti F, Antonello G, et al. Treatment of venous thromboembolic disease using low molecular weight CY216 heparin in patients with high risk of hemorrhage. Annali Italiani di Medicina Interna 1988;3(3):213-9.

\section{Prandoni 1990 \{published data only\}}

Prandoni P, Vigo M, Cattelan AM, Ruol A. Treatment of deep venous thrombosis by fixed doses of a low-molecular-weight heparin (CY216). Haemostasis 1990;20 Suppl 1:220-3.

\section{Prandoni 2005 \{published data only\}}

Prandoni P. How I treat venous thromboembolism in patients with cancer. Blood 2005;106(13):4027-33.

\section{Prins 2014 (EINSTEIN) \{published data only\}}

Prins MH, Lensing AWA, Brighton TA, Lyons RM, Rehm J, Trajanovic M, et al. Oral rivaroxaban versus enoxaparin with vitamin $\mathrm{K}$ antagonist for the treatment of symptomatic venous thromboembolism in patients with cancer (EINSTEIN-DVT and EINSTEIN-PE): a pooled subgroup analysis of two randomised controlled trials. Lancet Haematology 2014;1(1):e37-e46.

\section{Raskob 2016 (HOKUSAI) \{published data only\}}

Raskob GE, van Es N, Segers A, Angchaisuksiri P, Oh D, Boda Z, et al. Edoxaban for venous thromboembolism in patients with cancer: results from a non-inferiority subgroup analysis of the Hokusai-VTE randomised, double-blind, double-dummy trial. Lancet Haematology 2016;3(8):e379-87.

\section{Riess 2003 \{published data only\}}

Riess H, Koppenhagen K, Tolle A, Kemkes-Matthes B, Grave M, Patek F, et al. Fixed-dose, body weight-independent subcutaneous low molecular weight heparin Certoparin compared with adjusted-dose intravenous unfractionated heparin in patients with proximal deep venous thrombosis. Thrombosis and Haemostasis 2003;90(2):252-9.

\section{Sakon 2010 \{published data only\}}

Sakon M, Kobayashi T, Shimazui T. Efficacy and safety of enoxaparin in Japanese patients undergoing curative abdominal or pelvic cancer surgery: results from a multicenter, randomized, open-label study. Thrombosis Research 2010;125(3):e65-70.

\section{Sakuragi 2003 \{published data only\}}

Sakuragi T, Sakao Y, Furukawa K, Rititake K, Ohtsubo S, Okazaki Y, et al. Successful management of acute pulmonary embolism after surgery for lung cancer. European Journal of Cardio-thoracic Surgery 2003;24(4):580-7.

\section{Schulman 2003 \{published data only\}}

Schulman S, Wahlander K, Lundstrom T, Clason SB, Eriksson $\mathrm{H}$, Investigators $\mathrm{TI}$, et al. Secondary prevention of venous thromboembolism with the oral direct thrombin inhibitor ximelagatran. New England Journal of Medicine 2003;349(18):1713-21.

\section{Schulman 2013 (RE-MEDY) \{published data only\}}

Schulman S, Kearon C, Kakkar AK, Schellong S, Eriksson H, Baanstra D, et al. Extended use of dabigatran, warfarin, or placebo in venous thromboembolism. New England Journal of Medicine 2013;368(8):709-18.

\section{Schulman 2015 (RECOVER) \{published data only\}}

Schulman S, Goldhaber SZ, Kearon C, Kakkar AK, Schellong S, Eriksson $\mathrm{H}$, et al. Treatment with dabigatran or warfarin in patients with venous thromboembolism and cancer. Thrombosis and Haemostasis 2015;114(1):150-7.

\section{Siragusa 2005 \{published data only\}}

Siragusa S, Arcara C, Malato A, Anastasio R, Valerio MR, Fulfaro F, et al. Home therapy for deep vein thrombosis and pulmonary embolism in cancer patients. Annals of Oncology 2005;16 Suppl 4:136-9.

\section{Song 2014 \{published data only\}}

Song KY, Yoo HM, Kim EY, Kim JI, Yim HW, Jeon HM, et al. Optimal prophylactic method of venous thromboembolism for gastrectomy in Korean patients: an interim analysis of prospective randomized trial. Annals of Surgical Oncology 2014;21(13):4232-8.

\section{Turchetti 2003 \{published data only\}}

Turchetti V, Bellini MA, Richichi MG, Boschi L, Postorino G, Naddeo S, et al. Venous thrombosis in the elderly: pathogenesis, diagnosis, treatment and follow-up. Giornale di Gerontologia 2003;51(4):212-8.

\section{Vadhan-Raj 2013 \{published data only\}}

Vadhan-Raj S, Zhou X, Varadhachary GR, Milind J, Fogelman D, Shroff R, et al. Randomized controlled trial of dalteparin for primary thromboprophylaxis for venous thromboembolism (VTE) in patients with advanced pancreatic cancer (APC): risk factors predictive of VTE. Blood 2013;122(21):580.

\section{Vedovati 2014 \{published data only\}}

Becattini C, Rondelli F, Vedovati MC, Camporese G, Giustozzi M, Boncompagni $\mathrm{M}$, et al. Incidence and risk factors for venous thromboembolism after laparoscopic surgery for colorectal cancer. Haematologica 2015;100(1):e35-8.

Becattini C, Rondelli F, Vedovati MC, Camporese G, Giustozzi M, Boncompagni $\mathrm{M}$, et al. Incidence and risk factors for venous thromboembolism after laparoscopic surgery for colorectal cancer. Haematologica 2015;100:e35-8.

Becattini C, Vedovati MC, Rondelli F, Boncompagni M, Camporese G, Balzarotti R, et al. One week vs. four week heparin prophylaxis after laparoscopic surgery for colorectal cancer. The Pro-lapspilot feasibility study. International Society on Thrombosis and Haemostasis 2013;11(Suppl 3):ATT05. 
Vedovati MC, Becattini C, Rondelli F, Boncompagni M, Camporese G, Balzarotti R, et al. A randomized study on 1 vs. 4 weeks prophylaxis for venous thromboembolism after laparoscopic surgery for colorectal cancer. Journal of Thrombosis and Haemostasis 2013;11:214.

* Vedovati MC, Becattini C, Rondelli F, Boncompagni M, Camporese G, Balzarotti R, et al. A randomized study on 1-week versus 4-week prophylaxis for venous thromboembolism after laparoscopic surgery for colorectal cancer. Annals of Surgery 2014;259(4):665-9.

\section{Verso 2008 \{published data only\}}

Agnelli G, Verso M, Bertoglio S, Ageno W, Bazzan M, Parise P, et al. A double-blind placebo-controlled randomized study on the efficacy and safety of enoxaparin for the prevention of upper limb deep vein thrombosis in cancer patients with central vein catheter. Journal of Clinical Oncology. 2004; Vol. 22:734S.

Verso M, Agnelli G, Bertoglio S, Di Somma FC, Paoletti F, Ageno W, et al. Enoxaparin for the prevention of venous thromboembolism associated with central vein catheter: a double-blind, placebo-controlled, randomized study in cancer patients. Journal of Clinical Oncology 2005;23(18):4057-62.

* Verso M, Agnelli G, Kamphuisen PW, Ageno W, Bazzan M, Lazzaro A, et al. Risk factors for upper limb deep vein thrombosis associated with the use of central vein catheter in cancer patients. Internal and Emergency Medicine 2008;3(2):117-22.

Verso M, Agnelli G, Bertoglio S, Di Somma C, Paoletti F, Ageno W, Bazzan M, Parise P, Quintavalla R, Naglieri E, Santoro A, Imberti D, Sorarù M. A double-blind placebo-controlled randomized study on the efficacy and safety of enoxaparin for the prevention of upper limb deep vein thrombosis in cancer patients with central vein catheter. 2003. Journal of thrombosis and haemostasis; Vol. 1:P0825.

\section{Ward 1998 \{published data only\}}

Ward B, Pradhan S. Comparison of low molecular weight heparin (Fragmin) with sodium heparin for prophylaxis against postoperative thrombosis in women undergoing major gynaecological surgery. Australian and New Zealand Journal of Obstetrics and Gynaecology 1998;38(1):91-2.

\section{Warkentin 1995 \{published data only\}}

Warkentin T. Heparin-induced thrombocytopenia in patients treated with low-molecular-weight heparin or unfractionated heparin. New England Journal of Medicine 1995;332:1330-6.

\section{Wester 1996 \{published data only\}}

* Wester JP, de Valk HW, Nieuwenhuis HK, Brouwer CB, van der Graaf Y, Meuwissen OJ, et al. Risk factors for bleeding during treatment of acute venous thromboembolism. Thrombosis and Haemostasis 1996;76(5):682-8.

de Valk HW, Banga JD, Wester JW, Brouwer CB, van Hessen MW, Meuwissen OJ, et al. Comparing subcutaneous danaparoid with intravenous unfractionated heparin for the treatment of venous thromboembolism: a randomized controlled trial. Annals of Internal Medicine 1995;123(1):1-9.
Wong 2003 \{published data only\}

Wong JEL. Are patients with cancer receiving adequate treatment for thrombosis? Results from FRONTLINE. Cancer Treatment Reviews 2003;29:11-3.

\section{Zheng 2014 \{published data only\}}

Zheng H, Gao Y, Yan X, Gao M, Gao W. Prophylactic use of low molecular weight heparin in combination with graduated compression stockings in post-operative patients with gynecologic cancer. Zhonghua Zhong Liu za Zhi [Chinese Journal of Oncology] 2014;36(1):39-42.

\section{Zwicker 2013 (MICRO TEC) \{published data only\}}

Zwicker J, Liebman HA, Bauer KA, Caughey T, Rosovsky R, Mantha $\mathrm{S}$, et al. A randomized-controlled phase II trial of primary thromboprophylaxis with enoxaparin in cancer patients with elevated tissue factor bearing microparticles (the Microtec study). Journal of Thrombosis and Haemostasis 2013;11:6.

* Zwicker JI, Liebman HA, Bauer KA, Caughey T, Campigotto F, Rosovsky R, et al. Prediction and prevention of thromboembolic events with enoxaparin in cancer patients with elevated tissue factor-bearing microparticles: a randomized-controlled phase II trial (the Microtec study). British Journal of Haematology 2013;160(4):530-7.

\section{Additional references}

\section{Akl 2013}

Akl EA, Johnston BC, Alonso-Coello P, Neumann I, Ebrahim S, Briel $\mathrm{M}$, et al. Addressing dichotomous data for participants excluded from trial analysis: a guide for systematic reviewers. PloS One 2013;8(2):e57132.

\section{Akl 2016}

Akl EA, Kahale LA, Ebrahim S, Alonso-Coello P, Schünemann HJ, Guyatt $\mathrm{GH}$. Three challenges described for identifying participants with missing data in trials reports, and potential solutions suggested to systematic reviewers. Journal of Clinical Epidemiology 2016;76:147-54.

\section{Alshurafa 2012}

Alshurafa M, Briel M, Akl EA, Haines T, Moayyedi P, Gentles SJ, et al. Inconsistent definitions for intention-to-treat in relation to missing outcome data: systematic review of the methods literature. PloS One 2012;7(11):e49163.

\section{Deeks 2001}

Deeks JJ, Altman DG, Bradburn MJ. Statistical methods for examining heterogeneity and combining results from several studies in meta-analysis. In: Egger M, Davey Smith G, Altman DG editor(s). Systematic Reviews in Health Care: Meta-Analysis in Context. 2nd Edition. London (UK): BMJ Publication Group, 2001.

\section{Ebrahim 2013}

Ebrahim S, Akl EA, Mustafa RA, Sun X, Walter SD, HeelsAnsdell $D$, et al. Addressing continuous data for participants excluded from trial analysis: a guide for systematic reviewers. Journal of Clinical Epidemiology 2013;66(9):1014-21. 


\section{Erkens 2010}

Erkens PMG, Prins MH. Fixed dose subcutaneous low molecular weight heparins versus adjusted dose unfractionated heparin for venous thromboembolism. Cochrane Database of Systematic Reviews 2010, Issue 9. [DOI: 10.1002/14651858.CD001100.pub3]

\section{Gallus 1997}

Gallus AS. Prevention of post-operative deep leg vein thrombosis in patients with cancer. Thrombosis and Haemostasis 1997;78(1):126-32.

\section{GRADE handbook}

Schünemann H, Brożek J, Guyatt G, Oxman A. GRADE handbook for grading quality of evidence and strength of recommendations. The GRADE Working Group. Updated October 2013. gdt.guidelinedevelopment.org/app/handbook/ handbook.htmlG (accessed prior to 8 January 2018).

\section{Guyatt 2017}

Guyatt GH, Ebrahim S, Alonso-Coello P, Johnston BC, Mathioudakis AG, Briel M, et al. GRADE guidelines 17: assessing the risk of bias associated with missing participant outcome data in a body of evidence. Journal of Clinical Epidemiology 2017; Vol. 87:14-22.

\section{Haynes 2002}

Haynes RB, Devereaux PJ, Guyatt GH. Clinical expertise in the era of evidence-based medicine and patient choice. Vox Sanguinis 2002;83(Suppl 1):383-6.

\section{Heit 2000}

Heit JA, Silverstein MD, Mohr DN, Petterson TM, O'Fallon WM, Melton LJ 3rd. Risk factors for deep vein thrombosis and pulmonary embolism: a population-based case-control study. Archives of Internal Medicine 2000;160(6):809-15.

\section{Hettiarachchi 1999}

Hettiarachchi RJ, Smorenburg SM, Ginsberg J, Levine M, Prins MH, Buller HR. Do heparins do more than just treat thrombosis? The influence of heparins on cancer spread. Thrombosis and Haemostasis 1999;82:947-52.

\section{Higgins 2003}

Higgins JPT, Thompson SG, Deeks JJ, Altman DG. Measuring inconsistency in meta-analysis. BMJ 2003;327:557-60.

\section{Higgins 2011}

Higgins JPT, Green S, editor(s). Cochrane Handbook for Systematic Reviews of Interventions Version 5.1.0 (updated March 2011). The Cochrane Collaboration, 2011. Available from handbook.cochrane.org.

\section{Hirsh 1993}

Hirsh J. Low molecular weight heparin. Thrombosis and Haemostasis 1993;70(1):204-7.

\section{Hirsh 2008}

Hirsh J, Bauer KA, Donati MB, Gould M, Samama MM, Weitz JI. Parenteral anticoagulants: American College of Chest Physicians Evidence-Based Clinical Practice Guidelines (8th Edition). Chest 2008;133 Suppl:141-59.

\section{Hutten 2000}

Hutten BA, Prins MH, Gent M, Ginsberg J, Tijssen JG, Buller HR. Incidence of recurrent thromboembolic and bleeding complications among patients with venous thromboembolism in relation to both malignancy and achieved international normalized ratio: a retrospective analysis. Journal of Clinical Oncology 2000;18(17):3078-83.

\section{Kakkar 1970}

Kakkar VV, Howe CT, Nicolaides AN, Renney JT, Clarke MB. Deep vein thrombosis of the leg. Is there a "high risk" group?. American Journal of Surgery 1970;120(4):527-30.

\section{Levitan 1999}

Levitan N, Dowlati A, Remick SC, Tahsildar HI, Sivinski LD, Beyth R. Rates of initial and recurrent thromboembolic disease among patients with malignancy versus those without malignancy: risk analysis using Medicare claims data. Medicine 1999;78(5):285-91.

\section{O'Brien 1999}

O'Brien B, Levine M, Willan A, Goeree R, Haley S, Blackhouse G, Gent M. Economic evaluation of outpatient treatment with low-molecular-weight heparin for proximal vein thrombosis. Archives of Internal Medicine 1999;159(19):2298-304.

\section{Othieno 2007}

Othieno R, Abu Affan M, Okpo E. Home versus inpatient treatment for deep vein thrombosis. Cochrane Database of Systematic Reviews 2007, Issue 3. [DOI: 10.1002/14651858.CD003076.pub2]

\section{Prandoni 2002}

Prandoni P, Lensing AWA, Piccioli A, Bernardi E, Simioni P, Girolami B, et al. Recurrent venous thromboembolism and bleeding complications during anticoagulant treatment in patients with cancer and venous thrombosis. Blood 2002;100(10):3484-8.

\section{Robertson 2017}

Robertson L, Jones LE. Fixed dose subcutaneous low molecular weight heparins versus adjusted dose unfractionated heparin for the initial treatment of venous thromboembolism. Cochrane Database of Systematic Reviews 2017, Issue 2. [DOI: 10.1002/14651858.CD001100.pub4]

\section{Sorensen 2000}

Sorensen HT, Mellemkjaer L, Olsen JH, Baron JA. Prognosis of cancers associated with venous thromboembolism. New England Journal of Medicine 2000;343(25):1846-50.

\section{References to other published versions of this review Akl 2008a}

Akl EA, Rohilla S, Barba M, Sperati F, Terrenato I, Muti P, Schünemann H. Anticoagulation for the initial treatment of venous thromboembolism in patients with cancer. Cochrane Database of Systematic Reviews 2008, Issue 1. [DOI: 10.1002/14651858.CD006649.pub2] 


\section{Akl 2008b}

Akl EA, Barba M, Muti P, Rohilla S, Schünemann H, Sperati F, et al. Anticoagulation for the initial treatment of venous thromboembolism in patients with cancer. Cancer 2008;113(7):1685-94. [DOI: 10.1002/14651858.CD006649]

\section{Akl 2011a}

Akl EA, Vasireddi SR, Gunukula S, Barba M, Sperati F, Terrenato I, et al. Anticoagulation for the initial treatment of venous thromboembolism in patients with cancer. Cochrane Database of Systematic Reviews 2011, Issue 6. [DOI: 10.1002/14651858.CD006649.pub3]

\section{Akl 2011b}

Akl EA, Vasireddi SR, Gunukula S, Barba M, Sperati F, Terrenato I, et al. Anticoagulation for the initial treatment of venous thromboembolism in patients with cancer.

\section{CHARACTERISTICS OF STUDIES}

Characteristics of included studies [ordered by study ID]
Cochrane Database of Systematic Reviews 2011, Issue 6. [DOI: 10.1002/14651858.CD006649.pub4]

\section{Akl 2011c}

Akl EA, Vasireddi SR, Gunukula S, Barba M, Sperati F, Terrenato I, et al. Anticoagulation for the initial treatment of venous thromboembolism in patients with cancer. Cochrane Database of Systematic Reviews 2011, Issue 6. [DOI: 10.1002/14651858.CD006649.pub5]

\section{Akl 2014}

Akl EA, Kahale LA, Neumann I, Barba M, Sperati F, Terrenato I, et al. Anticoagulation for the initial treatment of venous thromboembolism in patients with cancer. Cochrane Database of Systematic Reviews 2014, Issue 6. [DOI: 10.1002/14651858.CD006649.pub6]

* Indicates the major publication for the study

\section{Breddin 2001}

Methods Randomized controlled open-label trial.

Participants $\quad 137(12 \%)$ people with cancer with DVT but not PE (study subgroup); minimum age 18 years.

Interventions Intervention: reviparin weight-based SC twice daily.

Control: UFH IV (continuous infusion of 1250 IU/hour) x 5-7 days.

Vitamin $\mathrm{K}$ antagonist (target INR > 2) started on day $1 \times 90$ days.

A third group received reviparin SC once daily $x 28$ days and vitamin $\mathrm{K}$ antagonist on days 21-90.

Discontinued treatment: not reported for cancer subgroup.

Outcomes Duration of follow-up: 90 days.

- Mortality.

- Symptomatic DVT or PE (unclear whether asymptomatic events included).

- Major bleeding.

Screening and diagnostic testing for DVT/PE: venography or scintigraphy if DVT or PE suspected.

$\begin{array}{ll}\text { Notes } & \text { - Setting: not reported. } \\ \text { - Funding: Knoll, Germany. } \\ \text { - Ethical approval: "The protocol was approved by the local institutional review boards and was con- } \\ \text { - Conflict of interest: not reported. } \\ \text { - ITT analysis: not reported. }\end{array}$

\section{Risk of bias}


Breddin 2001 (Continued)

Random sequence genera- Low risk Quote: "Patients were randomly assigned to one of three groups, stratified action (selection bias)

cording to site."

Allocation concealment $\quad$ Unclear risk $\quad$ Not reported.
(selection bias)

(selection bias)

Blinding of participants High risk Open-label trial.

and personnel (perfor-

mance bias)

All outcomes

Comment: definitely not blinded; knowledge of the assigned intervention may have led to differential behaviors across intervention groups (e.g. differential dropout, differential cross-over to an alternative intervention, or differential administration of co interventions).

Blinding of outcome as- Low risk sessment (detection bias)

All outcomes

Quote: "The venograms were assessed by two members of an independent committee who were unaware of the patients' treatment assignments and of whether the venograms were obtained before or after treatment."

Comment: definitely blinded.

\begin{tabular}{|c|c|c|}
\hline $\begin{array}{l}\text { Incomplete outcome data } \\
\text { addressed? }\end{array}$ & Low risk & $\begin{array}{l}\text { Comment: judgment based on comparison between MPD rate (LMWH 11/95 } \\
(11.5 \%) ; \text { UFH 1/42 (2.4\%)) and event rate (mortality: LMWH 14/84 (16.6\%); UFH } \\
6 / 41(14.6 \%)) \text {. }\end{array}$ \\
\hline
\end{tabular}
$6 / 41(14.6 \%))$.

$\begin{array}{ll}\begin{array}{l}\text { Free of selective report- } \\ \text { ing? }\end{array} & \text { Low risk } \\ \end{array}$

Free of other bias? Low risk

Study not reported as stopped early for benefit.

No other bias suspected.

Buller 1997 (COLOMBUS)

\begin{tabular}{ll}
\hline Methods & Randomized controlled trial, subgroup of a large study. \\
\hline Participants & 232 people with cancer with proximal or distal DVT, PE, or both; minimum age 18 years. \\
\hline Interventions & Intervention: reviparin weight-based SC twice daily at home. \\
& Control: UFH IV (target aPTT 1.5-2.5) in hospital x 5 days. \\
Coumarin derivative (target INR $>2$ ) started on 1st or 2 nd day x 12 weeks. & Discontinued treatment: not reported for cancer subgroup. \\
\hline
\end{tabular}

Outcomes

Duration of follow-up: 12 weeks.

- Death

- Symptomatic DVT.

- PE.

- Major bleeding.

Screening and diagnostic testing for DVT/PE: not reported.

\begin{tabular}{ll}
\hline Notes & Setting: participants could be treated at home, but the decision to do so was left to the treating physi- \\
& cian. \\
- Funding: Knoll, AG.
\end{tabular}


Buller 1997 (COLOMBUS) (Continued)

- Ethical approval: "The study protocol was approved by the institutional review boards of all the clinical centers."

- Conflict of interest: not reported.

- ITT analysis: not reported.

\section{Risk of bias}

\begin{tabular}{lll}
\hline Bias & Authors' judgement & Support for judgement \\
\hline $\begin{array}{l}\text { Random sequence genera- } \\
\text { tion (selection bias) }\end{array}$ & Low risk & Quote: "Randomization was performed with a computer algorithm." \\
\hline $\begin{array}{l}\text { Allocation concealment } \\
\text { (selection bias) }\end{array}$ & Low risk & $\begin{array}{l}\text { Quote: "Randomization was performed with a computer algorithm and the use } \\
\text { of a central 24-hour telephone service that recorded information on the pa- } \\
\text { tient before the treatment assignment was disclosed." }\end{array}$ \\
\hline $\begin{array}{l}\text { Blinding of participants } \\
\text { and personnel (perfor- } \\
\text { mance bias) } \\
\text { All outcomes }\end{array}$ & High risk & $\begin{array}{l}\text { Open-label study. } \\
\text { Comment: definitely not blinded; knowledge of the assigned intervention may } \\
\text { have led to differential behaviors across intervention groups (e.g. differential } \\
\text { dropout, differential cross-over to an alternative intervention, or differential } \\
\text { administration of cointerventions). }\end{array}$
\end{tabular}

Blinding of outcome as- Low risk
sessment (detection bias)

All outcomes

Quote: "Information on all suspected outcome events and deaths was reviewed and classified by a central adjudication committee whose members were unaware of the treatment assignments."

Comment: definitely blinded.

Incomplete outcome data Low risk Complete follow-up.
addressed?

\begin{tabular}{lll}
\hline $\begin{array}{l}\text { Free of selective report- } \\
\text { ing? }\end{array}$ & Low risk & $\begin{array}{l}\text { Study not registered and no published protocol identified. All relevant out- } \\
\text { comes listed in the methods section were reported on in the results section. }\end{array}$ \\
\hline Free of other bias? & Low risk & $\begin{array}{l}\text { Study not reported as stopped early for benefit. } \\
\text { No other bias suspected. }\end{array}$ \\
\end{tabular}

\section{Duroux 1991}

\begin{tabular}{|c|c|}
\hline Methods & Randomized controlled trial. \\
\hline Participants & 18 people with cancer with proximal DVT but no PE; minimum age 18 years. \\
\hline \multirow[t]{4}{*}{ Interventions } & Intervention: CY216 (Fraxiparin (nadroparin)) 255 antiXa U/kg twice daily x 10 days. \\
\hline & Control: UFH IV (target aPTT 1.5-2) x 10 days. \\
\hline & $\begin{array}{l}\text { After day } 10 \text {, each center continued its usual anticoagulant regimen either by SC UFH at adjusted doses } \\
\text { or by oral anticoagulants x } 12 \text { weeks. }\end{array}$ \\
\hline & Discontinued treatment: not reported for cancer subgroup. \\
\hline \multirow[t]{3}{*}{ Outcomes } & Duration of follow-up: 12 weeks. \\
\hline & - Mortality. \\
\hline & - Recurrent VTE. \\
\hline
\end{tabular}


Duroux 1991 (Continued)

$$
\text { - Major bleeding. }
$$

Screening and diagnostic testing for DVT: venography surveillance for DVT conducted at day 0 and day 10.

Screening and diagnostic testing for PE: lung scan by injecting IV with the participant in the supine position microspheres labelled with technetium $99 \mathrm{~m}$ albumin.

\begin{tabular}{ll}
\hline Notes & - Setting: not reported. \\
- Funding: Sanofi-Choay. \\
- Ethical approval: not reported. \\
- Conflict of interest: not reported. \\
ITT analysis: "An intention-to-treat analysis including patients with premature cessation of treatment \\
but in whom there was a D10 venogram was also undertaken."
\end{tabular}

\section{Risk of bias}

\begin{tabular}{|c|c|c|}
\hline Bias & Authors' judgement & Support for judgement \\
\hline $\begin{array}{l}\text { Random sequence genera- } \\
\text { tion (selection bias) }\end{array}$ & Low risk & Quote: "Study was a randomized parallel group trial." \\
\hline $\begin{array}{l}\text { Allocation concealment } \\
\text { (selection bias) }\end{array}$ & Unclear risk & Not reported. \\
\hline $\begin{array}{l}\text { Blinding of participants } \\
\text { and personnel (perfor- } \\
\text { mance bias) } \\
\text { All outcomes }\end{array}$ & High risk & $\begin{array}{l}\text { Quote: "Treatment could not be given double-blinded because of the different } \\
\text { methods of administration and primarily the need for dose adjustment in the } \\
\text { UFH group." } \\
\text { Comment: definitely not blinded; knowledge of the assigned intervention may } \\
\text { have led to differential behaviors across intervention groups (e.g. differential } \\
\text { dropout, differential cross-over to an alternative intervention, or differential } \\
\text { administration of cointerventions). }\end{array}$ \\
\hline
\end{tabular}

Blinding of outcome as- Low risk

Quote: "Treatment could not be given double-blinded because of the different All outcomes methods of administration and primarily the need for dose adjustment in the UFH group."

Comment: probably not blinded; knowledge of the assigned intervention may not have impacted the assessment of the physiological outcomes (mortality, DVT, PE, bleeding, etc.).

\begin{tabular}{ll}
\hline $\begin{array}{l}\text { Incomplete outcome data } \\
\text { addressed? }\end{array}$ & No information about follow-up in cancer subgroup reported. \\
& $\begin{array}{l}\text { Comment: we analyzed the available data assuming that any possibly missing } \\
\text { data were missing at random. }\end{array}$
\end{tabular}

\begin{tabular}{|c|c|c|}
\hline $\begin{array}{l}\text { Free of selective report- } \\
\text { ing? }\end{array}$ & Low risk & $\begin{array}{l}\text { Study not registered and no published protocol identified. All relevant out- } \\
\text { comes listed in the methods section were reported on in the results section }\end{array}$ \\
\hline
\end{tabular}

Free of other bias? Low risk Study not reported as stopped early for benefit.

No other bias suspected.

Methods Randomized controlled trial.


Hull 1992 (Continued)

Participants 95 people with cancer with proximal DVT (study subgroup); minimum age 18 years.

\begin{tabular}{ll}
\hline Interventions & Intervention: tinzaparin 175 antiXa U/kg SC once daily. \\
Control: UFH IV (target aPTT 1.5-2.5) x 6 days \\
Warfarin (target INR 2-3) started on day 2 for 3 months. \\
Discontinued treatment: not reported for cancer subgroup. \\
\hline Duration of follow-up: 3 months. \\
- Mortality. \\
- Symptomatic VTE. \\
- Major bleeding. \\
Screening and diagnostic testing for DVT/PE: impedance plethysmography, venography, perfusion \\
lung scan. \\
- Setting: inpatient. \\
- Funding: Heart and Stroke Foundation of Alberta and Novo Nordisk. \\
- Conflict of interest: not reported. \\
- ITT analysis: all participants randomized were included in the analyses of outcomes.
\end{tabular}

Risk of bias

\begin{tabular}{|c|c|c|}
\hline Bias & Authors' judgement & Support for judgement \\
\hline $\begin{array}{l}\text { Random sequence genera- } \\
\text { tion (selection bias) }\end{array}$ & Low risk & $\begin{array}{l}\text { Quote: "A randomized, computer-derived treatment schedule was used to as- } \\
\text { sign the patients to receive intravenous heparin or subcutaneous low molecu- } \\
\text { lar-weight heparin." }\end{array}$ \\
\hline $\begin{array}{l}\text { Allocation concealment } \\
\text { (selection bias) }\end{array}$ & Low risk & $\begin{array}{l}\text { Quote: "Before randomization, patients were stratified into groups accord- } \\
\text { ing to a randomized, computer-derived treatment schedule was used to as- } \\
\text { sign the patients to receive intravenous heparin or subcutaneous low molecu- } \\
\text { lar-weight heparin." }\end{array}$ \\
\hline $\begin{array}{l}\text { Blinding of participants } \\
\text { and personnel (perfor- } \\
\text { mance bias) } \\
\text { All outcomes }\end{array}$ & Low risk & $\begin{array}{l}\text { Double-blind clinical trial. } \\
\text { Comment: definitely blinded. }\end{array}$ \\
\hline
\end{tabular}

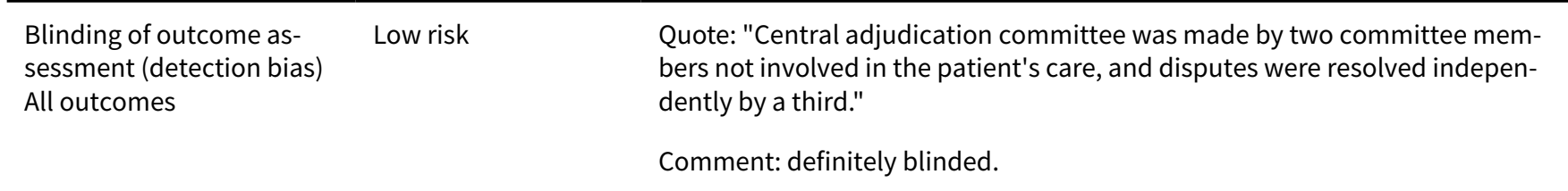

\begin{tabular}{lll}
\hline $\begin{array}{l}\text { Incomplete outcome data } \\
\text { addressed? }\end{array}$ & Low risk & Complete follow-up. \\
\hline $\begin{array}{l}\text { Free of selective report- } \\
\text { ing? }\end{array}$ & Low risk & $\begin{array}{l}\text { Study not registered and no published protocol identified. All relevant out- } \\
\text { comes listed in the methods section were reported on in the results section. }\end{array}$ \\
\hline Free of other bias? & Low risk & Study not reported as stopped early for benefit.
\end{tabular}


Hull 1992 (Continued)

No other bias suspected.

Koopman 1996

\begin{tabular}{|c|c|}
\hline Methods & Randomized controlled trial. \\
\hline Participants & $\begin{array}{l}70 \text { people with cancer with proximal DVT without PE (study subgroup); minimum age } 18 \text { years; mini- } \\
\text { mum life expectancy } 6 \text { months. }\end{array}$ \\
\hline \multirow[t]{4}{*}{ Interventions } & Intervention: nadroparin weight-based SC twice daily at home. \\
\hline & Control: UFH IV (target aPTT 1.5-2) x 5 days. \\
\hline & Oral anticoagulation (target INR 2-3) started x 3 months. \\
\hline & Discontinued treatment: not reported for cancer subgroup. \\
\hline \multirow[t]{5}{*}{ Outcomes } & Duration of follow-up: 6 months. \\
\hline & - Mortality. \\
\hline & - Symptomatic recurrent VTE. \\
\hline & - Major bleeding. \\
\hline & $\begin{array}{l}\text { Screening and diagnostic testing for DVT/PE: venography, pulmonary angiography, perfusion lung } \\
\text { scan. }\end{array}$ \\
\hline \multirow[t]{5}{*}{ Notes } & $\begin{array}{l}\text { - Setting: standard heparin was administered at the hospital and participants receiving LMWH were } \\
\text { allowed to be treated at home. }\end{array}$ \\
\hline & - Funding: Sanofi Winthrop. \\
\hline & $\begin{array}{l}\text { - Ethical approval: "The study protocol was approved by the institutional review boards at all the par- } \\
\text { ticipating institutions." }\end{array}$ \\
\hline & • Conflict of interest: "Dr. Büller is an Established Investigator of the Dutch Heart Foundation." \\
\hline & - ITT analysis: analyses were performed on an ITT basis. \\
\hline
\end{tabular}

\section{Risk of bias}

\begin{tabular}{|c|c|c|}
\hline Bias & Authors' judgement & Support for judgement \\
\hline $\begin{array}{l}\text { Random sequence genera- } \\
\text { tion (selection bias) }\end{array}$ & Low risk & $\begin{array}{l}\text { Quote: "After the patients gave informed consent, randomization (stratified } \\
\text { according to center) was achieved by means of a central } 24 \text { hour telephone } \\
\text { service." }\end{array}$ \\
\hline $\begin{array}{l}\text { Allocation concealment } \\
\text { (selection bias) }\end{array}$ & Low risk & $\begin{array}{l}\text { Quote: "After the patients gave informed consent, randomization (stratified } \\
\text { according to center) was achieved by means of a central } 24 \text { hour telephone } \\
\text { service." }\end{array}$ \\
\hline $\begin{array}{l}\text { Blinding of participants } \\
\text { and personnel (perfor- } \\
\text { mance bias) } \\
\text { All outcomes }\end{array}$ & High risk & $\begin{array}{l}\text { Quote: "An unblinded trial." } \\
\text { Comment: definitely not blinded. Knowledge of the assigned intervention may } \\
\text { have led to differential behaviors across intervention groups (e.g. differential } \\
\text { dropout, differential cross-over to an alternative intervention, or differential } \\
\text { administration of cointerventions). }\end{array}$ \\
\hline
\end{tabular}

Blinding of outcome as- Low risk sessment (detection bias) All outcomes
Quote: "Documentation of all potential outcome events, including deaths, was submitted to an independent adjudication committee whose members were unaware of the treatment assignments." 
Koopman 1996 (Continued)

Comment: definitely blinded.

\begin{tabular}{lll}
\hline $\begin{array}{l}\text { Incomplete outcome data } \\
\text { addressed? }\end{array}$ & Low risk & Complete follow-up. \\
\hline $\begin{array}{l}\text { Free of selective report- } \\
\text { ing? }\end{array}$ & Low risk & $\begin{array}{l}\text { Study not registered and no published protocol identified. All relevant out- } \\
\text { comes listed in the methods section were reported on in the results section. }\end{array}$ \\
\hline Free of other bias? & Low risk & Study not reported as stopped early for benefit. \\
& No other bias suspected. \\
\hline
\end{tabular}

Levine 1996

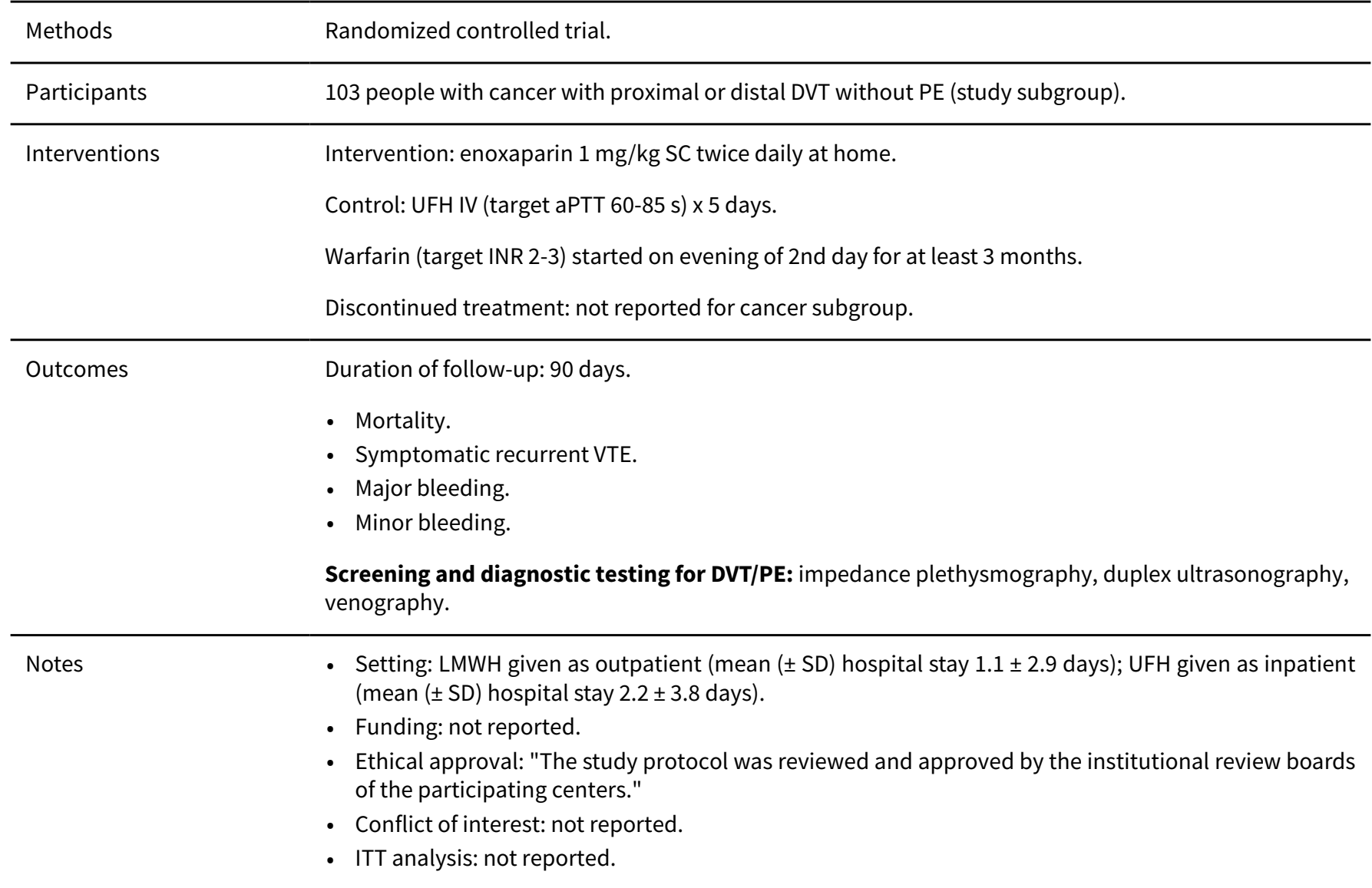

\section{Risk of bias}

\begin{tabular}{lll}
\hline Bias & Authors' judgement & Support for judgement \\
\hline $\begin{array}{l}\text { Random sequence genera- } \\
\text { tion (selection bias) }\end{array}$ & Low risk & $\begin{array}{l}\text { Quote: "Patients were assigned to treatment through randomization over the } \\
\text { telephone from a central line." }\end{array}$ \\
\hline $\begin{array}{l}\text { Allocation concealment } \\
\text { (selection bias) }\end{array}$ & Low risk & $\begin{array}{l}\text { Quote: "Patients were assigned to treatment through randomization over the } \\
\text { telephone from a central line." }\end{array}$ \\
\hline $\begin{array}{l}\text { Blinding of participants } \\
\text { and personnel (perfor- } \\
\text { mance bias) }\end{array}$ & High risk & Quote: "This was not a double-blind study." \\
\hline
\end{tabular}

Anticoagulation for the initial treatment of venous thromboembolism in people with cancer (Review) 
Levine 1996 (Continued)

All outcomes
Comment: definitely not blinded; knowledge of the assigned intervention may have led to differential behaviors across intervention groups (e.g. differential dropout, differential cross-over to an alternative intervention, or differential administration of cointerventions).

\begin{tabular}{|c|c|c|}
\hline $\begin{array}{l}\text { Blinding of outcome as- } \\
\text { sessment (detection bias) } \\
\text { All outcomes }\end{array}$ & Low risk & $\begin{array}{l}\text { Quote: "All reported outcome events were reviewed by a central adjudication } \\
\text { committee whose members were unaware of the treatment assignments." } \\
\text { Comment: definitely blinded. }\end{array}$ \\
\hline
\end{tabular}

Incomplete outcome data Low risk Complete follow-up.

addressed?

\begin{tabular}{|c|c|c|}
\hline $\begin{array}{l}\text { Free of selective report- } \\
\text { ing? }\end{array}$ & Low risk & $\begin{array}{l}\text { Study not registered and no published protocol identified. All relevant out- } \\
\text { comes listed in the methods section were reported on in the results section. }\end{array}$ \\
\hline
\end{tabular}

Free of other bias? Low risk Study not reported as stopped early for benefit.

No other bias suspected.

Lindmarker 1994

\begin{tabular}{ll}
\hline Methods & Randomized controlled trial. \\
\hline Participants & $\begin{array}{l}16 \text { people with cancer with DVT (below the inguinal ligament) but no PE (study subgroup); minimum } \\
\text { age } 18 \text { years. }\end{array}$
\end{tabular}

Interventions

Intervention: dalteparin $200 \mathrm{IU} / \mathrm{kg}$ SC once daily.

Control: UFH IV (target aPTT 1.5-3) x 5 days.

Warfarin (target INR 2-3) × 3 months.

Discontinued treatment: not reported for cancer subgroup.

Outcomes Duration of follow-up: 6 months.

- Mortality.

- Symptomatic PE.

- Bleeding.

Screening and diagnostic testing for DVT/PE: not reported.

\begin{tabular}{ll}
\hline Notes & - Setting: not reported. \\
& - Funding: Pharmacia AB. \\
- Ethical approval: not reported. \\
- Conflict of interest: not reported. \\
\hline
\end{tabular}

\section{Risk of bias}

\begin{tabular}{lll}
\hline Bias & Authors' judgement & Support for judgement \\
\hline $\begin{array}{l}\text { Random sequence genera- } \\
\text { tion (selection bias) }\end{array}$ & Low risk & $\begin{array}{l}\text { Quote: "Randomization was organized centrally using sealed envelopes strati- } \\
\text { fied for each center in a block size of 20." }\end{array}$ \\
\hline
\end{tabular}


Lindmarker 1994 (Continued)

$\begin{aligned} & \text { Allocation concealment } \\ & \text { (selection bias) }\end{aligned} \quad$ Low risk
fuote: "Randomization was organized centrally using sealed envelopes strati-
(selection bias) fied for each center in a block size of 20."

Blinding of participants mance bias)

All outcomes and personnel (perfor-

\section{High risk}

\section{Not reported.}

Comment: definitely not blinded; knowledge of the assigned intervention may have led to differential behaviors across intervention groups (e.g. differential dropout, differential cross-over to an alternative intervention, or differential administration of cointerventions).

\section{Blinding of outcome as- Low risk} sessment (detection bias) All outcomes
Quote: "All venograms were interpreted by a radiologist who did not know which of the treatments the patient had received or in which order the venogram has been performed."

Comment: definitely blinded.

\begin{tabular}{lll}
\hline $\begin{array}{l}\text { Incomplete outcome data } \\
\text { addressed? }\end{array}$ & Low risk & Complete follow-up. \\
\hline $\begin{array}{l}\text { Free of selective report- } \\
\text { ing? }\end{array}$ & Low risk & $\begin{array}{l}\text { Study not registered and no published protocol identified. All relevant out- } \\
\text { comes listed in the methods section were reported on in the results section. }\end{array}$ \\
\hline Free of other bias? & Low risk & Study not reported as stopped early for benefit. \\
& No other bias suspected. \\
\hline
\end{tabular}

Lopaciuk 1992

\begin{tabular}{|c|c|}
\hline Methods & Randomized controlled trial. \\
\hline Participants & 9 people with cancer with proximal or calf DVT without PE (study subgroup). \\
\hline \multirow[t]{4}{*}{ Interventions } & Intervention: nadroparin 92 antiXa U/kg twice daily. \\
\hline & Control: UFH 1st dose IV, subsequent dose SC twice daily (target aPTT 1.5-2.5) x 10 days. \\
\hline & Acenocoumarol (target INR 2-3) started the 7th day $x$ at least 3 months. \\
\hline & Discontinued treatment: not reported for cancer subgroup. \\
\hline \multirow[t]{6}{*}{ Outcomes } & Duration of follow-up: 3 months. \\
\hline & - Mortality. \\
\hline & - Symptomatic PE. \\
\hline & - Recurrent DVT. \\
\hline & - Bleeding. \\
\hline & Screening and diagnostic testing for DVT/PE: not reported. \\
\hline \multirow[t]{5}{*}{ Notes } & - Setting: not reported. \\
\hline & - Funding: Sanofi. \\
\hline & - Ethical approval: not reported. \\
\hline & - Conflict of interest: not reported. \\
\hline & - ITT analysis: not reported. \\
\hline
\end{tabular}

\section{Risk of bias}

Anticoagulation for the initial treatment of venous thromboembolism in people with cancer (Review) 
Lopaciuk 1992 (Continued)

\begin{tabular}{lll} 
Bias & Authors' judgement & Support for judgement \\
\hline $\begin{array}{l}\text { Random sequence genera- } \\
\text { tion (selection bias) }\end{array}$ & Low risk & $\begin{array}{l}\text { Quote: "Study was a prospective, open, stratified, and randomized multicenter } \\
\text { trial with a blind evaluation of phlebographic results." }\end{array}$ \\
\hline $\begin{array}{l}\text { Allocation concealment } \\
\text { (selection bias) }\end{array}$ & Low risk & $\begin{array}{l}\text { Quote: "they were randomly allocated by using a sealed envelope to either } \\
\text { Fraxiparine [nadroparin] or UFH group." }\end{array}$ \\
& Comment: no mention of sequential numbering and opacity. \\
\hline
\end{tabular}

\begin{tabular}{|c|c|c|}
\hline $\begin{array}{l}\text { Blinding of participants } \\
\text { and personnel (perfor- } \\
\text { mance bias) } \\
\text { All outcomes }\end{array}$ & High risk & $\begin{array}{l}\text { Not reported. } \\
\text { Comment: definitely not blinded; knowledge of the assigned intervention may } \\
\text { have led to differential behaviors across intervention groups (e.g. differential } \\
\text { dropout, differential cross-over to an alternative intervention, or differential } \\
\text { administration of cointerventions). }\end{array}$ \\
\hline
\end{tabular}

\begin{tabular}{lll}
\hline $\begin{array}{l}\text { Blinding of outcome as- } \\
\text { sessment (detection bias) } \\
\text { All outcomes }\end{array}$ & Low risk & Quote: "blind evaluation of phlebographic results." \\
& & Comment: definitely blinded. \\
\hline $\begin{array}{l}\text { Incomplete outcome data } \\
\text { addressed? }\end{array}$ & Low risk & Complete follow-up. \\
\hline $\begin{array}{l}\text { Free of selective report- } \\
\text { ing? }\end{array}$ & Low risk & $\begin{array}{l}\text { Study not registered and no published protocol identified. All relevant out- } \\
\text { comes listed in the methods section were reported on in the results section. }\end{array}$ \\
\hline $\begin{array}{l}\text { Free of other bias? } \\
\text { Low risk }\end{array}$ & $\begin{array}{l}\text { Study not reported as stopped early for benefit. } \\
\text { No other bias suspected. }\end{array}$ \\
\hline
\end{tabular}

Merli 2001

\begin{tabular}{ll}
\hline Methods & Randomized controlled trial. \\
\hline Participants & 141 people with cancer with DVT or PE (study subgroup); minimum age 18 years. \\
\hline Interventions & Intervention: enoxaparin $1 \mathrm{mg} / \mathrm{kg} \mathrm{SC}$ twice daily or $1.5 \mathrm{mg} / \mathrm{kg}$ SC once daily. \\
& Control: UFH IV (target aPTT 55-80 s) x 5 days. \\
& Warfarin (target INR 2-3) started within 72 hours $\times 3$ months. \\
& Discontinued treatment: not reported for cancer subgroup. \\
\hline
\end{tabular}

\section{Outcomes}

Duration of follow-up: 3 months.

- Mortality.

- Recurrent DVT or PE.

- Major bleed.

- Minor bleed.

Screening and diagnostic testing for DVT: venography, ultrasonography, or both.

Screening and diagnostic testing for PE: lung perfusion scanning, pulmonary angiography, or both. 
Merli 2001 (Continued)

- Funding: Aventis.

- Ethical approval: "approved by the institutional review board or ethics committees at each location."

- Conflict of interest: Aventis Pharmaceuticals Participants Study Co-ordinators: Kimberly Miller, BS, RN; Ghislaine Pisapia; Annette Stevenson, MS; Patrick Valode. Data Management: Todd Koser, Patrick Poinot. Biostatistics: Marie-Josée Cossec-Vion; Eric Genevois, PhD; Alain Vasseur. Project Director: Theodore E Spiro, MD.

- ITT analysis: "The efficacy analysis was performed on two study samples: all treated patients, who received at least one dose of study medication, and evaluable patients, which excluded all patients who met at least one of the criteria for non evaluability."

- Comment: first analysis was ITT.

\section{Risk of bias}

\begin{tabular}{|c|c|c|}
\hline Bias & Authors' judgement & Support for judgement \\
\hline $\begin{array}{l}\text { Random sequence genera- } \\
\text { tion (selection bias) }\end{array}$ & Low risk & Quote: "Patients were randomly assigned." \\
\hline $\begin{array}{l}\text { Allocation concealment } \\
\text { (selection bias) }\end{array}$ & Low risk & $\begin{array}{l}\text { Quote: "Randomization numbers were affixed to sealed treatment kits that } \\
\text { contained study medication and were provided by the study sponsor." }\end{array}$ \\
\hline $\begin{array}{l}\text { Blinding of participants } \\
\text { and personnel (perfor- } \\
\text { mance bias) } \\
\text { All outcomes }\end{array}$ & High risk & $\begin{array}{l}\text { Not reported. } \\
\text { Comment: definitely not blinded; knowledge of the assigned intervention may } \\
\text { have led to differential behaviors across intervention groups (e.g. differential } \\
\text { dropout, differential cross-over to an alternative intervention, or differential } \\
\text { administration of cointerventions). }\end{array}$ \\
\hline $\begin{array}{l}\text { Blinding of outcome as- } \\
\text { sessment (detection bias) } \\
\text { All outcomes }\end{array}$ & Low risk & $\begin{array}{l}\text { Quote: "Outcome adjudication committee, which provided blinded outcome } \\
\text { assignments for incidence outcomes." } \\
\text { Comment: definitely blinded. }\end{array}$ \\
\hline $\begin{array}{l}\text { Incomplete outcome data } \\
\text { addressed? }\end{array}$ & Low risk & $\begin{array}{l}\text { No information about the follow-up in cancer subgroup was reported. } \\
\text { Comment: we analyzed the available data assuming that any possibly missing } \\
\text { data were missing at random. }\end{array}$ \\
\hline $\begin{array}{l}\text { Free of selective report- } \\
\text { ing? }\end{array}$ & Low risk & $\begin{array}{l}\text { Study not registered and no published protocol identified. All relevant out- } \\
\text { comes listed in the methods section were reported on in the results section. }\end{array}$ \\
\hline Free of other bias? & Low risk & $\begin{array}{l}\text { Study not reported as stopped early for benefit. } \\
\text { No other bias suspected. }\end{array}$ \\
\hline
\end{tabular}

Prandoni 1992

\begin{tabular}{ll}
\hline Methods & Randomized controlled trial. \\
\hline Participants & 33 people with cancer with proximal DVT (study subgroup); minimum age 18 years. \\
\hline Interventions & Intervention: Fraxiparin (nadroparin) weight -based SC twice daily. \\
& Control: UFH IV (target aPTT 1.5-2.0) x 10 days. \\
Coumarin (target INR 2-3) started on day 7 for at least 3 months.
\end{tabular}


Prandoni 1992 (Continued)

Discontinued treatment: not reported for cancer subgroup.

Duration of follow-up: 6 months.
- Mortality.
- Symptomatic recurrent DVT.
- Symptomatic PE.
- Major bleeding.
- Minor bleeding

Screening and diagnostic testing for DVT/PE: contrast venography, perfusion lung scanning, and chest radiography.

\begin{tabular}{ll}
\hline Notes & - Setting: not reported. \\
& - Funding: not reported. \\
& - Ethical approval: "The study protocol was approved by the institutional review board." \\
& - Conflict of interest: not reported. \\
\hline
\end{tabular}

\section{Risk of bias}

\begin{tabular}{lll}
\hline Bias & Authors' judgement & Support for judgement \\
\hline $\begin{array}{l}\text { Random sequence genera- } \\
\text { tion (selection bias) }\end{array}$ & Low risk & $\begin{array}{l}\text { Quote: "Patients were allocated treatment by a prescribed randomisation } \\
\text { schedule." }\end{array}$ \\
\hline $\begin{array}{l}\text { Allocation concealment } \\
\text { (selection bias) }\end{array}$ & Low risk & Quote: "Treatment was allocated by the sealed envelop method." \\
\hline $\begin{array}{l}\text { Blinding of participants } \\
\text { and personnel (perfor- } \\
\text { mance bias) } \\
\text { All outcomes }\end{array}$ & High risk & $\begin{array}{l}\text { Quote: "Because the two regimens were given by different routes and because } \\
\text { dose adjustments were necessary in the standard heparin group, we could not } \\
\text { use a double blind design." }\end{array}$ \\
& $\begin{array}{l}\text { Comment: definitely not blinded; knowledge of the assigned intervention may } \\
\text { have led to differential behaviors across intervention groups (e.g. differential } \\
\text { dropout, differential cross-over to an alternative intervention, or differential } \\
\text { administration of cointerventions). }\end{array}$
\end{tabular}

\begin{tabular}{|c|c|c|}
\hline $\begin{array}{l}\text { Blinding of outcome as- } \\
\text { sessment (detection bias) } \\
\text { All outcomes }\end{array}$ & Low risk & $\begin{array}{l}\text { Quote: "All clinical endpoints were reviewed by an adjudication committee } \\
\text { from the coordinating center, unaware of treatment allocation or other details } \\
\text { of patients." }\end{array}$ \\
\hline
\end{tabular}

\begin{tabular}{lll}
\hline $\begin{array}{l}\text { Incomplete outcome data } \\
\text { addressed? }\end{array}$ & Low risk & Complete follow-up. \\
\hline $\begin{array}{l}\text { Free of selective report- } \\
\text { ing? }\end{array}$ & Low risk & $\begin{array}{l}\text { Study not registered and no published protocol identified. All relevant out- } \\
\text { comes listed in the methods section were reported on in the results section. }\end{array}$ \\
\hline Free of other bias? & Low risk & Study not reported as stopped early for benefit. \\
& No other bias suspected. \\
\hline
\end{tabular}


Prandoni 2004 (GALILEI)

\begin{tabular}{ll}
\hline Methods & Randomized controlled trial. \\
\hline Participants & $\begin{array}{l}156 \text { people with cancer (study subgroup) with DVT of lower extremities, PE, or both; minimum age } 18 \\
\text { years; minimum life expectancy } 3 \text { months. }\end{array}$
\end{tabular}

Interventions Intervention: nadroparin $80 \mathrm{U} / \mathrm{kg}$ twice daily.

Control: UFH 1st dose weight adjusted IV, subsequent doses SC twice daily (target aPTT 50-90 s) x 5 days.

Warfarin (target INR 2-3) started the first 2 days $x 12$ weeks.

Discontinued treatment: not reported for cancer subgroup.

Duration of follow-up: 3 months.
- Mortality.
- Symptomatic recurrent VTE.
- Major bleeding.
Screening and diagnostic testing for DVT: venogram, compression ultrasound.
Screening and diagnostic testing for PE: pulmonary angiography or computed tomographic scan.
- Setting: not reported.
- Funding: Gentium SpA, Como, Italy.
- Ethical approval: "The study was approved by the ethical board of all participating centers."
- article."
- ITT analysis: "analyses were performed on an intention-to-treat basis."

\section{Risk of bias}

\begin{tabular}{|c|c|c|}
\hline Bias & Authors' judgement & Support for judgement \\
\hline $\begin{array}{l}\text { Random sequence genera- } \\
\text { tion (selection bias) }\end{array}$ & Low risk & Quote: "Randomization was performed with a computer algorithm." \\
\hline $\begin{array}{l}\text { Allocation concealment } \\
\text { (selection bias) }\end{array}$ & Low risk & $\begin{array}{l}\text { Quote: "Randomization was performed with a computer algorithm and the use } \\
\text { of a } 24 \text { hour telephone service that recorded patient information before disclo- } \\
\text { sure of the treatment assigned." }\end{array}$ \\
\hline $\begin{array}{l}\text { Blinding of participants } \\
\text { and personnel (perfor- } \\
\text { mance bias) } \\
\text { All outcomes }\end{array}$ & High risk & $\begin{array}{l}\text { Quote: "open multicenter clinical trial." } \\
\text { Comment: definitely not blinded; knowledge of the assigned intervention may } \\
\text { have led to differential behaviors across intervention groups (e.g. differential } \\
\text { dropout, differential cross-over to an alternative intervention, or differential } \\
\text { administration of cointerventions). }\end{array}$ \\
\hline $\begin{array}{l}\text { Blinding of outcome as- } \\
\text { sessment (detection bias) } \\
\text { All outcomes }\end{array}$ & Low risk & $\begin{array}{l}\text { Quote: "Information on all suspected outcome events and deaths was re- } \\
\text { viewed and classified by a central adjudication committee blinded to treat- } \\
\text { ment assignment." } \\
\text { Comment: definitely blinded. }\end{array}$ \\
\hline $\begin{array}{l}\text { Incomplete outcome data } \\
\text { addressed? }\end{array}$ & Low risk & Complete follow-up. \\
\hline
\end{tabular}


Simonneau 1993 (Continued)

Blinding of outcome as- Low risk Q Q Luote: "Venograms, perfusion lung scans, and pulmonary angiograms were sessment (detection bias) subsequently reviewed by a central independent panel of two consultant speAll outcomes cialists unaware of the treatment allocation."

Comment: definitely blinded.

Incomplete outcome data Low risk Complete follow-up.

addressed?

Free of selective report- Low risk Study not registered and no published protocol identified. All relevant outing? comes listed in the methods section were reported on in the results section.

Free of other bias? Low risk Study not reported as stopped early for benefit.

No other bias suspected.

Simonneau 1997 (THESEE)

Methods Randomized controlled trial.

$\begin{array}{ll}\text { Participants } & \begin{array}{l}60 \text { people with cancer with PE (study subgroup); minimum age } 18 \text { years; minimum life expectancy } 3 \\ \text { months. }\end{array}\end{array}$
months.

Interventions Intervention: tinzaparin 175 antiXa U/kg SC once daily.

Control: UFH IV (target aPTT 2-3) x 5 days.

Oral anticoagulation (target INR 2-3) started on 1st to 3rd day $\mathrm{x}$ at least 3 months.

Discontinued treatment: not reported for cancer subgroup.

Outcomes Duration of follow-up: 90 days.

- Mortality.

- Symptomatic recurrent VTE.

- Major bleeding.

Screening and diagnostic testing for DVT: ultrasonography or venography.

Screening and diagnostic testing for PE: ventilation-perfusion scanning or angiography.

$\begin{array}{ll}\text { Notes } & \text { - Setting: not reported. } \\ \text { - Funding: Leo Pharmaceuticals. } \\ \text { - Ethical approval: "The study protocol was approved by the institutional review boards of all the par- } \\ \text { - Conflict of interest: not reported. } \\ \text { - ITT analysis: "The primary analysis was performed on an intention to treat basis." }\end{array}$

\section{Risk of bias}

\section{Bias}

Random sequence genera- Low risk tion (selection bias)

\section{Authors' judgement Support for judgement}

Quote: "central randomization was performed." 
Simonneau 1997 (THESEE) (Continued)
Allocation concealment Low risk
Quote: "central randomization was performed with the use of a 24 hour com- (selection bias) puter service."

Blinding of participants High risk and personnel (performance bias)

All outcomes

\section{Quote: "unblinded trial."}

Comment: definitely not blinded; knowledge of the assigned intervention may have led to differential behaviors across intervention groups (e.g. differential dropout, differential cross-over to an alternative intervention, or differential administration of cointerventions).

\section{Blinding of outcome as- Low risk} sessment (detection bias)

All outcomes

Quote: "All the scans were reviewed independently and scored accordingly to this method by two readers, each unaware of the patient's treatment assignment."

Comment: definitely blinded.

\begin{tabular}{lll}
\hline $\begin{array}{l}\text { Incomplete outcome data } \\
\text { addressed? }\end{array}$ & Low risk & Complete follow-up. \\
\hline $\begin{array}{l}\text { Free of selective report- } \\
\text { ing? }\end{array}$ & Low risk & $\begin{array}{l}\text { Study not registered and no published protocol identified. All relevant out- } \\
\text { comes listed in the methods section were reported on in the results section. }\end{array}$ \\
\hline Free of other bias? & Low risk & Study not reported as stopped early for benefit. \\
& No other bias suspected. \\
\hline
\end{tabular}

\section{van Doormaal 2009}

\begin{tabular}{|c|c|}
\hline Methods & Randomized controlled trial. \\
\hline Participants & 477 people with cancer with DVT; minimum age 18 years. \\
\hline \multirow[t]{4}{*}{ Interventions } & $\begin{array}{l}\text { Intervention: fondaparinux SC once daily in fixed dose }(5 \mathrm{mg} \text { if participants weighed }<50 \mathrm{~kg}, 7.5 \mathrm{mg} \text { if } \\
\text { they weighed } 50-100 \mathrm{~kg} \text {, or } 10 \mathrm{mg} \text { if they weighed }>100 \mathrm{~kg}) \text { and twice daily } \mathrm{SC} \text { injections of placebo that } \\
\text { appeared identical to enoxaparin. }\end{array}$ \\
\hline & $\begin{array}{l}\text { Control: enoxaparin SC twice daily } 1 \mathrm{mg} / \mathrm{kg} \text { of bodyweight and a once daily SC injection of placebo that } \\
\text { appeared identical to fondaparinux or UFH (target aPTT } 1.5 \text { to } 2.5 \text { ). }\end{array}$ \\
\hline & $\begin{array}{l}\text { Vitamin } \mathrm{K} \text { antagonist therapy was begun as soon as possible but not later than } 72 \text { hours after com- } \\
\text { mencing initial therapy. }\end{array}$ \\
\hline & Discontinued treatment: not reported for cancer subgroup. \\
\hline \multirow[t]{6}{*}{ Outcomes } & Duration of follow-up: 90 days. \\
\hline & - Mortality. \\
\hline & - Symptomatic recurrent VTE. \\
\hline & - Major bleeding. \\
\hline & - Minor bleeding. \\
\hline & Screening and diagnostic testing for DVT/PE: not reported. \\
\hline \multirow[t]{4}{*}{ Notes } & - Setting: drug administered by a home care service for home treatment. \\
\hline & - Funding: Sanofi/Organon. \\
\hline & - Ethical approval: Matisse clinical trial. \\
\hline & - Conflict of interest: not reported. \\
\hline
\end{tabular}


- ITT analysis: "The analyses were calculated in the intention to treat populations."

\section{Risk of bias}

\begin{tabular}{|c|c|c|}
\hline Bias & Authors' judgement & Support for judgement \\
\hline $\begin{array}{l}\text { Random sequence genera- } \\
\text { tion (selection bias) }\end{array}$ & Low risk & $\begin{array}{l}\text { Quote: "Patients were randomly assigned by a computerized interactive voice } \\
\text { response system." }\end{array}$ \\
\hline $\begin{array}{l}\text { Allocation concealment } \\
\text { (selection bias) }\end{array}$ & Low risk & $\begin{array}{l}\text { Quote: "Patients were randomly assigned by a computerized interactive voice } \\
\text { response system." }\end{array}$ \\
\hline $\begin{array}{l}\text { Blinding of participants } \\
\text { and personnel (perfor- } \\
\text { mance bias) } \\
\text { All outcomes }\end{array}$ & Low risk & $\begin{array}{l}\text { Quote: "double-blinded, placebo controlled study." } \\
\text { Comment: definitely blinded. }\end{array}$ \\
\hline $\begin{array}{l}\text { Blinding of outcome as- } \\
\text { sessment (detection bias) } \\
\text { All outcomes }\end{array}$ & Low risk & $\begin{array}{l}\text { Quote: "The study used central adjudication for all clinical outcome events." } \\
\text { Comment: definitely blinded. }\end{array}$ \\
\hline $\begin{array}{l}\text { Incomplete outcome data } \\
\text { addressed? }\end{array}$ & Low risk & Complete follow-up. \\
\hline $\begin{array}{l}\text { Free of selective report- } \\
\text { ing? }\end{array}$ & Low risk & $\begin{array}{l}\text { Study not registered and no published protocol identified. All relevant out- } \\
\text { comes listed in methods section are reported on in the results section. }\end{array}$ \\
\hline Free of other bias? & Low risk & $\begin{array}{l}\text { Study not reported as stopped early for benefit. } \\
\text { No other bias suspected. }\end{array}$ \\
\hline
\end{tabular}

Wells 2005

\begin{tabular}{ll}
\hline Methods & Randomized controlled trial, single blind. \\
\hline Participants & 113 people with cancer with upper or lower extremity DVT; minimum age 18 years. \\
\hline Interventions & Intervention: tinzaparin SC $175 \mathrm{IU} / \mathrm{kg}$ once daily. \\
& Control: dalteparin SC $200 \mathrm{IU} / \mathrm{kg}$ once daily. \\
& Discontinued treatment: 0 participants. \\
\hline
\end{tabular}

\begin{tabular}{ll}
\hline Outcomes & Duration of follow-up: 3 months. \\
- Mortality. \\
- Symptomatic recurrent VTE. \\
- Major bleeding. \\
- Minor bleeding.
\end{tabular}

Screening and diagnostic testing for DVT/PE: not reported.

Notes - Setting: participants had received therapy on outpatient basis.

- Funding: Canada Research Chair from the Canadian Research Chair Program, Ottawa, Ontario (Dr PS Wells); a research scholarship from Dalhousie University, Halifax, Nova Scotia (Dr Anderson); an internal scholarship from the Department of Medicine, University of Western Ontario, London (Dr Kovacs); 
Wells 2005 (Continued)

and the Maureen Andrew New Investigator Award from the Heart and Stroke Foundation of Ontario, London (Dr Rodger).

- Ethical approval: not reported.

- Conflict of interest: "Financial Disclosure: None."

- ITT analysis: "The primary analysis was intention to treat."

\section{Risk of bias}

\begin{tabular}{lll}
\hline Bias & Authors' judgement & Support for judgement \\
\hline $\begin{array}{l}\text { Random sequence genera- } \\
\text { tion (selection bias) }\end{array}$ & Low risk & $\begin{array}{l}\text { Quote: "Randomization was performed in a computer generated blocks, with } \\
\text { the block size unknown to the investigators." }\end{array}$ \\
\hline
\end{tabular}

Allocation concealment Low risk
(selection bias)

Quote: "Randomization assignments were concealed in opaque envelopes. Envelopes were opened sequentially and only after patient consent form was signed."

Blinding of participants Low risk and personnel (perfor-

Randomization assignments concealed in opaque envelopes. Envelopes opened sequentially and only after the participant consent form was signed. mance bias) All physicians and nurses who were involved in the participant's care were All outcomes blinded except for the nurse who provided the initial care to the participant. In all cases, 2 prescriptions were written for the participant, and the physician was unaware which drug was ultimately assigned. The nurse who was initially involved with the participant was not involved in follow-up assessment for recurrence or bleeding.

Comment: definitely blinded; knowledge of the assigned intervention may have led to differential behaviors across intervention groups (e.g. differential dropout, differential cross-over to an alternative intervention, or differential administration of cointerventions).

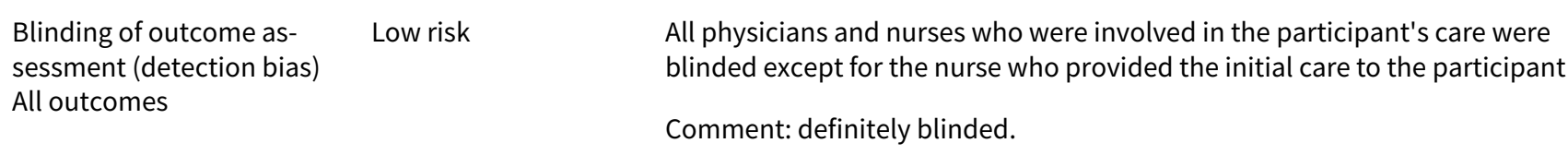

Incomplete outcome data Low risk Complete follow-up.
addressed?

\begin{tabular}{|c|c|c|}
\hline $\begin{array}{l}\text { Free of selective report- } \\
\text { ing? }\end{array}$ & Low risk & $\begin{array}{l}\text { Study not registered and no published protocol identified. All relevant out- } \\
\text { comes listed in methods section are reported on in the results section. }\end{array}$ \\
\hline
\end{tabular}

Free of other bias? Low risk
Study not reported as stopped early for benefit.

No other bias suspected.

antiXa: anti-factor Xa; aPTT: activated partial thromboplastin time; DVT: deep venous thrombosis; INR: international normalized ratio; ITT: intention to treat; IU: international units; IV: intravenous; LMWH: low molecular weight heparin; mg: milligram; MPD: missing participant data; PE: pulmonary embolism; s: second; SC: subcutaneous; SD: standard deviation; U: unit; UFH: unfractionated heparin; VTE: venous thromboembolism.

Characteristics of excluded studies [ordered by study ID]

\begin{tabular}{ll}
\hline Study & Reason for exclusion \\
\hline Agnelli 1998 & Not the population of interest (people without VTE). \\
\hline
\end{tabular}




\begin{tabular}{|c|c|}
\hline Study & Reason for exclusion \\
\hline Agnelli 2005 & Not the population of interest (people without VTE). \\
\hline Agnelli 2015 (AMPLIFY) & Not the intervention of interest (secondary treatment); included 2 reports. \\
\hline Albada 1989 & Data for cancer subgroup not available. \\
\hline Alikhan 2003 (MEDENOX) & Not the population of interest (people without VTE). \\
\hline Altundag 2005 & Letter to editor. \\
\hline Anton 2001 & Review. \\
\hline Auer 2011 & Not the population of interest (people without VTE). \\
\hline Bauer 2000 & Editorial. \\
\hline Belcaro 1999 & Data for cancer subgroup not available. \\
\hline Bick 2003 & Review. \\
\hline Bigg 1992 & Not the population of interest (people without VTE). \\
\hline Booth 1981 & Case report. \\
\hline Bratt 1985 & No relevant clinical outcomes. \\
\hline Bratt 1990 & Data for cancer subgroup not available. \\
\hline Brooks 1969 & Case report. \\
\hline Buller 2004 & Data for cancer subgroup not available. \\
\hline Cahan 2000 & Not the population of interest (people without VTE). \\
\hline Ciftci 2012 & Not the population of interest (ambulatory people with cancer without VTE). \\
\hline Clarke-Pearson 1993 & Not the population of interest (people without VTE). \\
\hline Cohen 1997 & Not the population of interest (people without VTE). \\
\hline Cohen 2006 & Not the population of interest (people without VTE). \\
\hline Cohen 2007 (PREVENT) & Not the population of interest (people without VTE) included 3 reports. \\
\hline Couban 2005 & Not the population of interest (people without VTE); included 3 reports. \\
\hline Dickinson 1998 & Not the population of interest (people without VTE). \\
\hline Dolovich 2004 & Review. \\
\hline Douketis 2000 & Cohort study. \\
\hline Eikelboom 1998 & Case series. \\
\hline Elly 1969 & Case report. \\
\hline
\end{tabular}




\begin{tabular}{|c|c|}
\hline Study & Reason for exclusion \\
\hline Fiessinger 1996 & Data for cancer subgroup not available. \\
\hline Goldhaber 2002 & Not the population of interest (people without VTE). \\
\hline Gould 1999 & Review. \\
\hline Green 1992 & Letter to editor. \\
\hline Haage 2002 & Review. \\
\hline Haas 2011 & Not the population of interest (people without VTE); included 3 reports. \\
\hline Handeland 1990 & No people with cancer in the study. \\
\hline Harenberg 2000 & Data for cancer subgroup not available. \\
\hline Harenberg 1990 & Data for cancer subgroup not available. \\
\hline Harenberg 1996 & Not the population of interest (people without VTE); included 2 reports. \\
\hline Hata 2016 & Not the population of interest (people without VTE). \\
\hline Hettiarachchi 1998 & Review. \\
\hline Holm 1986 & Data for cancer subgroup not available. \\
\hline Holmstrom 1999 & Review. \\
\hline Hull 2000 & Data for cancer subgroup not available. \\
\hline Hull 2006 & Not the intervention of interest (secondary treatment). \\
\hline Jahanzeb 2005 & Review. \\
\hline Kakkar 2010 (CANBESURE) & Not the population of interest (people without VTE); included 2 reports. \\
\hline Kakkar 2014 (SAVE-ABDO) & Not the population of interest (people without VTE); included 2 reports. \\
\hline Khorana 2017 (PHACS) & Not the population of interest (people without VTE); included 2 reports. \\
\hline Koppenhagen 1992 & Not the population of interest (people without VTE). \\
\hline Larocca 2012 & Not the population of interest (people without VTE). \\
\hline Lee 2015 (CATCH) & Not the intervention of interest (secondary treatment); included 9 reports. \\
\hline Leizorovicz 1994 & Review. \\
\hline Levine 2001 & Review. \\
\hline Luomanmaki 1996 & Data for cancer subgroup not available. \\
\hline Macbeth 2016 (FRAGMATIC) & Not the population of interest (people without VTE); included 4 reports. \\
\hline Martin-Carbonero 2002 & Cohort study. \\
\hline
\end{tabular}




\begin{tabular}{|c|c|}
\hline Study & Reason for exclusion \\
\hline Maxwell 2001 & Not the population of interest (people without VTE). \\
\hline Mazilu 2014 (OVIDIUS) & Not the population of interest (people without VTE). \\
\hline Menzoian 1983 & Retrospective study. \\
\hline Murakami 2002 & Not the population of interest (people without VTE). \\
\hline Nagata 2015 & Not the population of interest (people without VTE). \\
\hline Naschitz 1994 & Review. \\
\hline Nurmohamed 1996 & Not the population of interest (people without VTE). \\
\hline Palumbo 2011 & Not the population of interest (people without VTE); included 6 reports. \\
\hline Pelzer 2015 (CONKO-004) & Not the population of interest (people without VTE); included 10 reports. \\
\hline Prandoni 1988 & No control group. \\
\hline Prandoni 1990 & No cancer people in the study. \\
\hline Prandoni 2005 & Review. \\
\hline Prins 2014 (EINSTEIN) & Not the intervention of interest (secondary treatment). \\
\hline Raskob 2016 (HOKUSAI) & Not the intervention of interest (secondary treatment). \\
\hline Riess 2003 & Data for cancer subgroup not available. \\
\hline Sakon 2010 & Not the population of interest (people without VTE). \\
\hline Sakuragi 2003 & Retrospective study. \\
\hline Schulman 2003 & Not the intervention of interest (secondary treatment). \\
\hline Schulman 2013 (RE-MEDY) & Not the intervention of interest (secondary treatment). \\
\hline Schulman 2015 (RECOVER) & Not the intervention of interest (secondary treatment). \\
\hline Siragusa 2005 & Not randomized. \\
\hline Song 2014 & Not the population of interest (people without VTE). \\
\hline Turchetti 2003 & Cohort study. \\
\hline Vadhan-Raj 2013 & Not the population of interest (people without VTE). \\
\hline Vedovati 2014 & Not the population of interest (people without VTE); included 5 reports. \\
\hline Verso 2008 & Not the population of interest (people without VTE); included 4 reports. \\
\hline Ward 1998 & Not the population of interest (people without VTE). \\
\hline Warkentin 1995 & No relevant outcome. \\
\hline
\end{tabular}




\begin{tabular}{ll}
\hline Study & Reason for exclusion \\
\hline Wester 1996 & $\begin{array}{l}\text { No relevant outcome (cancer subgroup reported without information about number randomized } \\
\text { to each study arm). }\end{array}$ \\
\hline Wong 2003 & Survey. \\
\hline Zheng 2014 & Not the population of interest (people without VTE). \\
\hline Zwicker 2013 (MICRO TEC) & Not the population of interest (people without VTE); includes 2 reports. \\
\hline
\end{tabular}

VTE: venous thromboembolism.

\section{DATA AND ANALYSES}

Comparison 1. Low molecular weight heparin (LMWH) versus unfractionated heparin (UFH)

\begin{tabular}{lllll}
\hline Outcome or subgroup title & No. of studies & $\begin{array}{l}\text { No. of partici- } \\
\text { pants }\end{array}$ & Statistical method & Effect size \\
\hline 1 Mortality (3 months) & 5 & 418 & $\begin{array}{l}\text { Risk Ratio (M-H, Random, 95\% } \\
\text { Cl) }\end{array}$ & $0.66[0.40,1.10]$ \\
\hline $\begin{array}{l}2 \text { Any recurrent venous thromboem- } \\
\text { bolism (3 months) }\end{array}$ & 3 & 422 & $\begin{array}{l}\text { Risk Ratio (M-H, Random, 95\% } \\
\text { Cl) }\end{array}$ & $0.69[0.27,1.76]$ \\
\hline
\end{tabular}

Analysis 1.1. Comparison 1 Low molecular weight heparin (LMWH) versus unfractionated heparin (UFH), Outcome 1 Mortality (3 months).

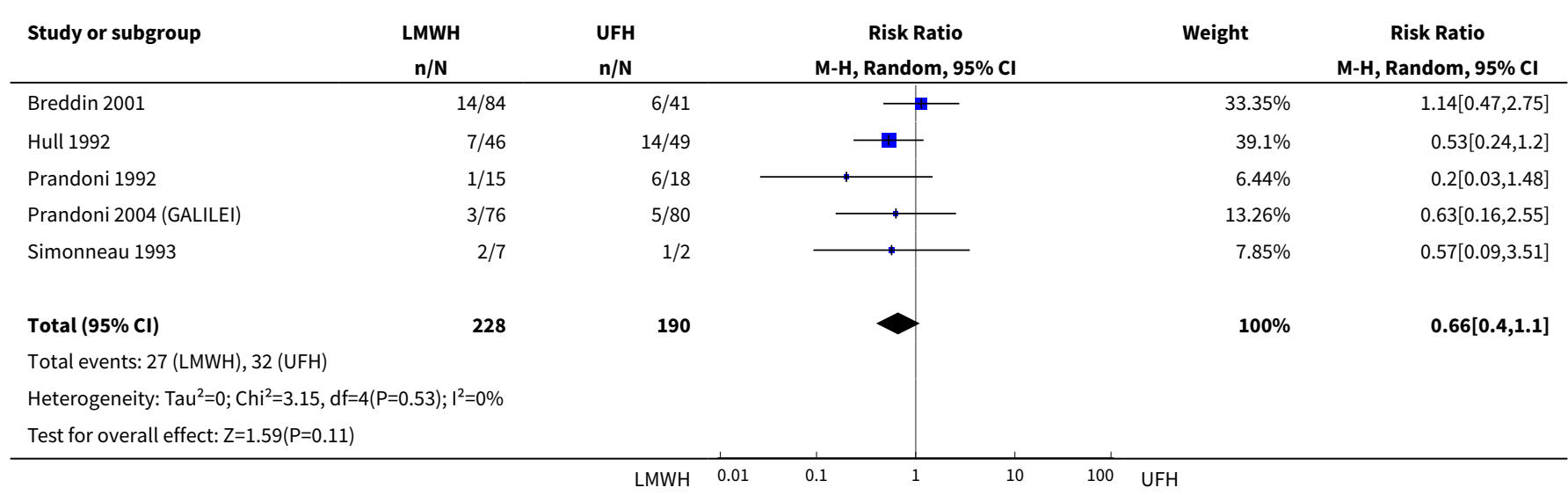


Analysis 1.2. Comparison 1 Low molecular weight heparin (LMWH) versus unfractionated heparin (UFH), Outcome 2 Any recurrent venous thromboembolism (3 months).

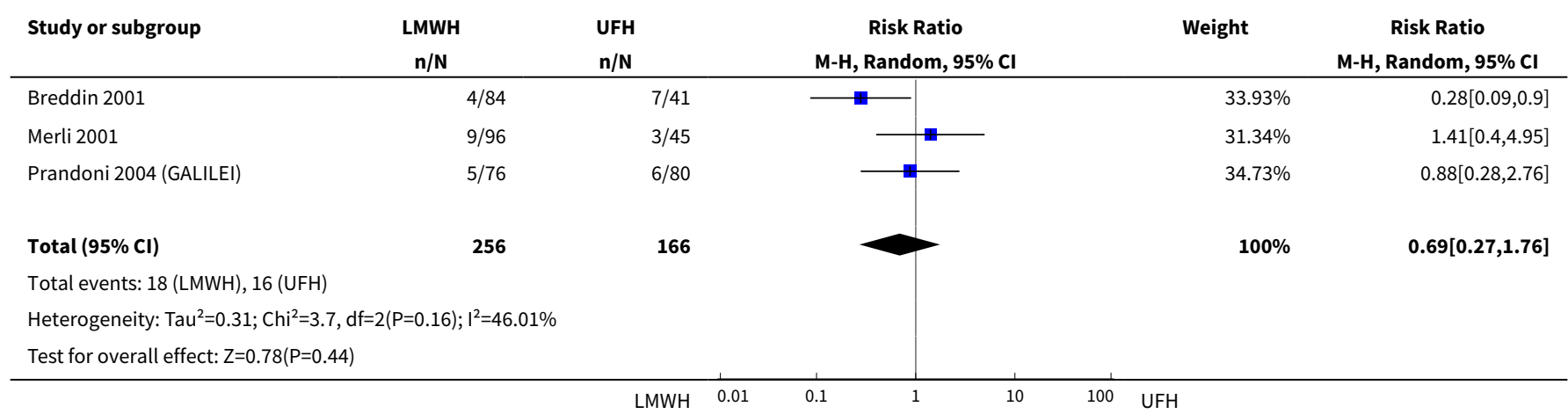

Comparison 2. Fondaparinux versus heparin (low molecular weight heparin (LMWH) + unfractionated heparin (UFH))

\begin{tabular}{|c|c|c|c|c|}
\hline Outcome or subgroup title & No. of studies & $\begin{array}{l}\text { No. of partici- } \\
\text { pants }\end{array}$ & Statistical method & Effect size \\
\hline 1 Mortality (3 months) & 1 & 477 & $\begin{array}{l}\text { Risk Ratio (M-H, Random, 95\% } \\
\mathrm{Cl})\end{array}$ & $1.25[0.86,1.81]$ \\
\hline $\begin{array}{l}2 \text { Recurrent venous thromboem- } \\
\text { bolism ( } 3 \text { months) }\end{array}$ & 1 & 477 & $\begin{array}{l}\text { Risk Ratio (M-H, Random, 95\% } \\
\mathrm{Cl} \text { ) }\end{array}$ & $0.93[0.56,1.54]$ \\
\hline 3 Major bleeding ( 3 months) & 1 & 477 & $\begin{array}{l}\text { Risk Ratio (M-H, Random, 95\% } \\
\mathrm{Cl})\end{array}$ & $0.82[0.40,1.66]$ \\
\hline 4 Minor bleeding ( 3 months) & 1 & 477 & $\begin{array}{l}\text { Risk Ratio (M-H, Random, 95\% } \\
\mathrm{Cl} \text { ) }\end{array}$ & $1.53[0.88,2.66]$ \\
\hline
\end{tabular}

Analysis 2.1. Comparison 2 Fondaparinux versus heparin (low molecular weight heparin (LMWH) + unfractionated heparin (UFH)), Outcome 1 Mortality (3 months).

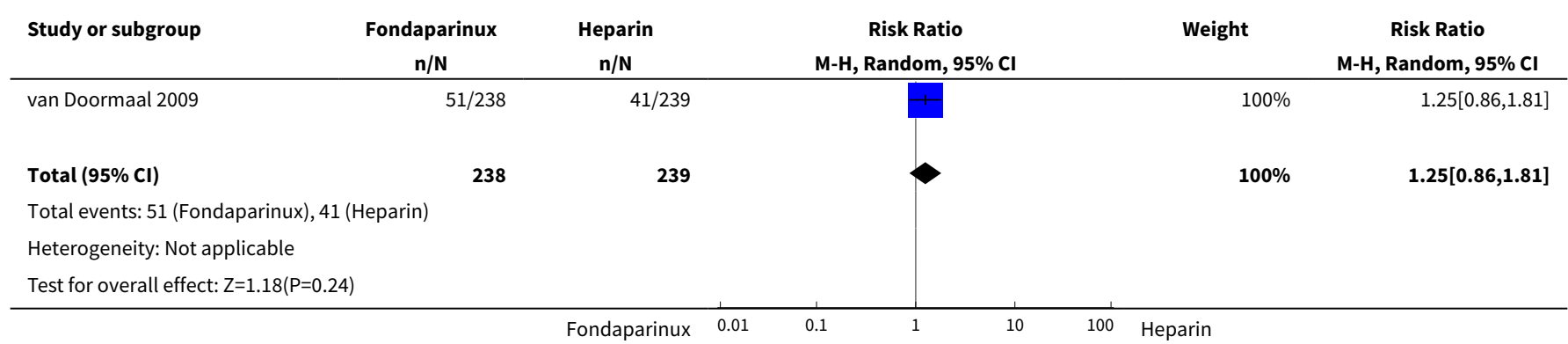


Analysis 2.2. Comparison 2 Fondaparinux versus heparin (low molecular weight heparin (LMWH)

+ unfractionated heparin (UFH)), Outcome 2 Recurrent venous thromboembolism (3 months).

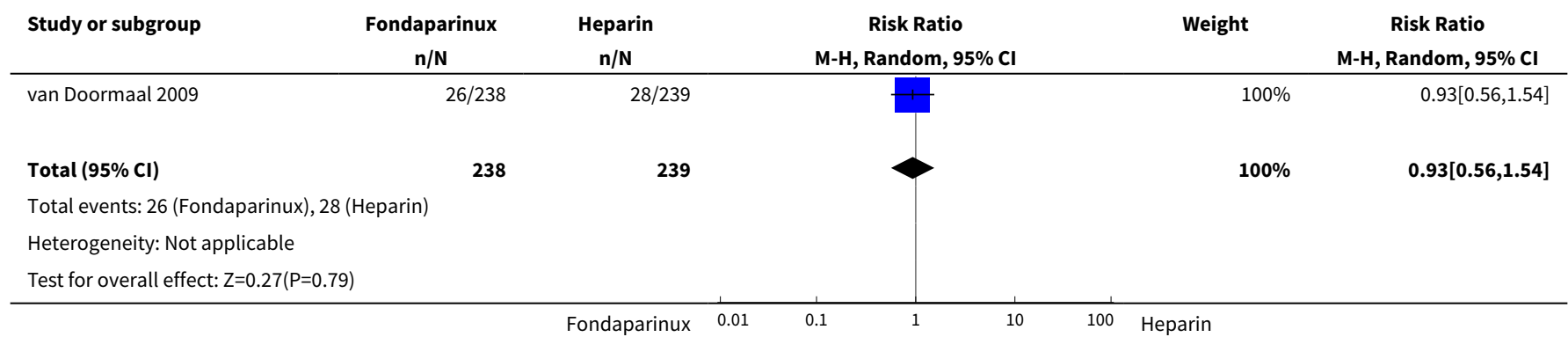

Analysis 2.3. Comparison 2 Fondaparinux versus heparin (low molecular weight heparin (LMWH) + unfractionated heparin (UFH)), Outcome 3 Major bleeding (3 months).

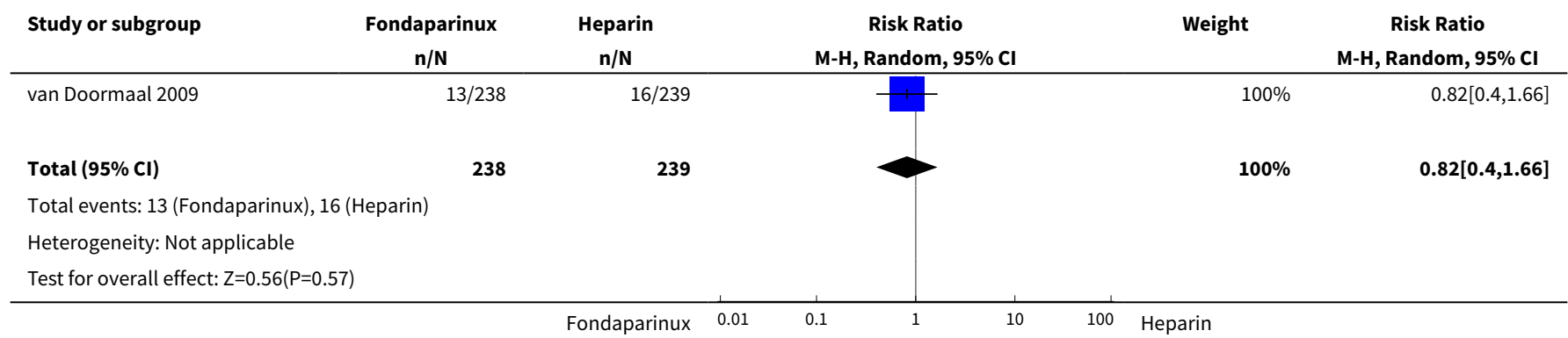

Analysis 2.4. Comparison 2 Fondaparinux versus heparin (low molecular weight heparin (LMWH) + unfractionated heparin (UFH)), Outcome 4 Minor bleeding (3 months).

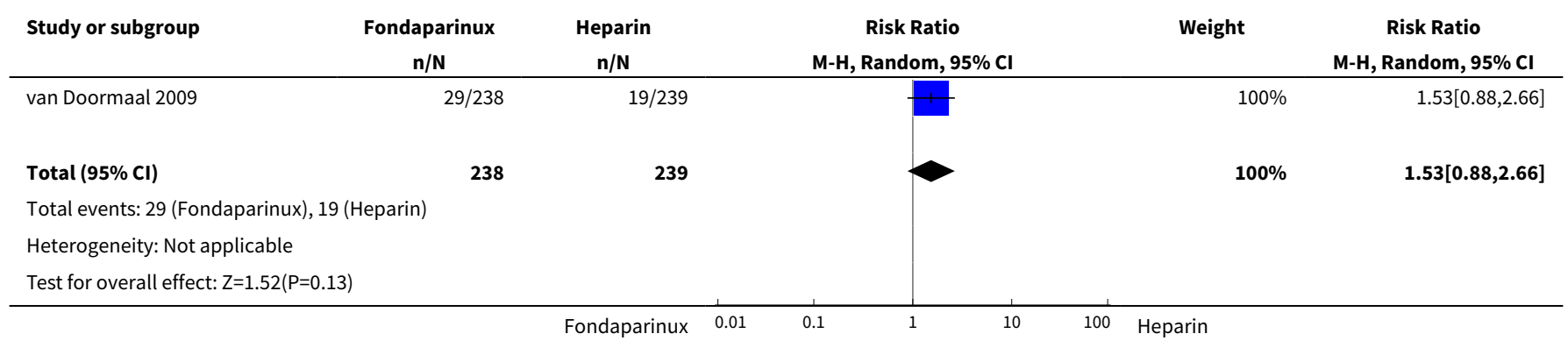

\section{Comparison 3. Dalteparin versus tinzaparin}

\begin{tabular}{lllll}
\hline Outcome or subgroup title & No. of studies & $\begin{array}{l}\text { No. of partici- } \\
\text { pants }\end{array}$ & Statistical method & Effect size \\
\hline 1 Mortality (3 months) & 1 & 113 & $\begin{array}{l}\text { Risk Ratio (M-H, Random, 95\% } \\
\text { Cl) }\end{array}$ & $0.86[0.43,1.73]$ \\
\hline
\end{tabular}




\begin{tabular}{lllll}
\hline Outcome or subgroup title & No. of studies & $\begin{array}{l}\text { No. of partici- } \\
\text { pants }\end{array}$ & Statistical method & Effect size \\
\hline $\begin{array}{l}\text { 2 Recurrent venous thromboem- } \\
\text { bolism (3 months) }\end{array}$ & 1 & 113 & $\begin{array}{l}\text { Risk Ratio (M-H, Random, 95\% } \\
\text { Cl) }\end{array}$ & $0.44[0.09,2.16]$ \\
\hline 3 Major bleeding (3 months) & 1 & 113 & $\begin{array}{l}\text { Risk Ratio (M-H, Random, 95\% } \\
\text { Cl) }\end{array}$ & $2.19[0.20,23.42]$ \\
\hline 4 Minor bleeding (3 months) & 1 & 113 & $\begin{array}{l}\text { Risk Ratio (M-H, Random, 95\% } \\
\text { Cl) }\end{array}$ & $0.82[0.30,2.21]$ \\
\hline
\end{tabular}

\section{Analysis 3.1. Comparison 3 Dalteparin versus tinzaparin, Outcome 1 Mortality ( 3 months).}

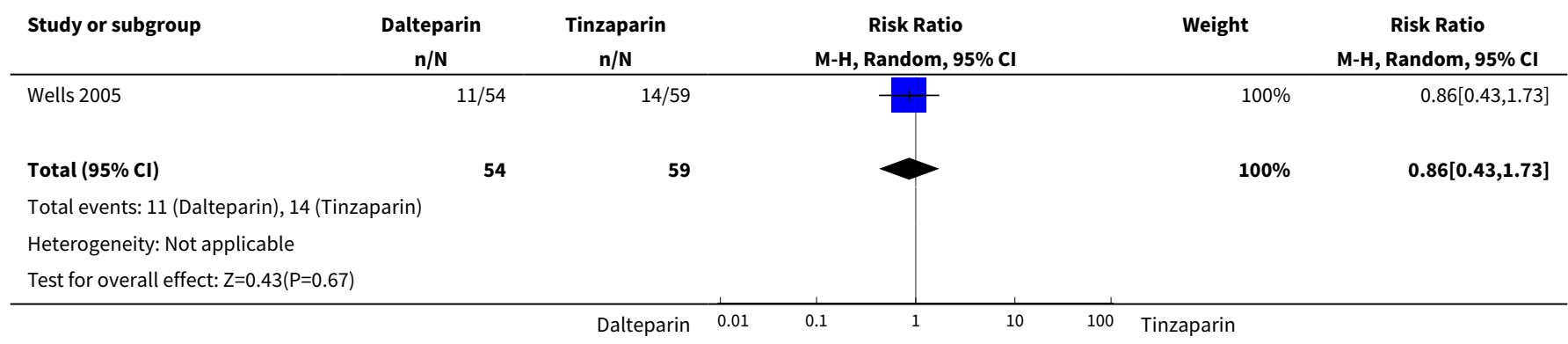

Analysis 3.2. Comparison 3 Dalteparin versus tinzaparin, Outcome 2 Recurrent venous thromboembolism (3 months).

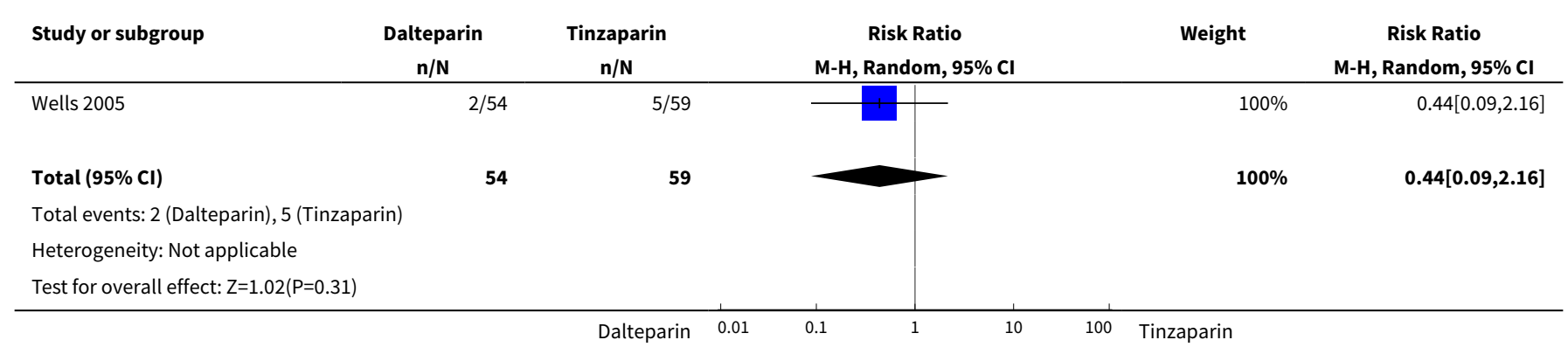

Analysis 3.3. Comparison 3 Dalteparin versus tinzaparin, Outcome 3 Major bleeding ( 3 months).

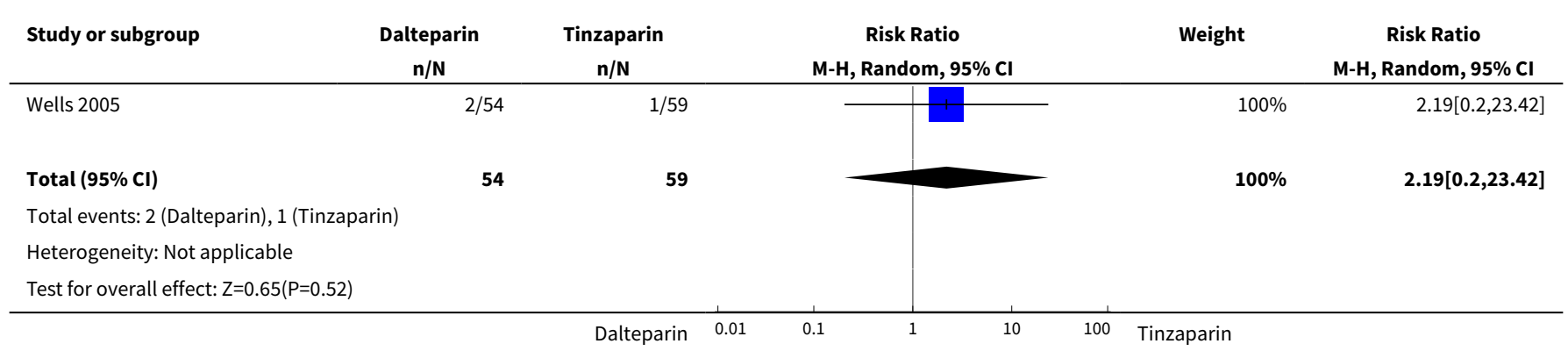




\section{Analysis 3.4. Comparison 3 Dalteparin versus tinzaparin, Outcome 4 Minor bleeding ( 3 months).}

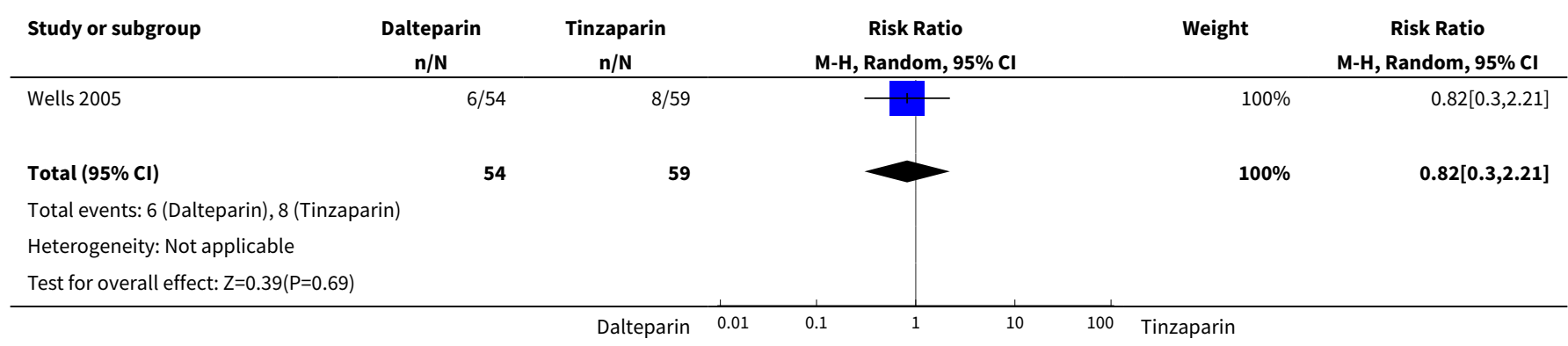

ADDITIONAL TABLES

Table 1. Glossary

\begin{tabular}{|c|c|}
\hline Term & Definition \\
\hline A priori & Made before or without exam; not supported by factual study. \\
\hline Adjuvant therapy & Assisting in the amelioration or cure of disease. \\
\hline Anticoagulation & Process of hindering the clotting of blood especially by treatment with an anticoagulant. \\
\hline Antithrombotic & Used against or tending to prevent thrombosis (clotting). \\
\hline Coagulation & Clotting. \\
\hline Deep vein thrombosis (DVT) & $\begin{array}{l}\text { Condition marked by the formation of a thrombus within a deep vein (as of the leg or pelvis) that } \\
\text { may be asymptomatic or be accompanied by symptoms (as swelling and pain) and that is poten- } \\
\text { tially life threatening if dislodgment of the thrombus results in pulmonary embolism. }\end{array}$ \\
\hline Fondaparinux & Anticoagulant medication. \\
\hline Dalteparin & Anticoagulant medication. \\
\hline Tinzaparin & Anticoagulant medication. \\
\hline Hemostatic system & System that shortens the clotting time of blood and stops bleeding. \\
\hline Heparin & $\begin{array}{l}\text { Enzyme occurring especially in the liver and lungs that prolongs the clotting time of blood by pre- } \\
\text { venting the formation of fibrin. } 2 \text { forms of heparin that are used as anticoagulant medications are: } \\
\text { unfractionated heparin (UFH) and low molecular weight heparins (LMWH). }\end{array}$ \\
\hline Heterogeneity & $\begin{array}{l}\text { Quality or state of being heterogeneous, i.e. incongruous. Statistical technique to check whether } \\
\text { study results are consistent. }\end{array}$ \\
\hline Hypercoagulable state & State of excessive affinity to clotting. \\
\hline Impedance plethysmography & $\begin{array}{l}\text { Technique that measures the change in blood volume (venous blood volume as well as the pulsa- } \\
\text { tion of the arteries) for a specific body segment. }\end{array}$ \\
\hline
\end{tabular}


Table 1. Glossary (Continued)
Kappa statistic
Measure of degree of nonrandom agreement between observers, measurements of a specific cate- gorical variable, or both.

\begin{tabular}{ll}
\hline Metastasis & Spread of a cancer cells from the initial or primary site of disease to another part of the body. \\
\hline Parenteral nutrition & Practice of feeding a person intravenously, circumventing the gastrointestinal tract. \\
\hline Pulmonary embolism (PE) & $\begin{array}{l}\text { Embolism of a pulmonary artery or } 1 \text { of its branches that is produced by foreign matter and most } \\
\text { often a blood clot originating in a vein of the leg or pelvis and that is marked by labored breathing, } \\
\text { chest pain, fainting, rapid heart rate, cyanosis, shock, and sometimes death. }\end{array}$ \\
\hline Thrombocytopenia & $\begin{array}{l}\text { Persistent decrease in the number of blood platelets that is often associated with hemorrhagic } \\
\text { conditions. }\end{array}$ \\
\hline Thrombosis & Formation or presence of a blood clot within a blood vessel. \\
\hline Vitamin K antagonists & Anticoagulant medications that are used for anticoagulation. Warfarin is a vitamin $\mathrm{K}$ antagonist. \\
\hline Warfarin & Anticoagulant medication that is a vitamin $\mathrm{K}$ antagonist that is used for anticoagulation. \\
\hline Ximelagatran & Anticoagulant medication. \\
\hline
\end{tabular}

\section{AP PENDICES}

\section{Appendix 1. Full search strategies for the electronic databases - update 2010}

\begin{tabular}{|c|c|}
\hline Database & Strategy \\
\hline MEDLINE & $\begin{array}{l}\text { \#1 Heparin/ } \\
\text { \#2 Heparin.tw } \\
\text { \#3 Heparin, Low-Molecular-Weight/ } \\
\text { \#4 (LMWH OR low molecular weight heparin OR nadroparin OR fraxiparin OR enoxaparin OR clex- } \\
\text { ane OR lovenox OR dalteparin OR fragmin OR ardeparin OR normiflo OR tinzaparin OR logiparin OR } \\
\text { innohep OR certoparin OR sandoparin OR reviparin OR clivarin OR danaproid OR orgaran).tw } \\
\text { \#5 } 1 \text { OR } 2 \text { OR } 3 \text { OR } 4 \\
\text { \#6 Coumarins/ } \\
\text { \#7 Warfarin/ } \\
\text { \#8 (warfarin OR coumadin OR acenocumarol OR phenprocumon OR 4-hydroxicoumarins OR oral } \\
\text { anticoagulant OR vitamin K antagonist OR VKA).tw } \\
\text { \#9 } 6 \text { OR } 7 \text { OR } 8 \\
\text { \#10 (fondaparinux OR Arixtra).tw } \\
\text { \#11 (ximelagatran OR Exanta).tw } \\
\text { \#12 (Pradaxa or Dabigatran or rivaroxaban or Xarelto or apixaban).tw. } \\
\text { \#13 } 5 \text { OR } 9 \text { OR } 10 \text { OR } 11 \text { OR } 12 \\
\text { \#14 Neoplasms/ } \\
\text { \#15 (malignan\$ OR neoplasm\$ OR cancer OR carcinoma\$ OR adenocarcinoma OR tumour OR tu- } \\
\text { mor).tw } \\
\text { \#16 } 14 \text { OR } 15 \\
\text { \#17 clinical trial.pt. OR random:.tw. OR tu.xs. } \\
\text { \#18 animals/ NOT human/ } \\
\text { \#19 } 17 \text { NOT } 18 \\
\text { \#20 } 13 \text { AND } 16 \text { AND } 19\end{array}$ \\
\hline
\end{tabular}


(Continued)

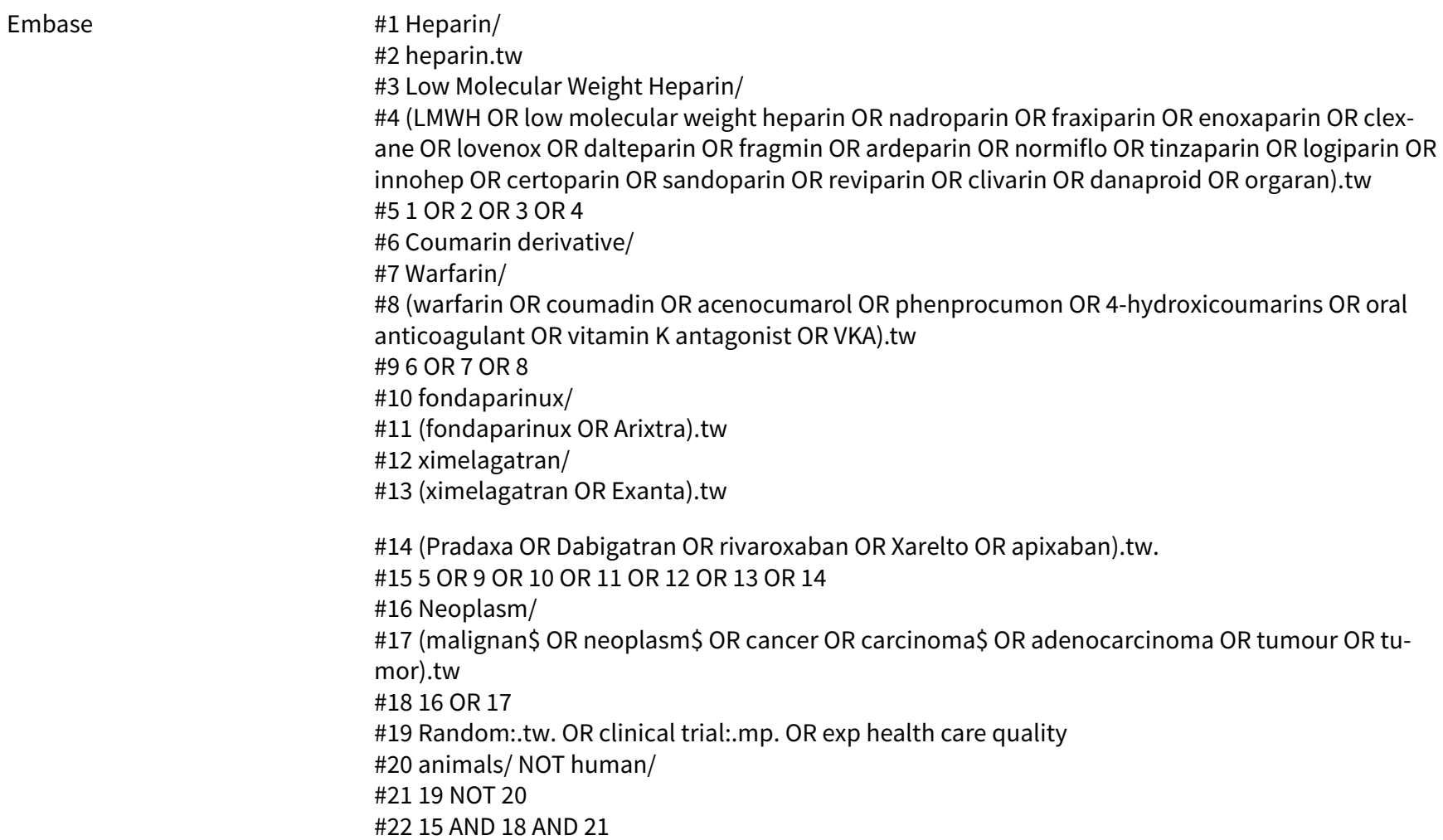

Embase

\#1 Heparin/

\#2 heparin.tw

\#3 Low Molecular Weight Heparin/

\#4 (LMWH OR low molecular weight heparin OR nadroparin OR fraxiparin OR enoxaparin OR clexane OR lovenox OR dalteparin OR fragmin OR ardeparin OR normiflo OR tinzaparin OR logiparin OR innohep OR certoparin OR sandoparin OR reviparin OR clivarin OR danaproid OR orgaran).tw \#5 1 OR 2 OR 3 OR 4

\#6 Coumarin derivative/

\#7 Warfarin/

\#8 (warfarin OR coumadin OR acenocumarol OR phenprocumon OR 4-hydroxicoumarins OR oral anticoagulant OR vitamin $\mathrm{K}$ antagonist OR VKA).tw

\#9 6 OR 7 OR 8

\#10 fondaparinux/

\#11 (fondaparinux OR Arixtra).tw

\#12 ximelagatran/

\#13 (ximelagatran OR Exanta).tw

\#14 (Pradaxa OR Dabigatran OR rivaroxaban OR Xarelto OR apixaban).tw.

\#15 5 OR 9 OR 10 OR 11 OR 12 OR 13 OR 14

\#16 Neoplasm/

\#17 (malignan\$ OR neoplasm\$ OR cancer OR carcinoma\$ OR adenocarcinoma OR tumour OR tu-

mor).tw

\#18 16 OR 17

\#19 Random:.tw. OR clinical trial:.mp. OR exp health care quality

\#20 animals/ NOT human/

\#21 19 NOT 20

\#22 15 AND 18 AND 21

ISI (International Scientific Information) the Web of Science

\#1 heparin OR low molecular weight heparin OR LMWH OR low-molecular-weight-heparin OR nadroparin OR fraxiparin OR enoxaparin OR clexane OR lovenox OR dalteparin OR fragmin OR ardeparin OR normiflo OR tinzaparin OR logiparin OR innohep OR certoparin OR sandoparin OR reviparin OR clivarin OR danaproid OR orgaran

\#2 Coumarins OR Warfarin OR coumadin OR acenocumarol OR phenprocumon OR 4-hydroxicoumarins OR oral anticoagulant OR vitamin $\mathrm{K}$ antagonist OR VKA

\#3 fondaparinux OR Arixtra

\#4 ximelagatran OR Exanta

\#5 Pradaxa OR Dabigatran OR rivaroxaban OR Xarelto OR apixaban \#6 1 OR 2 OR 3 OR 4 OR 5

\#7 malignan\$ OR neoplasm\$ OR cancer OR carcinoma\$ OR adenocarcinoma OR tumour OR tumor \#8 random $\$$ OR placebo $\$$ OR versus OR vs OR double blind OR double-blind OR compar\$ OR controlled

\#9 6 AND 7 AND 8

CENTRAL (the Cochrane Library, latest issue)
\#1 heparin OR low molecular weight heparin OR LMWH OR low-molecular-weight-heparin OR nadroparin OR fraxiparin OR enoxaparin OR clexane OR lovenox OR dalteparin OR fragmin OR ardeparin OR normiflo OR tinzaparin OR logiparin OR innohep OR certoparin OR sandoparin OR reviparin OR clivarin OR danaproid OR orgaran

\#2 Coumarins OR Warfarin OR coumadin OR acenocumarol OR phenprocumon OR 4-hydroxicoumarins OR oral anticoagulant OR vitamin $\mathrm{K}$ antagonist OR VKA

\#3 fondaparinux OR Arixtra

\#4 ximelagatran OR Exanta

\#5 Pradaxa or Dabigatran or rivaroxaban or Xarelto or apixaban

\#6 1 OR 2 OR 3 OR 4 OR 5

\#7 malignan\$ OR neoplasm\$ OR cancer OR carcinoma\$ OR adenocarcinoma OR tumour OR tumor \#8 6 AND 7 
Appendix 2. Full search strategies for the electronic databases - update 2013

\begin{tabular}{|c|c|}
\hline Database & Strategy \\
\hline \multirow[t]{24}{*}{ MEDLINE } & $\# 1$ exp Heparin/ \\
\hline & $\begin{array}{l}\text { \#2 (LMWH or heparin or nadroparin or fraxiparin or enoxaparin or clexane or lovenox or dalteparin } \\
\text { or fragmin or ardeparin or normiflo or tinzaparin or logiparin or innohep or certoparin or san- } \\
\text { doparin or reviparin or clivarin or danaproid or orgaran or bemiparin or hibor, badyket, semu- } \\
\text { loparin, parnaparin, fluxum).tw. }\end{array}$ \\
\hline & \#3 exp Coumarins/ \\
\hline & $\begin{array}{l}\text { \#4 (warfarin or coumadin or acenocumarol or phenprocumon or 4-hydroxicoumarins or oral anti- } \\
\text { coagulant or vitamin } \mathrm{K} \text { antagonist or VKA).tw. }\end{array}$ \\
\hline & \#5 (fondaparinux or arixtra).tw. \\
\hline & \#6 (ximelagatran or exanta).tw. \\
\hline & $\begin{array}{l}\text { \#7 (pradaxa or dabigatran or rivaroxaban or xarelto or apixaban or eliquis or edoxaban or lixiana or } \\
\text { betrixaban or edoxaban or otamixaban).tw. }\end{array}$ \\
\hline & $\# 81$ or 2 or 3 or 4 or 5 or 6 or 7 \\
\hline & \#9 exp Neoplasms/ \\
\hline & $\begin{array}{l}\# 10 \text { (malignan* or neoplasm }{ }^{\star} \text { or cancer }{ }^{\star} \text { or carcinoma* or adenocarcinoma* } \text { or tumour }^{\star} \text { or tu- } \\
\text { mor }^{\star} \text {.tw. }\end{array}$ \\
\hline & \#11 9 or 10 \\
\hline & $\# 128$ and 11 \\
\hline & \#13 randomized controlled trial.pt. \\
\hline & \#14 controlled clinical trial.pt. \\
\hline & \#15 randomized.ab. \\
\hline & \#16 placebo.ab. \\
\hline & \#17 drug therapy.fs. \\
\hline & \#18 randomly.ab. \\
\hline & \#19 trial.ab. \\
\hline & \#20 groups.ab. \\
\hline & $\# 2113$ or 14 or 15 or 16 or 17 or 18 or 19 or 20 \\
\hline & \#22 12 and 21 \\
\hline & \#23 exp animals/ not humans.sh. \\
\hline & $\# 2422$ not 23 \\
\hline
\end{tabular}

Embase

\#1 heparin/

\#2 exp low molecular weight heparin/

\#3 (LMWH or heparin or nadroparin or fraxiparin or enoxaparin or clexane or lovenox or dalteparin or fragmin or ardeparin or normiflo or tinzaparin or logiparin or innohep or certoparin or san- 
doparin or reviparin or clivarin or danaproid or orgaran or bemiparin or hibor, badyket, semuloparin, parnaparin, fluxum).tw.

\#4 exp coumarin derivative/

\#5 (warfarin or coumadin or acenocumarol or phenprocumon or 4-hydroxicoumarins or oral anticoagulant or vitamin $\mathrm{K}$ antagonist or VKA).tw.

\#6 (fondaparinux or arixtra).tw.

\#7 (ximelagatran or exanta).tw.

\#8 (pradaxa or dabigatran or rivaroxaban or xarelto or apixaban or eliquis or edoxaban or lixiana or betrixaban or edoxaban or otamixaban).tw.

\#9 1 or 2 or 3 or 4 or 5 or 6 or 7 or 8

\#10 exp neoplasm/

\#11 (malignan* or neoplasm* or cancer* or carcinoma* or adenocarcinoma* or tumour* or tumor $\left.^{\star}\right)$.tw.

$\# 1210$ or 11

$\# 139$ and 12

\#14 crossover procedure/

\#15 double-blind procedure/

\#16 randomized controlled trial/

\#17 single-blind procedure/

\#18 random ${ }^{\star} . \mathrm{mp}$.

\#19 factorial ${ }^{\star} . \mathrm{mp}$.

\#20 (crossover ${ }^{\star}$ or cross over $^{\star}$ or cross-over $\left.{ }^{\star}\right) . \mathrm{mp}$.

\#21 placebo*.mp.

\#22 (double* adj blind $\left.{ }^{\star}\right)$.mp.

$\# 23$ (singl* adj blind $\left.{ }^{\star}\right) . m p$.

\#24 assign*.mp.

\#25 allocat*.mp.

\#26 volunteer*.mp.

\#27 14 or 15 or 16 or 17 or 18 or 19 or 20 or 21 or 22 or 23 or 24 or 25 or 26

\#28 13 and 27

\#29 (exp animal/ or nonhuman/ or exp animal experiment/) not human/

\#3028 not 29

CENTRAL (the Cochrane Library, latest issue)
\#1 MeSH descriptor: [Heparin] explode all trees

\#2 (LMWH or heparin or nadroparin or fraxiparin or enoxaparin or clexane or lovenox or dalteparin or fragmin or ardeparin or normiflo or tinzaparin or logiparin or innohep or certoparin or sandoparin or reviparin or clivarin or danaproid or orgaran or bemiparin or hibor, badyket, semuloparin, parnaparin, fluxum) 
\#3 MeSH descriptor: [Coumarins] explode all trees

\#4 (warfarin or coumadin or acenocumarol or phenprocumon or 4-hydroxicoumarins or oral anticoagulant or vitamin $\mathrm{K}$ antagonist or VKA)

\#5 (fondaparinux or arixtra)

\#6 (ximelagatran or exanta)

\#7 (pradaxa or dabigatran or rivaroxaban or xarelto or apixaban or eliquis or edoxaban or lixiana or betrixaban or edoxaban or otamixaban)

\#8 \#1 or \#2 or \#3 or \#4 or \#5 or \#6 or \#7

\#9 MeSH descriptor: [Neoplasms] explode all trees

\#10 (malignan ${ }^{\star}$ or neoplasm* or cancer ${ }^{\star}$ or carcinoma* or adenocarcinoma* or tumour ${ }^{\star}$ or tumor ${ }^{\star}$ )

$\# 11$ \#9 or \#10

$\# 12 \# 8$ and \#10

Appendix 3. Full search strategies for the electronic databases - update 2018

\begin{tabular}{|c|c|}
\hline Database & Strategy \\
\hline \multirow[t]{9}{*}{ MEDLINE } & RCT search strategy: \\
\hline & 1. exp Anticoagulants/ \\
\hline & $\begin{array}{l}\text { 2. (LMWH* or heparin* or nadroparin }{ }^{\star} \text { or frixiparin* or enoxaparin }{ }^{\star} \text { or clexane or klexane or lovenox } \\
\text { or dalteparin or fragmin or ardeparin* or normiflo or tinzaparin or logiparin or innohep or cer- } \\
\text { toparin or sandoparin or reviparin or clivarin* or danaproid or danaparoid or orgaran or antixarin } \\
\text { or bemiparin* or hibor or zibor or ivor or badyket or semuloparin or parnaparin or tedelparin or } \\
\text { fluxum or lohepa or lowhepa or parvoparin or seleparin^ or tedelgliparin or lomoparan or orgaran } \\
\text { or sulodexide or zivor or embolex or xaparin or clivarine or fondaparinux or Arixtra or UFH or He- } \\
\text { palean or Calcilean or Calciparine or Liquaemin or Liquemin or Multiparin or Novoheparin or Epa- } \\
\text { rina or Hep-lock or Heparinate or Heparinic acid or Panheprin or Hepalean or Heparin Leo or He- } \\
\text { parin Lock).mp. }\end{array}$ \\
\hline & $\begin{array}{l}\text { 3. (FR-860 or FR } 860 \text { or FR } 860 \text { or PK-10,169 or PK } 10,169 \text { or PK10,169 or PK- } 10169 \text { or PK } 10169 \text { or } \\
\text { PK10169 or EMT-967 or EMT } 967 \text { or EMT967 or EMT-966 or EMT } 966 \text { or EMT966 or CY } 216 \text { or CY-216 or } \\
\text { CY216 or LMF CY-216 or LMF CY } 216 \text { or LMF CY216).mp. }\end{array}$ \\
\hline & 4. exp Coumarins/ \\
\hline & $\begin{array}{l}\text { 5. (4-Hydroxycoumarin* or warfarin* or acenocoumarol or nicoumalone or sinthrome or Sintrom or } \\
\text { phenindione or dicoumarol or coumadin or phenprocoumon or phepromaron or ethyl-biscoumac- } \\
\text { etate or phenindione or Diphenadione or Tioclomarol or Racumi or Marcoumar or Marcumar or } \\
\text { Falithrom or Jantoven or vitamin K antagonist* or VKA or fluindione or difenacoum or coumatetra- } \\
\text { lyl).mp. }\end{array}$ \\
\hline & $\begin{array}{l}\text { 6. (Dermatan Sulfate or (Chondroitin Sulfate adj B) or Dermatan Sulfphate or DS } 435 \text { or MF-701 or } \\
\text { OP-370 or b-Heparin or Mistral or Venorix).mp. }\end{array}$ \\
\hline & 7. (thrombin adj inhibitor $\left.{ }^{\star}\right) \cdot \mathrm{mp}$. \\
\hline & 8. (factor Xa inhibitor ${ }^{\star}$ or antithrombin* or anticoagul*).mp. \\
\hline
\end{tabular}


9. (rivaroxaban or Xarelto or apixaban or Eliquis or dabigatran etexilate or Edoxaban or Savaysa or Betrixaban or ximelagatran or pradaxa or lixiana or exanta or Darexaban or Otamixaban* or Razaxaban or Bivalirudin or Desirudin or Lepirudin or Melagatran or YM 150 or Iprivask or argatrovan or pradax or BIBR-953 or BIBR-953ZW or BAY 59-7939 or BMS-562247 or DU-176 or DU-176b).mp.

10. $\left(\mathrm{TSOAC}^{\star}\right.$ or NOAC* or DOAC*).ti,ab,kw.

11.1 or 2 or 3 or 4 or 5 or 6 or 7 or 8 or 9 or 10

12. exp Neoplasms/

13. (malignan* or neoplasm ${ }^{\star}$ or cancer ${ }^{\star}$ or carcinoma* or adenocarcinoma* or tumour* or tumor ${ }^{\star}$ or glioma* or myeloma* or lymphoma* or leukemia* or leukaemia* or epithelioma* or adeno$\left.m a^{\star}\right)$.tw.

\section{12 or 13}

15. 11 and 14

16. randomized controlled trial.pt.

17. controlled clinical trial.pt.

18. randomized.ab.

19. placebo.ab.

20. clinical trials as topic.sh.

21. randomly.ab.

22. trial.ti.

23. 16 or 17 or 18 or 19 or 20 or 21 or 22

24. (animals not (humans and animals)).sh.

25. 23 not 24

26. 15 and 25

\section{Systematic Review search strategy:}

1. exp Anticoagulants/

2. (LMWH* or heparin* or nadroparin* or frixiparin* or enoxaparin* or clexane or klexane or lovenox or dalteparin or fragmin or ardeparin* or normiflo or tinzaparin or logiparin or innohep or certoparin or sandoparin or reviparin or clivarin ${ }^{\star}$ or danaproid or danaparoid or orgaran or antixarin or bemiparin* or hibor or zibor or ivor or badyket or semuloparin or parnaparin or tedelparin or fluxum or lohepa or lowhepa or parvoparin or seleparin* or tedelgliparin or lomoparan or orgaran or sulodexide or zivor or embolex or xaparin or clivarine or fondaparinux or Arixtra or UFH or Hepalean or Calcilean or Calciparine or Liquaemin or Liquemin or Multiparin or Novoheparin or Eparina or Hep-lock or Heparinate or Heparinic acid or Panheprin or Hepalean or Heparin Leo or Heparin Lock).mp.

3. (FR-860 or FR 860 or FR860 or PK-10,169 or PK 10,169 or PK10,169 or PK-10169 or PK 10169 or PK10169 or EMT-967 or EMT 967 or EMT967 or EMT-966 or EMT 966 or EMT966 or CY 216 or CY-216 or CY216 or LMF CY-216 or LMF CY 216 or LMF CY216).mp.

\section{4. exp Coumarins/}

5. (4-Hydroxycoumarin* or warfarin* or acenocoumarol or nicoumalone or sinthrome or Sintrom or phenindione or dicoumarol or coumadin or phenprocoumon or phepromaron or ethyl-biscoumacetate or phenindione or Diphenadione or Tioclomarol or Racumi or Marcoumar or Marcumar or Falithrom or Jantoven or vitamin $\mathrm{K}$ antagonist ${ }^{\star}$ or VKA or fluindione or difenacoum or coumatetralyl).mp. 
6. (Dermatan Sulfate or (Chondroitin Sulfate adj B) or Dermatan Sulfphate or DS 435 or MF-701 or OP-370 or b-Heparin or Mistral or Venorix).mp.

7. (thrombin adj inhibitor $\left.{ }^{\star}\right) \cdot \mathrm{mp}$.

8. (factor Xa inhibitor ${ }^{\star}$ or antithrombin* or anticoagul $\left.{ }^{\star}\right)$.mp.

9. (rivaroxaban or Xarelto or apixaban or Eliquis or dabigatran etexilate or Edoxaban or Savaysa or Betrixaban or ximelagatran or pradaxa or lixiana or exanta or Darexaban or Otamixaban* or Razaxaban or Bivalirudin or Desirudin or Lepirudin or Melagatran or YM 150 or Iprivask or argatrovan or pradax or BIBR-953 or BIBR-953ZW or BAY 59-7939 or BMS-562247 or DU-176 or DU-176b).mp.

10. (TSOAC* or NOAC* or DOAC*).ti,ab,kw.

\section{1 or 2 or 3 or 4 or 5 or 6 or 7 or 8 or 9 or 10}

12. exp Neoplasms/

13. (malignan* or neoplasm* or cancer ${ }^{\star}$ or carcinoma* or adenocarcinoma* or tumour* or tumor ${ }^{\star}$ or glioma* or myeloma* or lymphoma* or leukemia* or leukaemia* or epithelioma* or adeno$\left.m a^{\star}\right)$.tw.

\section{12 or 13}

\section{11 and 14}

16. (review or review,tutorial or review, academic).pt.

17. (medline or medlars or embase or pubmed or cochrane).tw,sh.

18. (scisearch or psychinfo or psycinfo).tw,sh.

19. (psychlit or psyclit).tw,sh.

20. cinahl.tw,sh.

21. ((hand adj2 $\left.\operatorname{search}^{\star}\right)$ or (manual ${ }^{\star}$ adj2 $\left.\left.\operatorname{search}^{\star}\right)\right)$. tw,sh.

22. (electronic database ${ }^{\star}$ or bibliographic database* or computeri?ed database ${ }^{\star}$ or online database*).tw,sh.

23. (pooling or pooled or mantel haenszel).tw,sh.

24. (peto or dersimonian or der simonian or fixed effect).tw,sh.

25. (retraction of publication or retracted publication).pt.

26.17 or 18 or 19 or 20 or 21 or 22 or 23 or 24 or 25

27. 16 and 26

28. meta-analysis.pt.

29. meta-analysis.sh.

30. (meta-analys ${ }^{\star}$ or meta analys ${ }^{\star}$ or metaanalys $\left.{ }^{\star}\right)$. tw,sh.

31. (systematic ${ }^{\star} \operatorname{adj} 5$ review$\left.^{\star}\right) . t w$, sh.

32. (systematic ${ }^{\star}$ adj5 overview*).tw,sh.

33. (quantitativ* adj5 review*).tw,sh.

34. (quantitativ* adj5 overview $\left.{ }^{\star}\right)$. tw,sh.

35. (methodologic ${ }^{\star}$ adj5 review*).tw,sh. 
36. (methodologic ${ }^{\star}$ adj5 overview*).tw,sh.

37. (integrative research review* or research integration).tw.

38.28 or 29 or 30 or 31 or 32 or 33 or 34 or 35 or 36 or 37

39.27 or 38

41. 15 and 39

Embase

\section{RCT search strategy:}

1. exp anticoagulant agent/

2. (LMWH* or heparin* or nadroparin* or frixiparin* or enoxaparin* or clexane or klexane or lovenox or dalteparin or fragmin or ardeparin* or normiflo or tinzaparin or logiparin or innohep or certoparin or sandoparin or reviparin or clivarin* or danaproid or danaparoid or orgaran or antixarin or bemiparin* or hibor or zibor or ivor or badyket or semuloparin or parnaparin or tedelparin or fluxum or lohepa or lowhepa or parvoparin or seleparin* or tedelgliparin or lomoparan or orgaran or sulodexide or zivor or embolex or xaparin or clivarine or fondaparinux or Arixtra or UFH or Hepalean or Calcilean or Calciparine or Liquaemin or Liquemin or Multiparin or Novoheparin or Eparina or Hep-lock or Heparinate or Heparinic acid or Panheprin or Hepalean or Heparin Leo or Heparin Lock).mp.

\section{3. (FR-860 or FR 860 or FR860 or PK-10,169 or PK 10,169 or PK10,169 or PK-10169 or PK 10169 or PK10169 or EMT-967 or EMT 967 or EMT967 or EMT-966 or EMT 966 or EMT966 or CY 216 or CY-216 or CY216 or LMF CY-216 or LMF CY 216 or LMF CY216).mp.}

\section{4. exp coumarin derivative/}

5. (4-Hydroxycoumarin* or warfarin* or acenocoumarol or nicoumalone or sinthrome or Sintrom or phenindione or dicoumarol or coumadin or phenprocoumon or phepromaron or ethyl-biscoumacetate or phenindione or Diphenadione or Tioclomarol or Racumi or Marcoumar or Marcumar or Falithrom or Jantoven or vitamin $\mathrm{K}$ antagonist ${ }^{\star}$ or VKA or fluindione or difenacoum or coumatetralyl).mp.

6. (Dermatan Sulfate or (Chondroitin Sulfate adj B) or Dermatan Sulfphate or DS 435 or MF-701 or OP-370 or b-Heparin or Mistral or Venorix).mp.

7. (thrombin adj inhibitor $\left.{ }^{\star}\right) \cdot \mathrm{mp}$.

8. (factor Xa inhibitor ${ }^{\star}$ or antithrombin ${ }^{\star}$ or anticoagul $\left.{ }^{\star}\right) \cdot \mathrm{mp}$.

9. (rivaroxaban or Xarelto or apixaban or Eliquis or dabigatran etexilate or Edoxaban or Savaysa or Betrixaban or ximelagatran or pradaxa or lixiana or exanta or Darexaban or Otamixaban* or Razaxaban or Bivalirudin or Desirudin or Lepirudin or Melagatran or YM 150 or Iprivask or argatrovan or pradax or BIBR-953 or BIBR-953ZW or BAY 59-7939 or BMS-562247 or DU-176 or DU-176b).mp.

10. $\left(\right.$ TSOAC $^{\star}$ or NOAC* or DOAC*).ti,ab,kw.

11. 1 or 2 or 3 or 4 or 5 or 6 or 7 or 8 or 9 or 10

12. exp neoplasm/

13. (malignan* or neoplasm ${ }^{\star}$ or cancer ${ }^{\star}$ or carcinoma* or adenocarcinoma* or tumour* or tumor ${ }^{\star}$ or glioma* or myeloma* or lymphoma* or leukemia* or leukaemia* or epithelioma* or adenoma*).tw.

\section{12 or 13}

15. 11 and 14

16. crossover procedure/

17. double-blind procedure/ 
18. randomized controlled trial/

19. single-blind procedure/

20. random*.mp.

21. factorial ${ }^{\star} \cdot \mathrm{mp}$.

22. (crossover ${ }^{\star}$ or cross over ${ }^{\star}$ or cross-over $\left.{ }^{\star}\right) \cdot \mathrm{mp}$.

23. placebo*.mp.

24. $\left(\right.$ double $^{\star}$ adj blind $\left.{ }^{\star}\right) \cdot \mathrm{mp}$.

25. $\left(\right.$ singl ${ }^{\star}$ adj blind $\left.{ }^{\star}\right) \cdot m p$.

26. assign ${ }^{\star} \cdot \mathrm{mp}$.

27. allocat*.mp.

28. volunteer ${ }^{\star} . \mathrm{mp}$.

29. 16 or 17 or 18 or 19 or 20 or 21 or 22 or 23 or 24 or 25 or 26 or 27 or 28

30. 15 and 29

\section{Systematic Review search strategy:}

1. exp anticoagulant agent/

2. $\left(\mathrm{LMWH}^{\star}\right.$ or heparin ${ }^{\star}$ or nadroparin ${ }^{\star}$ or frixiparin* or enoxaparin ${ }^{\star}$ or clexane or klexane or lovenox or dalteparin or fragmin or ardeparin* or normiflo or tinzaparin or logiparin or innohep or certoparin or sandoparin or reviparin or clivarin* or danaproid or danaparoid or orgaran or antixarin or bemiparin* or hibor or zibor or ivor or badyket or semuloparin or parnaparin or tedelparin or fluxum or lohepa or lowhepa or parvoparin or seleparin* or tedelgliparin or lomoparan or orgaran or sulodexide or zivor or embolex or xaparin or clivarine or fondaparinux or Arixtra or UFH or Hepalean or Calcilean or Calciparine or Liquaemin or Liquemin or Multiparin or Novoheparin or Eparina or Hep-lock or Heparinate or Heparinic acid or Panheprin or Hepalean or Heparin Leo or Heparin Lock).mp.

3. (FR-860 or FR 860 or FR860 or PK-10,169 or PK 10,169 or PK10,169 or PK-10169 or PK 10169 or PK10169 or EMT-967 or EMT 967 or EMT967 or EMT-966 or EMT 966 or EMT966 or CY 216 or CY-216 or CY216 or LMF CY-216 or LMF CY 216 or LMF CY216).mp.

4. exp coumarin derivative/

5. (4-Hydroxycoumarin* or warfarin* or acenocoumarol or nicoumalone or sinthrome or Sintrom or phenindione or dicoumarol or coumadin or phenprocoumon or phepromaron or ethyl-biscoumacetate or phenindione or Diphenadione or Tioclomarol or Racumi or Marcoumar or Marcumar or Falithrom or Jantoven or vitamin $\mathrm{K}$ antagonist ${ }^{\star}$ or VKA or fluindione or difenacoum or coumatetralyl).mp.

6. (Dermatan Sulfate or (Chondroitin Sulfate adj B) or Dermatan Sulfphate or DS 435 or MF-701 or OP-370 or b-Heparin or Mistral or Venorix).mp.

7. (thrombin adj inhibitor $\left.{ }^{\star}\right) \cdot m p$.

8. (factor Xa inhibitor* or antithrombin* or anticoagul $\left.{ }^{\star}\right)$.mp.

9. (rivaroxaban or Xarelto or apixaban or Eliquis or dabigatran etexilate or Edoxaban or Savaysa or Betrixaban or ximelagatran or pradaxa or lixiana or exanta or Darexaban or Otamixaban* or Razaxaban or Bivalirudin or Desirudin or Lepirudin or Melagatran or YM 150 or Iprivask or argatrovan or pradax or BIBR-953 or BIBR-953ZW or BAY 59-7939 or BMS-562247 or DU-176 or DU-176b).mp.

10. $\left(\right.$ TSOAC $^{\star}$ or $\mathrm{NOAC}^{\star}$ or DOAC*).ti,ab,kw. 


\section{1 or 2 or 3 or 4 or 5 or 6 or 7 or 8 or 9 or 10}

12. exp neoplasm/

13. (malignan* or neoplasm* or cancer* or carcinoma* or adenocarcinoma* or tumour* or tumor ${ }^{\star}$ or glioma* or myeloma* or lymphoma* or leukemia* or leukaemia* or epithelioma* or adeno$\left.m a^{\star}\right)$.tw.

\section{12 or 13}

15. 11 and 14

16. exp review/

17. (literature adj3 review $\left.^{\star}\right)$.ti,ab.

18. exp meta analysis/

19. exp "Systematic Review"/

\section{16 or 17 or 18 or 19}

21. (medline or medlars or embase or pubmed or cinahl or amed or psychlit or psyclit or psychinfo or psycinfo or scisearch or cochrane).ti,ab.

\section{RETRACTED ARTICLE/}

\section{21 or 22}

\section{20 and 23}

25. (systematic ${ }^{\star}$ adj2 (review* or overview)).ti,ab.

26. (meta?anal* or meta anal* or meta-anal* or metaanal* or metanal*).ti,ab.

\subsection{4 or 25 or 26}

\section{15 and 27}

CENTRAL (the Cochrane Library, latest issue)
\#1 MeSH descriptor: [Anticoagulants] explode all trees

\#2 (LMWH* or heparin* or nadroparin* or frixiparin* or enoxaparin* or clexane or klexane or lovenox or dalteparin or fragmin or ardeparin* or normiflo or tinzaparin or logiparin or innohep or certoparin or sandoparin or reviparin or clivarin* or danaproid or danaparoid or orgaran or antixarin or bemiparin* or hibor or zibor or ivor or badyket or semuloparin or parnaparin or tedelparin or fluxum or lohepa or lowhepa or parvoparin or seleparin* or tedelgliparin or lomoparan or orgaran or sulodexide or zivor or embolex or xaparin or clivarine or fondaparinux or Arixtra or UFH or Hepalean or Calcilean or Calciparine or Liquaemin or Liquemin or Multiparin or Novoheparin or Eparina or Hep-lock or Heparinate or Heparinic acid or Panheprin or Hepalean or Heparin Leo or Heparin Lock)

\#3 FR-860 or FR 860 or FR860 or PK-10,169 or PK 10,169 or PK10,169 or PK-10169 or PK 10169 or PK10169 or EMT-967 or EMT 967 or EMT967 or EMT-966 or EMT 966 or EMT966 or CY 216 or CY-216 or CY216 or LMF CY-216 or LMF CY 216 or LMF CY 216

\#4 MeSH descriptor: [Coumarins] explode all trees

\#5 (4-Hydroxycoumarin* or warfarin* or acenocoumarol or nicoumalone or sinthrome or Sintrom or phenindione or dicoumarol or coumadin or phenprocoumon or phepromaron or ethyl-biscoumacetate or phenindione or Diphenadione or Tioclomarol or Racumi or Marcoumar or Marcumar or Falithrom or Jantoven or vitamin K antagonist* or VKA or fluindione or difenacoum or coumatetralyl)

\#6 (Dermatan Sulfate or (Chondroitin Sulfate adj B) or Dermatan Sulfphate or DS 435 or MF-701 or OP-370 or b-Heparin or Mistral or Venorix) 


\author{
\#7 thrombin near inhibitor* \\ \#8 factor Xa inhibitor ${ }^{\star}$ or antithrombin * or anticoagul ${ }^{*}$ \\ \#9 rivaroxaban or Xarelto or apixaban or Eliquis or dabigatran etexilate or Edoxaban or Savaysa or \\ Betrixaban or ximelagatran or pradaxa or lixiana or exanta or Darexaban or Otamixaban* or Razax- \\ aban or Bivalirudin or Desirudin or Lepirudin or Melagatran or YM 150 or Iprivask or argatrovan or \\ pradax or BIBR-953 or BIBR-953ZW or BAY 59-7939 or BMS-562247 or DU-176 or DU-176b \\ \#10 TSOAC* or NOAC* or DOAC* \\ $\# 11 \# 1$ or \#2 or \#3 or \#4 or \#5 or \#6 or \#7 or \#8 or \#9 or \#10 \\ \#12 MeSH descriptor: [Neoplasms] explode all trees \\ \#13 malignan* or neoplasm* or cancer* or carcinoma* or adenocarcinoma* or tumour ${ }^{\star}$ or tumor ${ }^{\star}$ \\ or glioma* or myeloma* or lymphoma* or leukemia* or leukaemia* or epithelioma* or adenoma* \\ \#14 \#13 or \#14 \\ $\# 15 \# 11$ and \#14
}

\title{
Appendix 4. GRADE Evidence Profile low molecular weight heparin versus unfractionated heparin
}

Question: LMWH initial treatment compared to UFH initial treatment in people with cancer with VTE 


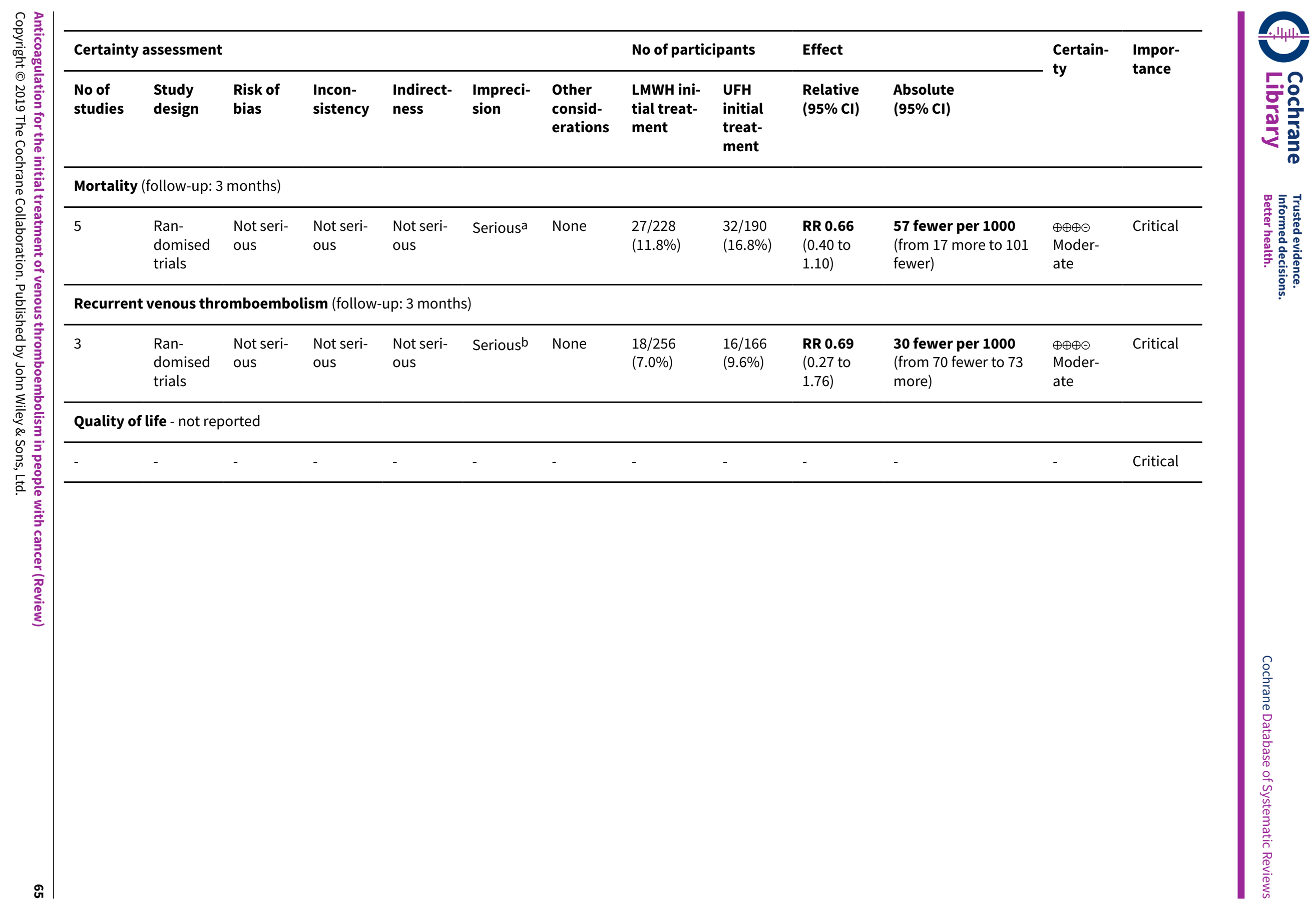


CI: confidence interval; LMWH : low molecular weight heparin; RR: risk ratio; UFH : unfractionated heparin.

\section{Explanations}

a95\% Cl was consistent with the possibility for important benefit (101 per 1000 absolute reduction) and possibility of important harm (17 per 1000 absolute increase), including 59 events in total.

b95\% Cl was consistent with the possibility for important benefit (70 per 1000 absolute reduction) and possibility of important harm (73 per 1000 absolute increase), including only 34 events in total.

\section{Appendix 5. GRADE Evidence Profile fondaparinux versus heparin}

Question: Fondaparinux initial treatment compared to heparin initial treatment in people with cancer with venous thromboembolism (Q15b-Initial) 


\begin{tabular}{|c|c|c|c|c|c|c|c|c|c|c|c|c|}
\hline \multicolumn{7}{|c|}{ Certainty assessment } & \multicolumn{2}{|c|}{ No of participants } & \multicolumn{2}{|l|}{ Effect } & \multirow{2}{*}{$\begin{array}{l}\text { Certain- } \\
\text { ty }\end{array}$} & \multirow{2}{*}{$\begin{array}{l}\text { Impor- } \\
\text { tance }\end{array}$} \\
\hline $\begin{array}{l}\text { No of } \\
\text { studies }\end{array}$ & $\begin{array}{l}\text { Study } \\
\text { design }\end{array}$ & $\begin{array}{l}\text { Risk of } \\
\text { bias }\end{array}$ & $\begin{array}{l}\text { Incon- } \\
\text { sistency }\end{array}$ & $\begin{array}{l}\text { Indirect- } \\
\text { ness }\end{array}$ & $\begin{array}{l}\text { Impreci- } \\
\text { sion }\end{array}$ & $\begin{array}{l}\text { Other } \\
\text { consid- } \\
\text { erations }\end{array}$ & $\begin{array}{l}\text { Fonda- } \\
\text { parin- } \\
\text { ux initial } \\
\text { treatment }\end{array}$ & $\begin{array}{l}\text { Heparin } \\
\text { initial } \\
\text { treat- } \\
\text { ment }\end{array}$ & $\begin{array}{l}\text { Relative } \\
\text { (95\% CI) }\end{array}$ & $\begin{array}{l}\text { Absolute } \\
(95 \% \mathrm{CI})\end{array}$ & & \\
\hline \multicolumn{13}{|c|}{ Mortality (follow-up: 3 months) } \\
\hline 1 & $\begin{array}{l}\text { Ran- } \\
\text { domised } \\
\text { trials }\end{array}$ & $\begin{array}{l}\text { Not seri- } \\
\text { ous }\end{array}$ & $\begin{array}{l}\text { Not seri- } \\
\text { ous }\end{array}$ & $\begin{array}{l}\text { Not seri- } \\
\text { ous }\end{array}$ & Seriousa & None & $\begin{array}{l}51 / 238 \\
(21.4 \%)\end{array}$ & $\begin{array}{l}41 / 239 \\
(17.2 \%)\end{array}$ & $\begin{array}{l}\text { RR 1.25 } \\
(0.86 \text { to } \\
1.81)\end{array}$ & $\begin{array}{l}\mathbf{4 3} \text { more per } 1000 \\
\text { (from } 24 \text { fewer to } \\
139 \text { more) }\end{array}$ & $\begin{array}{l}\oplus \oplus \oplus \ominus \\
\text { Moder- } \\
\text { ate }\end{array}$ & Critical \\
\hline \multicolumn{13}{|c|}{ Recurrent venous thromboembolism (follow-up: 3 months) } \\
\hline 1 & $\begin{array}{l}\text { Ran- } \\
\text { domised } \\
\text { trials }\end{array}$ & $\begin{array}{l}\text { Not seri- } \\
\text { ous }\end{array}$ & $\begin{array}{l}\text { Not seri- } \\
\text { ous }\end{array}$ & $\begin{array}{l}\text { Not seri- } \\
\text { ous }\end{array}$ & Seriousb & None & $\begin{array}{l}26 / 238 \\
(10.9 \%)\end{array}$ & $\begin{array}{l}28 / 239 \\
(11.7 \%)\end{array}$ & $\begin{array}{l}\text { RR } 0.93 \\
(0.56 \text { to } \\
1.54)\end{array}$ & $\begin{array}{l}\mathbf{8} \text { fewer per } 1000 \\
\text { (from } 52 \text { fewer to } \\
63 \text { more) }\end{array}$ & $\begin{array}{l}\oplus \oplus \oplus \ominus \\
\text { Moder- } \\
\text { ate }\end{array}$ & Critical \\
\hline \multicolumn{13}{|c|}{ Major bleeding (follow-up: 3 months) } \\
\hline 1 & $\begin{array}{l}\text { Ran- } \\
\text { domised } \\
\text { trials }\end{array}$ & $\begin{array}{l}\text { Not seri- } \\
\text { ous }\end{array}$ & $\begin{array}{l}\text { Not seri- } \\
\text { ous }\end{array}$ & $\begin{array}{l}\text { Not seri- } \\
\text { ous }\end{array}$ & Seriousc & None & $\begin{array}{l}13 / 238 \\
(5.5 \%)\end{array}$ & $\begin{array}{l}16 / 239 \\
(6.7 \%)\end{array}$ & $\begin{array}{l}\text { RR } 0.82 \\
(0.40 \text { to } \\
1.66)\end{array}$ & $\begin{array}{l}\mathbf{1 2} \text { fewer per } 1000 \\
\text { (from } 40 \text { fewer to } \\
44 \text { more) }\end{array}$ & $\begin{array}{l}\oplus \oplus \oplus \ominus \\
\text { Moder- } \\
\text { ate }\end{array}$ & Critical \\
\hline \multicolumn{13}{|c|}{ Minor bleeding (follow-up: 3 months) } \\
\hline 1 & $\begin{array}{l}\text { Ran- } \\
\text { domised } \\
\text { trials }\end{array}$ & $\begin{array}{l}\text { Not seri- } \\
\text { ous }\end{array}$ & $\begin{array}{l}\text { Not seri- } \\
\text { ous }\end{array}$ & $\begin{array}{l}\text { Not seri- } \\
\text { ous }\end{array}$ & Seriousd & None & $\begin{array}{l}29 / 238 \\
(12.2 \%)\end{array}$ & $\begin{array}{l}19 / 239 \\
(7.9 \%)\end{array}$ & $\begin{array}{l}\text { RR } 1.53 \\
(0.88 \text { to } \\
2.66)\end{array}$ & $\begin{array}{l}\mathbf{4 2} \text { more per } 1000 \\
\text { (from } 10 \text { fewer to } \\
132 \text { more) }\end{array}$ & $\begin{array}{l}\oplus \oplus \oplus \ominus \\
\text { Moder- } \\
\text { ate }\end{array}$ & Critical \\
\hline \multicolumn{13}{|c|}{ Quality of life - not reported } \\
\hline- & - & - & - & - & - & - & - & - & - & - & - & Critical \\
\hline
\end{tabular}


Cl: confidence interval; RR: risk ratio.

\section{Explanations}

a95\% Cl was consistent with the possibility for important benefit (24 per 1000 absolute reduction) and possibility of important harm (139 per 1000 absolute increase), including only 92 events in total.

b95\% $\mathrm{Cl}$ was consistent with the possibility for important benefit (52 per 1000 absolute reduction) and possibility of important harm (63 per 1000 absolute increase), including only 54 events in total.

c95\% $\mathrm{Cl}$ was consistent with the possibility for important benefit (40 per 1000 absolute reduction) and possibility of important harm (44 per 1000 absolute increase), including only 29 events in total.

d95\% $\mathrm{Cl}$ was consistent with the possibility for important benefit (10 per 1000 absolute reduction) and possibility of important harm (132 per 1000 absolute increase), including only 48 events in total.

\section{Appendix 6. GRADE Evidence profile dalteparin versus tinzaparin}

Question: Dalteparin initial treatment compared to tinzaparin initial treatment in people with cancer with venous thromboembolism 


\begin{tabular}{|c|c|c|c|c|c|c|c|c|c|c|c|c|}
\hline \multicolumn{7}{|c|}{ Quality assessment } & \multicolumn{2}{|c|}{ No of participants } & \multicolumn{2}{|l|}{ Effect } & \multirow[t]{2}{*}{ Quality } & \multirow{2}{*}{$\begin{array}{l}\text { Impor } \\
\text { tance }\end{array}$} \\
\hline $\begin{array}{l}\text { No of } \\
\text { studies }\end{array}$ & $\begin{array}{l}\text { Study } \\
\text { design }\end{array}$ & $\begin{array}{l}\text { Risk of } \\
\text { bias }\end{array}$ & $\begin{array}{l}\text { Incon- } \\
\text { sistency }\end{array}$ & $\begin{array}{l}\text { Indirect- } \\
\text { ness }\end{array}$ & $\begin{array}{l}\text { Impreci- } \\
\text { sion }\end{array}$ & $\begin{array}{l}\text { Other } \\
\text { consid- } \\
\text { erations }\end{array}$ & $\begin{array}{l}\text { Dal- } \\
\text { teparin }\end{array}$ & $\begin{array}{l}\text { Tinza- } \\
\text { parin }\end{array}$ & $\begin{array}{l}\text { Relative } \\
(95 \% \mathrm{CI})\end{array}$ & $\begin{array}{l}\text { Absolute } \\
(95 \% \mathrm{Cl})\end{array}$ & & \\
\hline \multicolumn{13}{|c|}{ Mortality (follow-up: 3 months) } \\
\hline 1 & $\begin{array}{l}\text { Ran- } \\
\text { domised } \\
\text { trials }\end{array}$ & $\begin{array}{l}\text { Not seri- } \\
\text { ous }\end{array}$ & $\begin{array}{l}\text { Not seri- } \\
\text { ous }\end{array}$ & $\begin{array}{l}\text { Not seri- } \\
\text { ous }\end{array}$ & $\begin{array}{l}\text { Very se- } \\
\text { riousa }\end{array}$ & None & $\begin{array}{l}11 / 54 \\
(20.4 \%)\end{array}$ & $\begin{array}{l}14 / 59 \\
(23.7 \%)\end{array}$ & $\begin{array}{l}\text { RR } 0.86 \\
(0.43 \text { to } \\
1.73)\end{array}$ & $\begin{array}{l}33 \text { fewer per } 1000 \\
\text { (from } 135 \text { fewer to } 173 \\
\text { more) }\end{array}$ & $\begin{array}{l}\oplus \oplus \ominus \ominus \\
\text { LOW }\end{array}$ & Critical \\
\hline \multicolumn{13}{|c|}{ Recurrent venous thromboembolism (follow-up: 3 months) } \\
\hline 1 & $\begin{array}{l}\text { Ran- } \\
\text { domised } \\
\text { trials }\end{array}$ & $\begin{array}{l}\text { Not seri- } \\
\text { ous }\end{array}$ & $\begin{array}{l}\text { Not seri- } \\
\text { ous }\end{array}$ & $\begin{array}{l}\text { Not seri- } \\
\text { ous }\end{array}$ & $\begin{array}{l}\text { Very se- } \\
\text { rious }{ }^{b}\end{array}$ & None & $\begin{array}{l}2 / 54 \\
(3.7 \%)\end{array}$ & $\begin{array}{l}5 / 59 \\
(8.5 \%)\end{array}$ & $\begin{array}{l}\text { RR } 0.44 \\
(0.09 \text { to } \\
2.16)\end{array}$ & $\begin{array}{l}\mathbf{4 7} \text { fewer per } 1000 \\
\text { (from } 77 \text { fewer to } 98 \\
\text { more) }\end{array}$ & $\begin{array}{l}\oplus \oplus \ominus \ominus \\
\text { LOW }\end{array}$ & Critical \\
\hline \multicolumn{13}{|c|}{ Major bleeding (follow-up: 3 months) } \\
\hline 1 & $\begin{array}{l}\text { Ran- } \\
\text { domised } \\
\text { trials }\end{array}$ & $\begin{array}{l}\text { Not seri- } \\
\text { ous }\end{array}$ & $\begin{array}{l}\text { Not seri- } \\
\text { ous }\end{array}$ & $\begin{array}{l}\text { Not seri- } \\
\text { ous }\end{array}$ & $\begin{array}{l}\text { Very se- } \\
\text { riousc }\end{array}$ & None & $\begin{array}{l}2 / 54 \\
(3.7 \%)\end{array}$ & $\begin{array}{l}1 / 59 \\
(1.7 \%)\end{array}$ & $\begin{array}{l}\text { RR 2.19 } \\
(0.20 \text { to } \\
23.42)\end{array}$ & $\begin{array}{l}\mathbf{2 0} \text { more per } 1000 \\
\text { (from } 14 \text { fewer to } 380 \\
\text { more) }\end{array}$ & $\begin{array}{l}\oplus \oplus \ominus \ominus \\
\text { LOW }\end{array}$ & Critical \\
\hline \multicolumn{13}{|c|}{ Minor bleeding (follow-up: 3 months) } \\
\hline 1 & $\begin{array}{l}\text { Ran- } \\
\text { domised } \\
\text { trials }\end{array}$ & $\begin{array}{l}\text { Not seri- } \\
\text { ous }\end{array}$ & $\begin{array}{l}\text { Not seri- } \\
\text { ous }\end{array}$ & $\begin{array}{l}\text { Not seri- } \\
\text { ous }\end{array}$ & $\begin{array}{l}\text { Very se- } \\
\text { riousd }\end{array}$ & None & $\begin{array}{l}6 / 54 \\
(11.1 \%)\end{array}$ & $\begin{array}{l}8 / 59 \\
(13.6 \%)\end{array}$ & $\begin{array}{l}\text { RR } 0.82 \\
(0.30 \text { to } \\
2.21)\end{array}$ & $\begin{array}{l}\mathbf{2 4} \text { fewer per } 1000 \\
\text { (from } 95 \text { fewer to } 164 \\
\text { more) }\end{array}$ & $\begin{array}{l}\oplus \oplus \oplus \ominus \\
\text { LOW }\end{array}$ & Critical \\
\hline
\end{tabular}


Cl: confidence interval; RR: risk ratio.

\section{Explanations}

a95\% $\mathrm{Cl}$ is consistent with the possibility for important benefit (135 per 1000 absolute reduction) and possibility of important harm (173 per 1000 absolute increase), including 25 events among included participants.

b95\% $\mathrm{Cl}$ is consistent with the possibility for important benefit (77 per 1000 absolute reduction) and possibility of important harm ( 98 per 1000 absolute increase), including 7 events among included participants.

c95\% $\mathrm{Cl}$ is consistent with the possibility for important benefit (14 per 1000 absolute reduction) and possibility of important harm ( 380 per 1000 absolute increase), including 3 events among included participants.

d95\% $\mathrm{Cl}$ is consistent with the possibility for important benefit (95 per 1000 absolute reduction) and possibility of important harm (164 per 1000 absolute increase), including 14 events among included participants

WHAT'S NEW

\begin{tabular}{lll}
\hline Date & Event & Description \\
\hline 25 February 2019 & Amended & Additional text added to Acknowledgements. \\
\hline
\end{tabular}

\section{H I S T O RY}

Protocol first published: Issue 3, 2007

Review first published: Issue 1, 2008

\begin{tabular}{lll}
\hline Date & Event & Description \\
\hline 28 June 2018 & Amended & Declaration of interest updated. \\
\hline 14 January 2018 & New search has been performed & Search updated 14 January 2018 (no new studies found). \\
\hline 14 January 2018 & $\begin{array}{l}\text { New citation required but conclusions } \\
\text { have not changed }\end{array}$ & Author list amended. \\
\hline
\end{tabular}

\section{CONTRIBUTIONS OF AUTHORS}

$\mathrm{MBH}$ : screening, full-text retrieval, data extraction, manuscript drafting.

LAK: searching for trials, screening, data extraction, data analysis, manuscript drafting, review co-ordination.

IGT: screening, full-text retrieval, data extraction, manuscript drafting.

CM: screening, full-text retrieval, data extraction.

VY: screening, full-text retrieval, data extraction.

IT: screening, full-text retrieval, data extraction.

FS: screening, full-text retrieval, data extraction.

MB: screening, full-text retrieval, data extraction.

HJS: protocol development, data interpretation, methodological expertise.

EAA: protocol development, data analysis, manuscript drafting, methodological expertise, review co-ordination.

\section{DECLARATIONSOF INTEREST}

HJS: panel member of the ASH VTE in cancer patients, Vice-Chair of the ASH VTE guidelines and played various leadership roles from 1999 until 2014 with ACCP VTE guidelines. EAA served on the executive committee the ACCP Antithrombotic Therapy Guidelines published in 2016. All other review authors declare no conflicts of interests. 


\section{SOURCES OF SUPPORT}

\section{Internal sources}

- No sources of support supplied

\section{External sources}

- NIHR Cochrane Review Incentive Scheme 2016. Award reference Number 16/72/24, UK.

This project was supported by the National Institute for Health Research (NIHR), via Cochrane Infrastructure funding to the Cochrane Gynaecological, Neuro-oncology and Orphan Cancer Group

- American Society of Hematology, USA.

This project was supported by the American Society of Hematology

\section{NDEX TERMS}

\section{Medical Subject Headings (MeSH)}

Anticoagulants [*therapeutic use]; Dalteparin [therapeutic use]; Fibrinolytic Agents [therapeutic use]; Fondaparinux; Hemorrhage [chemically induced]; Heparin [therapeutic use]; Heparin, Low-Molecular-Weight [therapeutic use]; Neoplasms [ ${ }^{*}$ complications]; Polysaccharides [therapeutic use]; Randomized Controlled Trials as Topic; Recurrence; Secondary Prevention; Tinzaparin; Venous Thromboembolism [*drug therapy] [mortality]

\section{MeSH check words}

Humans 